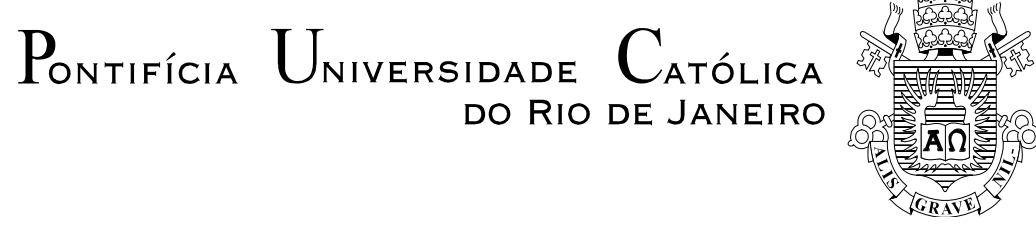

Carlos Alexandre Chang

Otimização Técnico Econômica de um Sistema Hibrido Fotovoltaico-Diesel com Banco de Baterias

Dissertação de Mestrado

Dissertação apresentada como requisito parcial para obtenção do título de Mestre pelo Programa de PósGraduação em Engenharia Elétrica da PUC-Rio.

Orientador: Prof. Álvaro de Lima Veiga Filho Co-Orientador: Prof. Alcir de Faro Orlando

Rio de Janeiro

Agosto de 2012 


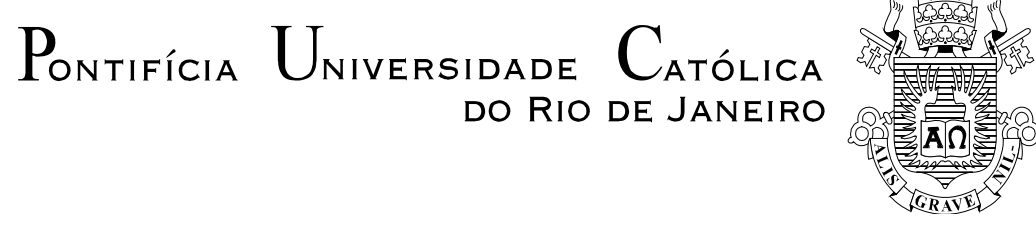

Carlos Alexandre Chang

\begin{abstract}
Otimização Técnico Econômica de um Sistema Hibrido Fotovoltaico-Diesel com Banco de Baterias
\end{abstract}

Dissertação apresentada como requisito parcial para obtenção do grau de Mestre pelo Programa de Pós-Graduação em Engenharia Elétrica do Departamento de Engenharia Elétrica do Centro Técnico Científico da PUC-Rio. Aprovada pela Comissão Examinadora abaixo assinada.

\author{
Prof. Álvaro de Lima Veiga Filho \\ Orientador \\ Departamento de Engenharia Elétrica - PUC-Rio \\ Prof. Alcir de Faro Orlando \\ Co-Orientador \\ Departamento de Engenharia Mecanica - PUC-Rio \\ Prof. Reinaldo Castro Souza \\ Departamento de Engenharia Elétrica - PUC-Rio
}

Prof. Gheisa Roberta Telles Esteves

Consultora

Prof. José Eugenio Leal Coordenador Setorial do Centro

Técnico Científico

Rio de Janeiro, 17 de agosto de 2012 
Todos os direitos reservados. É proibida a reprodução total ou parcial do trabalho sem autorização da universidade, do autor e do orientador.

\section{Carlos Alexandre Chang}

Graduou-se em Engenharia Agronômica pela Universidade Federal Rural do Rio de Janeiro em 2008.

Ficha Catalográfica

Chang, Carlos Alexandre

Otimização Técnico Econômica de um Sistema Hibrido Fotovoltaico-Diesel com Banco de Baterias / Carlos Alexandre Chang; orientador: Álvaro de Lima Veiga Filho; co-orientador: Alcir de Faro Orlando. - 2012.

99 f. : il. (color.) ; $30 \mathrm{~cm}$

Dissertação (mestrado) - Pontifícia Universidade Católica do Rio de Janeiro, Departamento de Engenharia Elétrica, 2012.

Inclui bibliografia

1. Engenharia elétrica - Teses. 2. Sistema de energia. 3. Otimização. 4. Energia fotovoltaica. 5. Energia renovável. I. Veiga Filho, Álvaro de Lima. II. Orlando, Alcir de Faro. III. Pontifícia Universidade Católica do Rio de Janeiro. Departamento de Engenharia Elétrica. IV. Título.

CDD: 621.3 


\section{Agradecimentos}

Agradeço a Deus pelas oportunidades que me foram dadas na vida e por ter iluminado o meu caminho diante de mais este desafio.

Aos meus amados filhos, grandes companheiros de caminhada, pelo amor, paciência, carinho, compreensão e, principalmente, por eles estarem sempre ao meu lado me incentivando.

Aos meus pais Cecília Chang e João Chang, assim como a minha irmã Claudia Chang, por me incentivarem, confiarem em mim.

Agradeço também ao meu orientador e professor Álvaro de Veiga Filho, pela confiança depositada em mim desde o início desta jornada e ao meu coorientador Alcir de Faro Orlando, por suas palavras amigas, incentivadoras e confortantes nos momentos difíceis.

A CAPES e à PUC-Rio, pelos auxílios concedidos, sem os quais este trabalho não poderia ter sido realizado.

A todo corpo docente ligado aos Departamentos de Engenharia Elétrica e de Engenharia Mecânica da Pontifícia Universidade Católica do Rio de Janeiro (PUC-RJ), meus sinceros agradecimentos por todo o conhecimento transmitido e dedicação.

Aos professores que participaram da minha Comissão examinadora.

Aos meus grandes amigos, Alexandre Cardoso, Betina Fernandes, Bruno Fanzêres, Erika Victorina, Flávia Fontanet, Frances Blank, Gláucia Estefânia, Keila Mara, João Paulo, Luciana Martins, Moisés, Rafael Moraes, Rafael Parga e Rodrigo Farinazzo obrigado por terem me ajudado a enxergar de uma forma mais fácil e clara as dificuldades, pelas horas despendidas nos grupos de estudo e de trabalho, além das conversas descontraídas.

Muito obrigado a todos que contribuíram de maneira direta ou indireta tornando este sonho uma realidade! 


\section{Resumo}

Chang, Carlos Alexandre; Veiga Filho, Álvaro de Lima (Orientador); Orlando, Alcir de Faro (Co-orientador). Otimização Técnico Econômica de um Sistema Híbrido Fotovoltaico-diesel com Banco de Baterias. Rio de Janeiro, 2012, 99p. Dissertação de Mestrado - Departamento de Engenharia Elétrica, Pontifícia Universidade Católica do Rio de Janeiro.

Esta dissertação analisa o custo, viabilidade e otimização do desempenho de um sistema híbrido de produção de energia elétrica, constituído de módulos fotovoltaicos, banco de baterias e gerador diesel. Foram realizadas simulações para diferentes configurações de sistema, variando tanto a profundidade de descarga quanto a capacidade total e operacional do banco de baterias, e o consumo total. O perfil do consumo foi mantido inalterado em todas as simulações realizadas. Para a simulação foi utilizado banco de dados constituído por informações meteorológicas, preços dos equipamentos do sistema, demanda de eletricidade e perfil de consumo da agrovila de Campinas (AM). Em posse desse conjunto de informações foi então elaborada análise de viabilidade econômica do fornecimento de eletricidade para uma comunidade rural localizada em uma região remota. Ou seja, localizada em uma região distante do acesso as redes de distribuição de energia elétrica. A simulação foi configurada para um sistema que possibilitasse acesso a equipamentos básicos (atendendo o Manual de Projetos Especiais - necessidade de atender refrigeração, comunicação e iluminação), fornecendo eletricidade com o menor custo possível. A avaliação do projeto demonstra que o mesmo é uma boa opção de investimento, considerando que o fornecimento elétrico é peça chave para o desenvolvimento econômico e social de qualquer localidade. Para a realização do estudo utilizou-se banco de dados de radiação solar e temperatura do município de Manaus, pertencente ao Estado do Amazonas, pressupondo-se que a localidade em questão possui condições meteorológicas semelhantes à área de estudo, desprezando-se possíveis diferenças. Além do que, o referido estudo adotou um período de vida útil de 25 anos ou mais para o sistema.

\section{Palavras-chave}

Sistema de Energia; Otimização; Energia Fotovoltaica; Energia Renovável; Eletrificação Rural. 


\section{Abstract}

Chang, Carlos Alexandre; Filho, Álvaro de Lima Veiga (Advisor); Orlando, Alcir de Faro (Co-Advisor). Technical Economic Optimization of a Hybrid Photovoltaic-diesel System with Battery Bank. Rio de Janeiro, 2012, 99p. MSc. Dissertation - Departamento de Engenharia Elétrica, Pontifícia Universidade Católica do Rio de Janeiro.

This dissertation analyses the cost, feasibility and optimization performance of a hybrid electric energy production system, composed of photovoltaic modules, storage batteries and a diesel generator. Several performance simulations were made for different system configurations, varying discharge depth, both total and operating capacity of the storage batteries, and total consumption, using the same profile shape. A data base was used for the simulations, using meteorological information, component prices, and electric energy power and consumption profiles for the rural Village of Campinas (AM). As a result, an economically feasible proposal was detailed for supplying electric energy to a rural village, which is away from available commercial networks. The simulation was used to determine the basic equipment configuration to minimize the electricity cost. The project evaluation shows it is a good investment option, considering that electric energy supply is fundamental for the social and economic development. Solar radiation and temperature data for the city of Manaus, AM, ware used for the simulations, which is considered to be approximately the same as for the rural Village of Campinas due to its proximity. In addition, this study adopted a working life of 25 years or more for the system.

\section{Keywords}

Energy systems; optimization; photovoltaic energy, renewable energy. 


\section{Sumário}

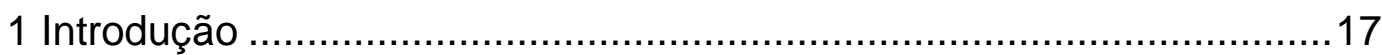

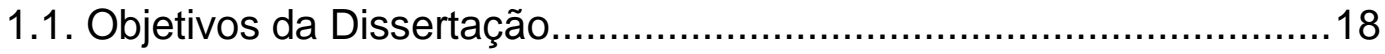

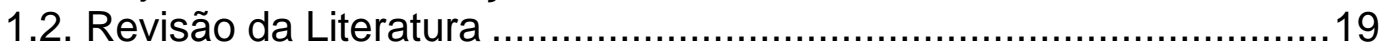

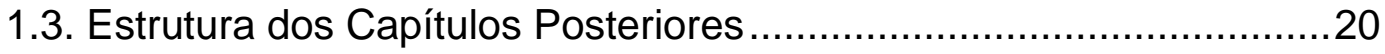

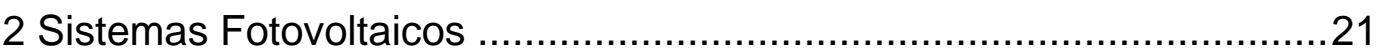

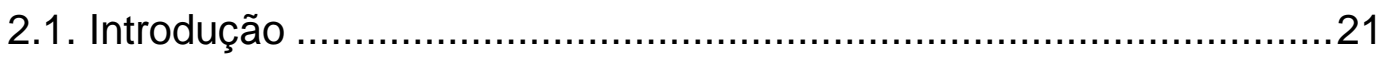

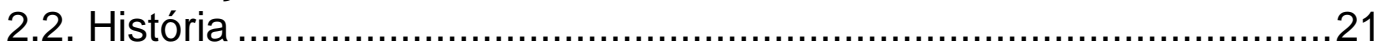

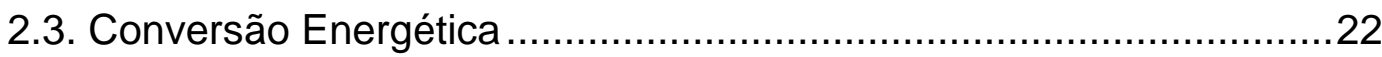

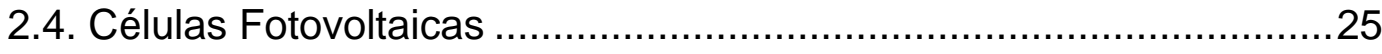

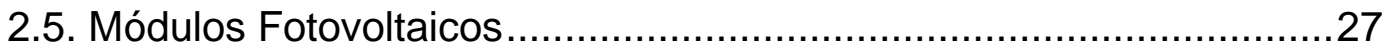

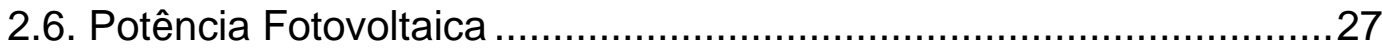

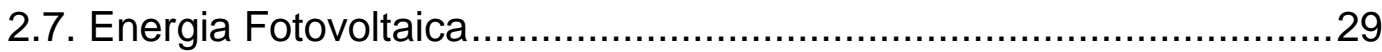

2.8. Fabricantes de Painéis Fotovoltaicos ...............................................31

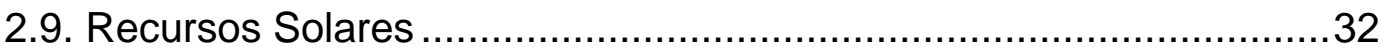

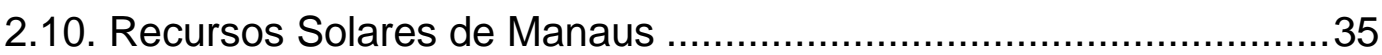

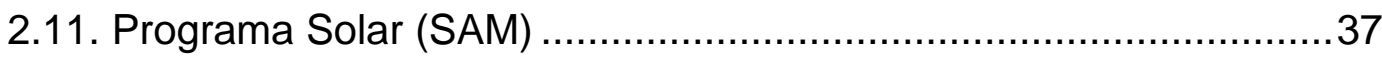

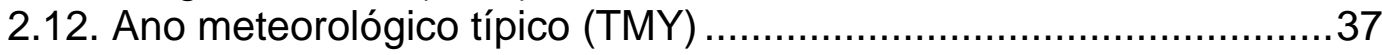

2.13. Cálculo da energia gerada por um módulo solar.............................38

3 Baterias, Gerador, Controladores PV e Inversores ............................40 40

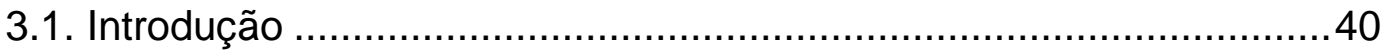

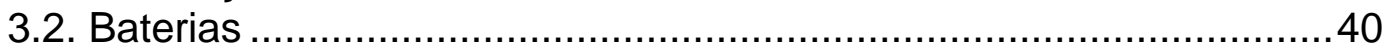

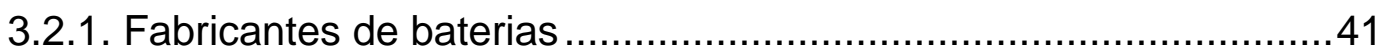

3.2.2. Dimensionamento do banco de baterias ....................................41

3.2.3. Exemplo do dimensionamento de um banco de bateriais .............454

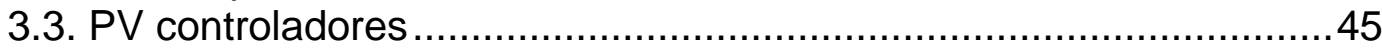

3.3.1. (MPPT) Controladores de Carga ............................................46

3.3.2. Dimensionamento do controlador (MPPT) .................................46

3.3.3. Exemplo do dimensionamento de um controlador ........................47

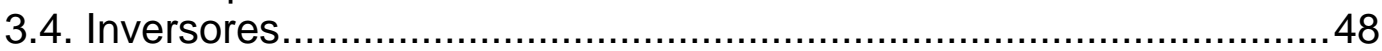

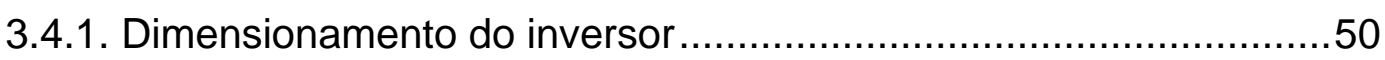

3.4.2. Exemplo de dimensionamento do inversor..................................50

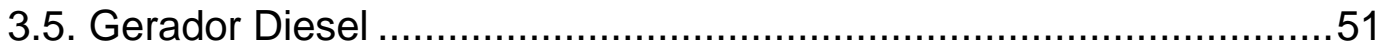

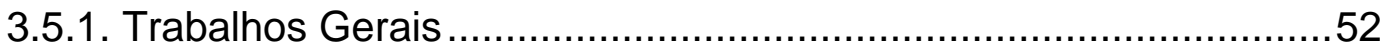

3.5.2. Questões Operacionais .......................................................... 52

3.5.3. Ignição-Parada em Motores Diesel .............................................53

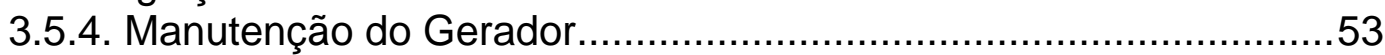

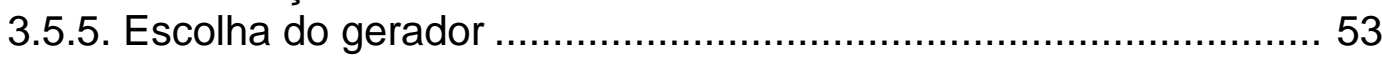

3.5.6. Gerador Diesel num Sistema Híbrido ..........................................55

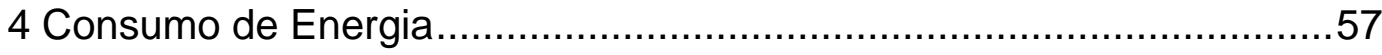

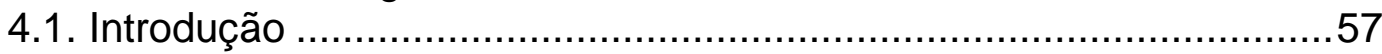

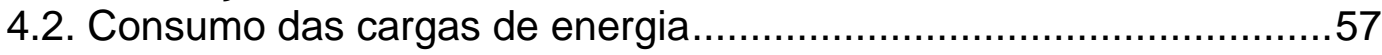

4.3. Estimativa do Consumo de Energia ............................................ 58

4.4. Exemplo de estimação do consumo de energia ..................................59 
4.5. Consumo de energia da agrovila.......................................60

5 Sistema Hibrído de Energia......................................................62

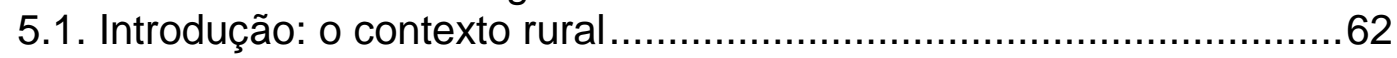

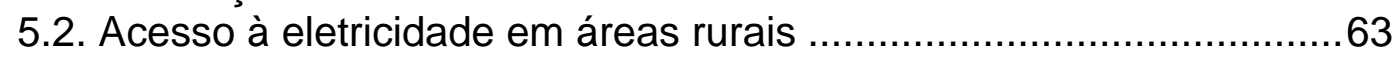

5.3. Produção elétrica auxiliar do sistema híbrido ..............................64

5.4. Aplicações e potencial para o sistema híbrido instalado e planejado.............................................................................. 65

5.5. Potencial para adaptação de sistemas diesel para sistemas

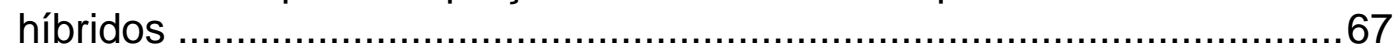

5.6. Sistema isolado típico e a eficiência de cada componente ..............6 69

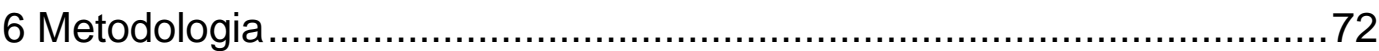

6.1. Procedimento proposto para a otimização do sistema isolado..........72

6.2. Análise de custo do gerador ............................................... 73

6.3. Custos do sistema (painéis, inversores, baterias e instalação) .........74

6.4. Custo da energia do sistema híbrido diesel-solar:..........................77

6.5. Avaliação estocástica .......................................................... 777

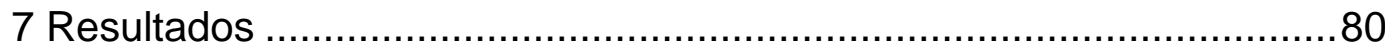

7.1. Simulações do sistema híbrido com dados solarimétricos diários

e horários:.................................................................................... 80

7.1.1. Variação da capacidade total de armazenamento das baterias .....81

7.1.2. Influência da demanda elétrica no custo da energia .....................85

7.1.3. Dissipação da produção solar de energia elétrica ........................ 87

7.1.4. Variação da capacidade operacional e total...............................88

7.1.5. Sistema autossuficiente (PV) ........................................... 91

7.2. Comparação entre o cálculo realizado com a do quantil...................92

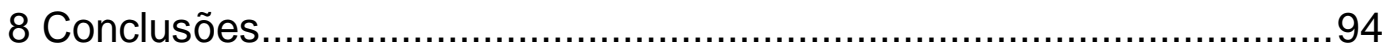

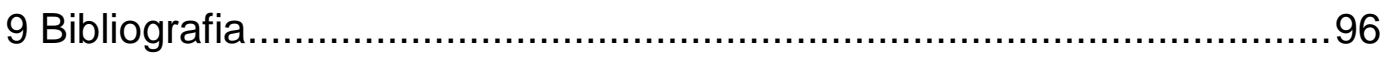




\section{Lista de figuras}

Figura 1: Produção mundial de módulos fotovoltaicos 1999 - 2011 .........22

Figura 2: Capacidade PV global instalada acumulada .........................22

Figura 3: Espectro de radiação ................................................... 23

Figura 4: n-camada e p-camada de célula de silício ............................ 24

Figura 5: Materiais fotovoltaicos e faixas de absorção ...........................225

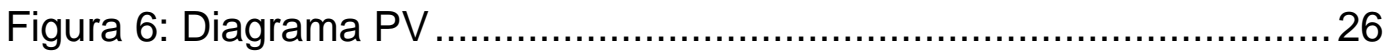

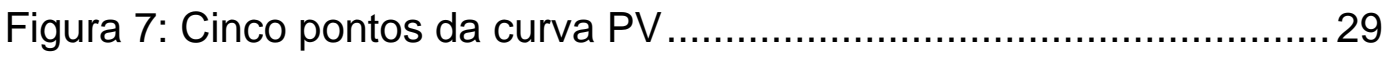

Figura 8: Eficiência da conversão (\%) .......................................... 30

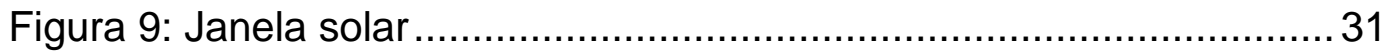

Figura 10: Irradiação direta e difusa................................................ 32

Figura 11: Média anual diária de radiação solar global ......................... 33

Figura 12: Localização de Manaus no Brasil........................................ 35

Figura 13: Localização de Manaus no Amazonas.................................. 34

Figura 14: Módulo Kyocera em $1000 \mathrm{~W} / \mathrm{m}^{2}$ e $340 \mathrm{~W} / \mathrm{m}^{2}$......................... 39

Figura 15: Módulo Kyocera em $1000 \mathrm{~W} / \mathrm{m}^{2}$ e $340 \mathrm{~W} / \mathrm{m}^{2}$....................... 39

Figura 16: Ciclos $X$ profundidade de descarga................................ 42

Figura 17: Exemplo de configuração de sistema de baterias .................. 45

Figura 18: Disposição do sistema .............................................. 48

Figura 19: O uso de combustível em função do fator de capacidade de

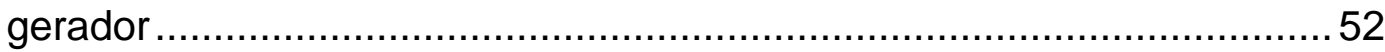

Figura 20: Grupo gerador diesel de 450 kVA .................................... 54

Figura 21: Consumo de energia de uma residência............................ 61

Figura 22: Configuração dos componentes de um sistema híbrido.......... 65

Figura 23: Sistema híbrido no arquipélago de São Pedro e São Paulo ...66

Figura 24: Limpeza dos módulos fotovoltaicos.................................66 66

Figura 25: Arranjo solar fotovoltaico de vila Campinas .........................68 68

Figura 26: Comunidade de Pouso da Cajaíba: E.M. Pouso da Cajíba.....68

Figura 27: Estação Científica do Arquipélago de São Pedro e São

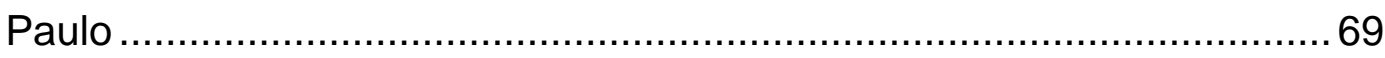

Figura 28: Configuração geral de um sistema isolado ..........................69 69

Figura 29: Relação entre potência instalada $\left(\mathrm{kW}_{\mathrm{p}}\right)$ versus energia

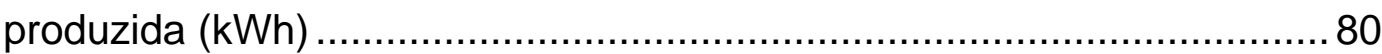


Figura 30: Relação entre a temperatura versus produção fotovoltaica .... 81 Figura 31: Variação do custo da energia com a capacidade total de armazenamento das baterias, usando-se dados diários.

Figura 32: Variação do custo da energia com a capacidade total de armazenamento das baterias, usando-se dados horários

Figura 33: Variação da energia produzida pelo gerador versus energia fotovoltaica com a capacidade total de armazenamento das baterias para a mesma profundidade de descarga (40\%).

Figura 34: Variação do custo da energia versus energia produzida pelo gerador diesel com a capacidade total de armazenamento das baterias para a mesma profundidade de descarga (40\%).

Figura 35: Influência da demanda elétrica no custo da energia (dados diários)

Figura 36: Influência da demanda elétrica no custo da energia (dados horários)

Figura 37: Dissipação (kWh dc) da produção solar da energia elétrica, para diferentes profundidades de descarga, capacidade total de 1027 kWh (dados diários)

Figura 38: Dissipação (kWh dc) da produção solar da energia elétrica, para diferentes profundidades de descarga, capacidade total de 1027 kWh, usando-se dados horários

Figura 39: Simulação horária com 40\% de profundidade de descarga e variação da capacidade total e operacional

Figura 40: Simulação horária com 40\% de profundidade de descarga e variação da capacidade total e operacional (energia dissipada versus kWh dc) 89

Figura 41: Variação da capacidade total, mas com profundidade de descarga constante (40\%) e sem a contribuição do gerador 91

Figura 42: Energia dissipada versus potência instalada ...................... 92

Figura 43: Quantil............................................................ 93

Figura 44: Histograma da distribuição dos custos de energia ................. 93

Figura 45: Seleção da potência instalada ............................................ 93

Figura 46: Seleção do sistema de baterias. ....................................... 93 


\section{Lista de tabelas}

Tabela 1: Médias Diárias Solarimétricas .............................................. 36

Tabela 2:Potência Típica dos Aparelhos .......................................... 58

Tabela 3: Cálculo da estimativa de consumo de energia .......................60

Tabela 4: Consumo mensal da agrovila ..........................................6 60

Tabela 5: Consumo horário em p.u e em kWh do mês de outubro da

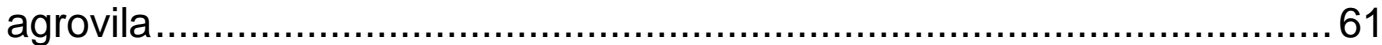

Tabela 6: Listas das Eficiências ....................................................... 70

Tabela 7: Dados de carga e de consumo diesel e lubrificante ............... 72

Tabela 8: Dados do sistema....................................................... 73

Tabela 9: Dados do sistema ...................................................... 74

Tabela 10: Dados do sistema ........................................................ 83

Tabela 11: Valores da fração solar, diesel e o custo da energia.............. 83

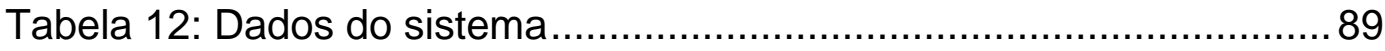

Tabela 13: Valores da fração solar, diesel e o custo da energia ..............90 90

\section{Nomenclatura}

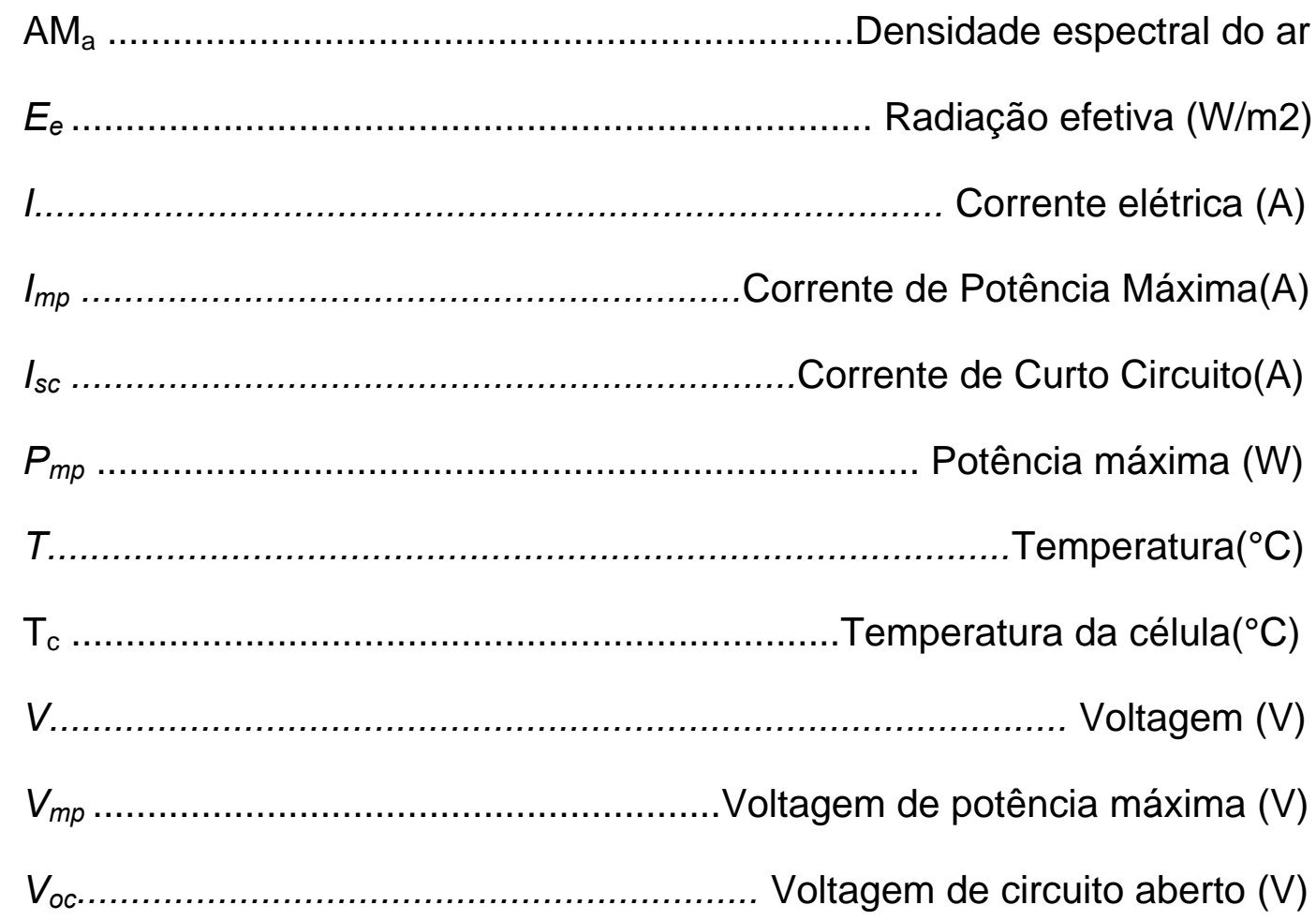




\section{Letras gregas}

$\alpha_{I m p}$......Coeficiente de temperatura de corrente de potência máxima $\left(\mathrm{A} /{ }^{\circ} \mathrm{C}\right)$

$\alpha_{l s c} \ldots \ldots . . . . .$. Coeficiente de temperatura de corrente de curto-circuito $\left(\mathrm{A} /{ }^{\circ} \mathrm{C}\right)$

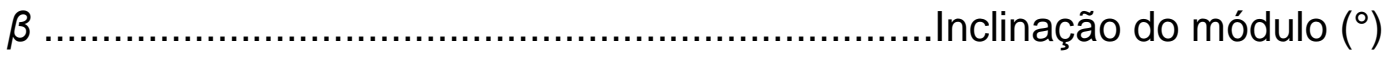

$\beta_{\vee m p}$..Coeficiente de temperatura de voltagem de potência máxima $\left(\mathrm{V} /{ }^{\circ} \mathrm{C}\right)$

$\beta_{\text {Voc }}$........Coeficiente de temperatura de voltagem de circuito aberto $\left(\mathrm{V} /{ }^{\circ} \mathrm{C}\right)$

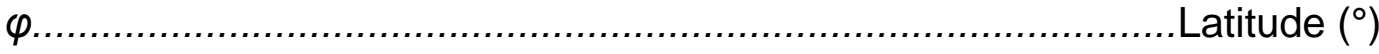




\section{Abreviações}

$A C$ Corrente alternada BOS. Gerenciador do sistema CEC Comissão de Energia da Califórnia DC. Corrente direta NREL .Laboratório Nacional de Energia Renovável PV. Fotovoltaico

SAM System Advisor Model STC Condições de teste padrão $T M Y$ Ano meteorológico típico (TMY2 e TMY3 são atualizações) TRNSYS. Programa de Sistema de Simulação Transiente

\section{Unidades usadas}

${ }^{\circ} \mathrm{C}$

Grau Celsius

$\mathrm{eV}$ elétron volt

$\mathrm{kW}$ kilowatt (1x103 Watts)

kWh. kilowatt-hora

$\mathrm{R} \$$ Reais

$\mathrm{m}$. metro

W. Watt $\mathrm{W}_{\mathrm{ac}}$ Watt corrente alternada $W_{\mathrm{dc}}$ Watt corrente direta $W_{p}$ Watt pi 


\section{Modelo King}

$a_{0}, a_{1}, a_{2}, a_{3}, a_{4}$

Coeficientes de densidade espectral do ar

AOI, $\theta$ Ângulo de incidência solar

$b_{0}, b_{1}, b_{2}, b_{3}, b_{4}, b_{5} \ldots \ldots \ldots . .$. Coeficientes modificadores do ângulo de incidência $C_{0}, C_{1} \ldots \ldots \ldots . . . .$. Coeficientes relacionados com o $I_{m p}$ da irradiância $\left(C_{0}+C_{1}=1\right)$ $C_{2}, C_{3} \ldots \ldots \ldots \ldots \ldots \ldots \ldots$. Coeficientes relacionados com o $V_{m p}$ da irradiância $C_{4}, C_{5} \ldots \ldots \ldots$..... Coeficientes relacionados com o $I_{x}$ da irradiância $\left(C_{4}+C_{5}=1\right)$

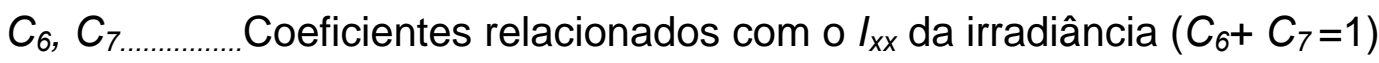

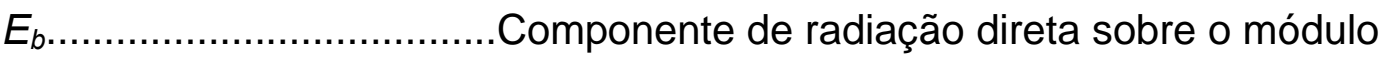

$E_{b}=E_{b n} \cdot \cos (\mathrm{AOI})$ $\left(\mathrm{W} / \mathrm{m}^{2}\right)$ $E_{\text {diff } \ldots \ldots \ldots \ldots \ldots \ldots \ldots \ldots \ldots \ldots \ldots \ldots \ldots \ldots \ldots \ldots}$ Componente difusa sobre o módulo $\left(\mathrm{W} / \mathrm{m}^{2}\right)$ $E_{e}$ Radiação efetiva adimensional $E_{o}$ Radiação na STC $\left(1000 \mathrm{~W} / \mathrm{m}^{2}\right)$ $f_{1}\left(\mathrm{AM}_{\mathrm{a}}\right) \ldots \ldots \ldots \ldots \ldots \ldots \ldots \ldots \ldots \ldots \ldots \ldots \ldots$ Influência espectral relativa a corrente $\left(I_{s c}\right)$

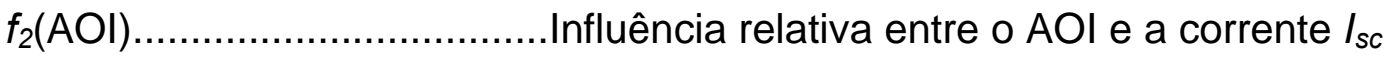

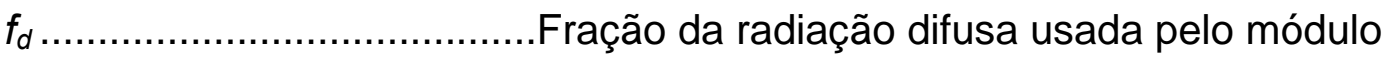

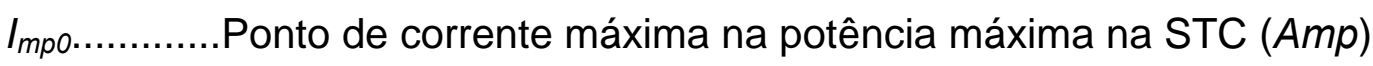
$I_{s c}$ Corrente de curto circuito $(A m p)$ $I_{s c 0}$ Ponto de corrente de curto circuito na STC (Amp) $I_{x}$ Corrente com $\mathrm{V}=0.5 \mathrm{~V}_{o}(A m p)$ $I_{x 0}$ Corrente com V=0.5 Voc na STC(Amp) $I_{x x}$ Corrente com $\mathrm{V}=0.5\left(V_{m p}+V_{o c}\right)(A m p)$ $I_{x x 0}$ Corrente com $\mathrm{V}=0.5\left(V_{m p}+V_{o c}\right)$ na STC $(A m p)$ k Constante de Boltzmann (1.38066e-23 J/K)(J/K) $q$ Carga elementar (1.60218e-19 Coulomb)(C) 


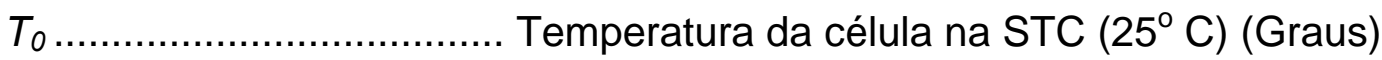

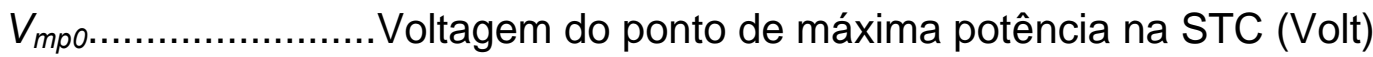

$V_{o c}$ Voltagem de circuito aberto(Volt)

$V_{\text {oco }}$ Voltagem de circuito aberto na STC (Volt) 


\section{Siglas do sistema de otimização}

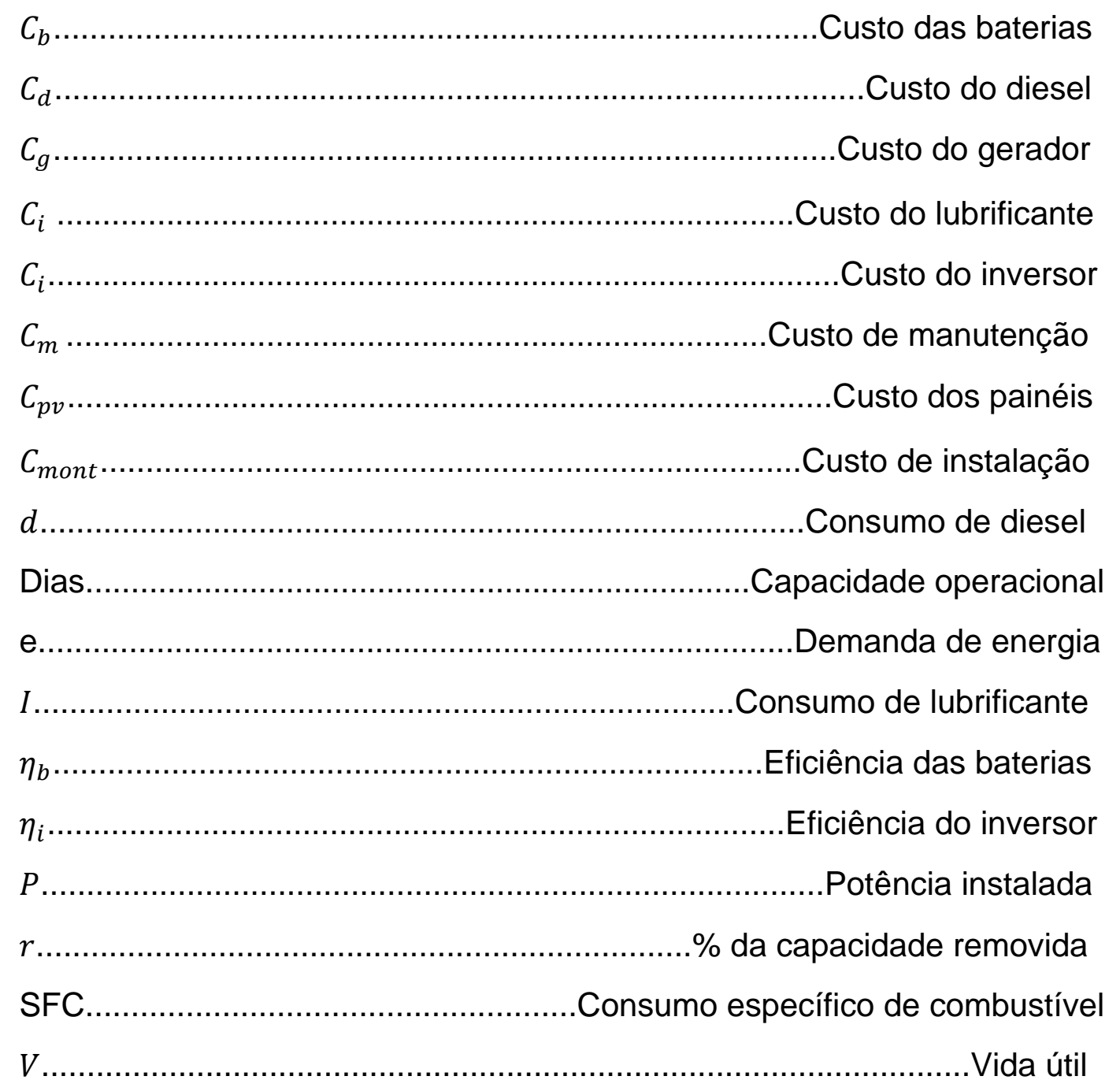




\section{Introdução}

O crescimento populacional tem causado inúmeros problemas ao nosso planeta, sendo um deles o aumento da escassez das fontes de energia usuais e, por conseguinte, o seu encarecimento. Portanto, um objetivo adicional de nossa sociedade tem sido procurar e desenvolver novas fontes. Nestas duas últimas décadas, a energia solar e eólica, tem sido o objeto de muitos estudos e pesquisas. Aumentar nossas possibilidades de produção de energia evidencia-se de suma importância, uma vez que em um futuro próximo ter-se-á mais instrumentos para enfrentar este desafio. Além disso, torna-se notório também a necessidade de se produzir fontes alternativas de energia de maneira sustentável como forma de se minimizar os impactos ambientais. Em outras palavras, necessita-se que a fonte de energia seja renovável e com ampla disponibilidade. Pelo exposto é possível verificar que energia solar, como fonte de energia elétrica, se encaixaria de maneira adequada. (MUHIDA et al., 2001) e (BARBOSA et al., 2004).

No passado, a produção de painéis fotovoltaicos possuía um custo elevado, inviabilizando sua expansão. Entretanto, nos últimos anos, houve uma forte redução do custo de aquisição do mesmo. O uso de novos materiais e processos de fabricação deixa claro, que em um futuro próximo, haverá uma grande expansão do seu uso. Uma maneira de baixar custos é o uso conciliado com outras fontes. Por isto, a questão que surge é, qual a melhor configuração e em qual nicho de mercado ela se encaixa.

No Brasil, um país de grande extensão geográfica, um sistema dessa natureza melhoraria a qualidade de vida das populações rurais e ribeirinhas, uma vez que diminuiria a dependência de energia subsidiada pelo país para as referidas populações. (AGHOSSOU et. al., 2001; KHAN E IQBAL, 2005; VALE et. al., 2004)

O objeto de estudo será a comunidade ribeirinha chamada Campinas, localizada no Estado do Amazonas. Os dados climáticos considerados para o dimensionamento do sistema são oriundos da capital do estado (Manaus), região equatorial com reduzidas diferenças climáticas entre as sub-regiões deste estado e com 
abundância de recursos solares, o que torna a análise bastante favorável. O horizonte da análise será de 25 anos.

\section{1.}

\section{Objetivos da Dissertação}

O objetivo principal desta dissertação é formular um modelo de energia solar híbrido que contribua para a diminuição dos custos de eletrificação de uma comunidade remota. Além disso, propor um procedimento de otimização capaz de determinar a melhor combinação entre a quantidade de energia solar disponibilizada e geração diesel do sistema (quantidades de painéis solares e geradores diesel) que atenderá de forma satisfatória a demanda pré-determinada com o menor custo possível.

Será mostrado que o uso de dados horários em contrapartida dos diários resultou em um melhor dimensionamento de projeto. Fontes de energia renovável como, por exemplo, a solar ou eólica podem se ajustar bem para a produção de eletricidade. No entanto, possuem um caráter intermitente que as faz pouco confiáveis em termos de estabilidade de produção. Por isto, no uso de tais fontes energéticas em sistemas offgrid (desconectados da rede) é também necessária a inclusão de um sistema de armazenamento de energia (um banco de baterias) de forma a atender a demanda da comunidade em momentos de redução ou não geração de energia. No entanto, a quantidade de armazenamento de energia necessária é tipicamente enorme, resultando em um custo de implementação expressivo. Assim, este trabalho observa a relevância do armazenamento como também o tamanho ideal para as condições da localidade.

Assim sendo, buscou-se com o dimensionamento do sistema viabilizar economicamente este conjunto, ou seja, objetivou-se maximizar o uso dos painéis fotovoltaicos, banco de baterias e gerador diesel. 


\section{2.}

\section{Revisão da Literatura}

Um sistema de energia isolado é definido como um sistema autônomo que fornece eletricidade sem conexões com a rede de eletricidade. São sistemas concebidos para serem implementados em áreas remotas com o intuito de que estas áreas adquiram independência energética. $\mathrm{O}$ sistema autônomo consiste de painéis $\mathrm{PV}$, gerador e baterias para fornecimento de eletricidade à carga sem acesso à rede. A natureza intermitente da energia solar torna mais difícil para regular a potência de saída gerada a partir desta fonte para atender à carga.

Existem vários fatores que afetam os sistemas autônomos como o tempo e localização, recursos energéticos, clima, meio ambiente, leis físicas e assim por diante. Vários autores consideram estes diversos fatores e analisam um sistema de energia solar híbrido para alimentar um vilarejo.

Esta seção revisa a literatura de sistemas isolados:

Em Borowy e Salameh (1994, 2006), os autores propuseram um método para calcular o tamanho ideal de um banco de baterias e um conjunto de painéis PV para um sistema isolado. Seu algoritmo Pascal calculou a quantidade de painéis PV e baterias necessárias para um sistema utilizando um tipo de turbina e painel, variando a quantidade de unidades PV.

Já em Kellogg et al. (1998), os autores utilizaram um método de otimização para calcular os componentes para um sistema isolado híbrido e determinar a capacidade de geração ótima com um determinado armazenamento. Eles usaram um tipo de módulo solar, um tipo de bateria e variaram o número de unidades a serem utilizados. Calcularam também, a distância mínima entre a linha de distribuição mais próxima e um vilarejo existente. Justificando assim, a instalação de um sistema autônomo de geração em oposição à construção de uma extensão de linha para alimentar a carga.

Daming et al. (2005), utilizaram um algoritmo genético para otimizar o dimensionamento de um sistema de energia híbrido PV. O objetivo era minimizar o capital total e o custo, sujeito à restrição de fornecimento de energia para o sistema. Eles provaram que algoritmos genéticos convergem muito bem para alcançar o custo mínimo de produção. A metodologia proposta mostrou-se viável para 
dimensionamento ideal de um sistema de energia híbrido. Os referidos autores observaram também que o uso de um algoritmo genético fornece um número de soluções possíveis para um determinado problema e a escolha de uma solução final é deixada para o usuário.

NREL, Laboratório Nacional de Energia Sustentável (2007), desenvolveu um programa chamado Homer. Este programa simplifica a tarefa de avaliar um projeto isolado ou ligado à rede, usando algoritmos para a otimização. O supracitado algoritmo, bem como a análise de sensibilidade do Homer permite o cálculo do tamanho ideal do sistema, além da escolha de uma gama de componentes que melhor se ajustem ao sistema com o menor custo de produção possível. Uma limitação do programa consiste no fato de que somente dois tipos de turbinas eólicas e um tipo de módulo solar podem ser utilizados em sua análise. No entanto, é um programa útil, se o usuário souber exatamente que tipo de turbina de vento e módulos solares que ele estará usando para o sistema híbrido.

\section{3.}

\section{Estrutura dos Capítulos Posteriores}

O capítulo 2 apresenta os conceitos básicos dos sistemas de atendimento (geração de energia elétrica) com energia solar, penetração da energia solar, tecnologias dos módulos e painéis solares, dados solares diários para cidade de Manaus e uma apresentação resumida do dimensionamento dos componentes. $\mathrm{O}$ Capítulo 3 apresenta equipamentos auxiliares, tais como baterias, controladores, inversores e gerador diesel. O capítulo 4 apresenta o consumo de energia e a estrutura da carga. Capítulo 5 apresenta o modelo proposto para otimização de um sistema isolado de produção de energia híbrida. O Capítulo 6 apresenta diferentes cenários simulados de um sistema autônomo, em Campinas, usando o proposto modelo de otimização. Finalmente as conclusões são apresentadas no Capítulo 7. 


\section{2}

\section{Sistemas Fotovoltaicos}

\section{1. \\ Introdução}

Células solares fotovoltaicas são feitas de material semicondutor que tem a propriedade de conduzir eletricidade, medida em watts ou kilowatts. Quando atingida por raios solares transformam diretamente radiação solar em eletricidade diferindo das fontes tradicionais, porque não utilizam conversão mecânica ou termal. Muitos painéis fotovoltaicos têm estado em operação nas mais variadas condições externas. Na Terra e no espaço por mais de 30 anos. (LUQUE et al., 2003).

\section{2. \\ História}

Tudo começa em 1839, com o físico francês Alexander Edmond Becquerel, que descobriu o efeito fotovoltaico ao conduzir uma experiência com uma célula eletrolítica composta de dois eletrodos de metal. Quando as células foram expostas à luz, produziram eletricidade USDE (2004). Em 1954, no Laboratório Bell foi produzida a primeira célula de silício. Logo foram encontradas aplicações nos programas espaciais dos EUA por sua alta capacidade de geração de energia por unidade de peso. Desde então, tem sido amplamente utilizada para converter luz solar em energia elétrica nos satélites que orbitam nosso planeta. $\mathrm{O}$ amadurecimento nas aplicações espaciais tornou a tecnologia PV em mais uma opção alternativa de produção energética. As aplicações energéticas terrestres vão desde o fornecimento de energia elétrica a locais remotos até a utilização da geração conectados a rede em diversas cidades no mundo. No passado o custo da geração solar e da tecnologia fotovoltaica era bastante elevado, o que inviabilizava seu uso em larga escala. Com isso seu uso estava limitado a locais remotos não conectados a rede. Entretanto com a queda dos preços dos painéis PV, este mercado tem crescido a uma taxa de 25 a $30 \%$ por ano, durante os últimos 5 anos (PATEL, 2006). A Fig. 1 mostra o crescimento da produção de PV de 2000 a 2011. Já a 
Fig. 2 expõe capacidade PV global instalada acumulada na Europa e em outras partes do mundo. É importante salientar que o mercado on grid europeu é o que tem mais crescido e especialmente o alemão, por causa do encarecimento das fontes tradicionais de energia, barateamento da tecnologia PV além de uma política de incentivos a geração distribuída.

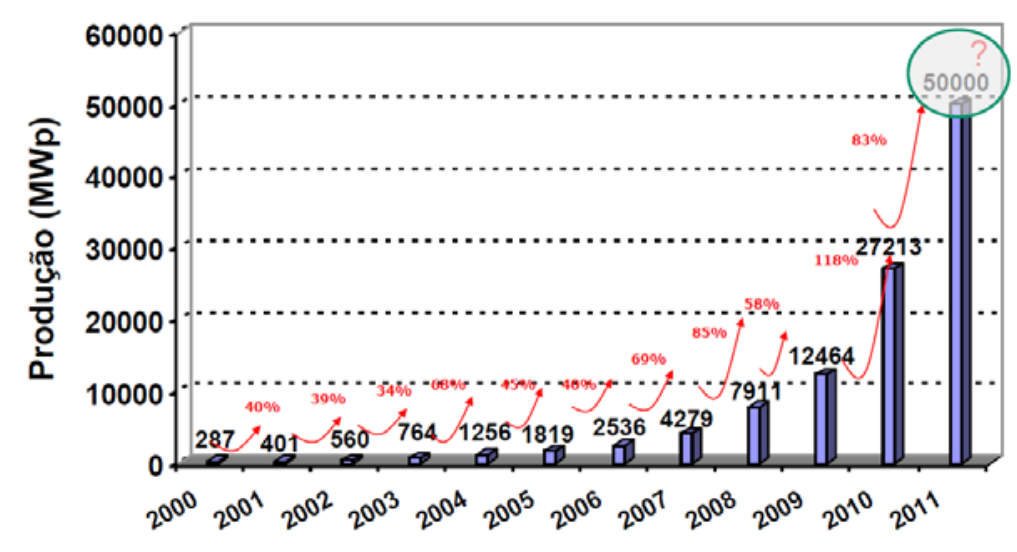

ano

Fonte: Internacional Photon ( 2011); Análise da produção de células(2011)

Células PV \& Módulos - Suprimento \& Demanda( 2011)

Figura 1: Produção mundial de módulos fotovoltaicos 1999 - 2011

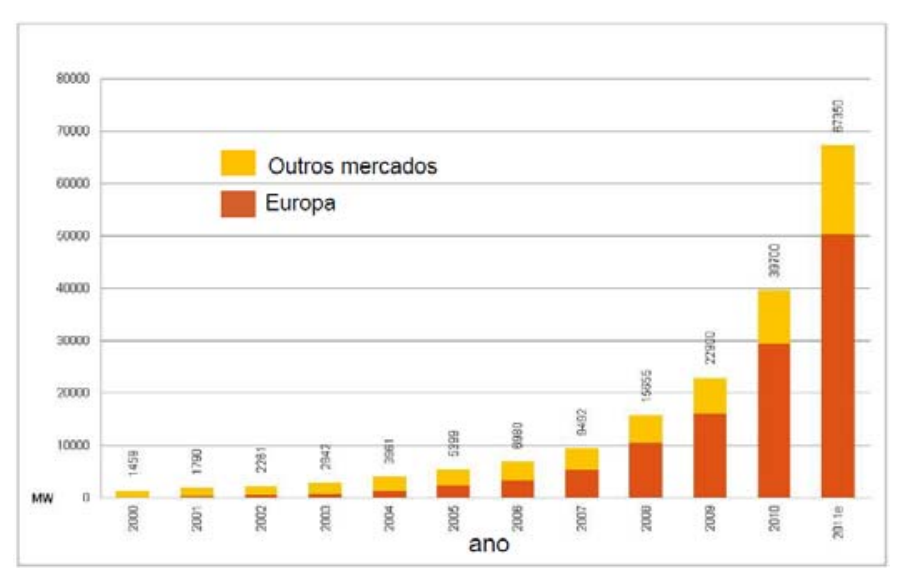

Fonte: EPIA - Relatório de mercado (2011)

Figura 2: Capacidade PV global instalada acumulada

\section{3.}

\section{Conversão Energética}

Radiação solar é a energia térmica emitida pelo sol. A radiação é emitida com uma frequência $(f)$ e comprimento de onda $(\lambda)$. A frequência e comprimento de onda estão relacionados com a velocidade $(v)$ em que o fóton viaja $3,0 \times 10^{8} \mathrm{~m} /$ s para a luz: 


$$
v=f . \lambda
$$

A energia $(E)$ de um fóton de radiação solar é em função da frequência $(f)$, representado a constante de Planck $(h)$ por:

$$
E=h . f
$$

O espectro total da radiação é mostrado na Fig. 3. O sol emite a maioria da sua radiação em uma pequena banda em torno do espectro da luz visível, como ilustrado na Fig. 3. O espectro de luz solar cobre comprimentos de onda de $2 \times 10^{-7}$ $\mathrm{m}$ de $4 \times 10^{-6} \mathrm{~m}$, e as energias de $0,5 \mathrm{eV}$ a $2,9 \mathrm{eV}$. Cada comprimento de onda tem uma frequência e energia associada a ela, o mais curto comprimento de onda (em unidades de m), maior a frequência (em unidades de $\mathrm{Hz}$ ) e maior o fóton de energia (em unidades de elétron-volts, ou eV).

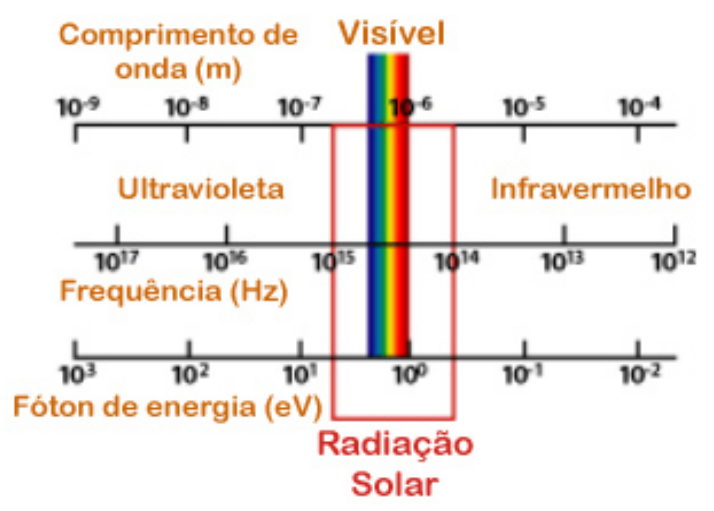

Fonte: MYERS, 2010

Figura 3: Espectro de radiação

O efeito fotovoltaico é criado quando um fóton de radiação solar é absorvido por um átomo na estrutura cristalina de silício. Se a energia do fóton é alta o suficiente, um elétron da camada mais externa do átomo de silício será liberado. O resultado é um par elétron-buraco, no qual há um buraco criado pelo elétron vago na estrutura cristalina. O elétron é impedido de se recombinar com o buraco, criando uma barreira de potencial, através da qual existe uma carga estática. A eletricidade estática, ou tensão, é a força que impulsiona o fluxo de elétrons através da célula. A barreira para a recombinação é criada por uma saturação de silício em um lado da barreira com boro para formar uma camada de silício-p (carga positiva), que tem uma deficiência de elétrons. O outro lado da barreira é saturado com 
fósforo para formar uma camada n-silício (carga negativa), que tem um excesso de elétrons. As camadas são conectadas por um circuito através do qual os elétrons possam fluir, formando corrente elétrica. Quando a n-camada absorve fótons, o fluxo de elétrons atravessa por um fio para a p-camada. Um esquema de construção de uma célula de silício mono cristalino é mostrado na Fig. 4 (DEPARTAMENTO DE ENERGIA, USA, 2009). O Departamento de Energia dos EUA possui muitas informações sobre o funcionamento de células solares fotovoltaicas através de seu Programa Solar Energy Technologies (SETP) disponível no site: http://www1.eere.energy.gov/solar/photovoltaics.html.

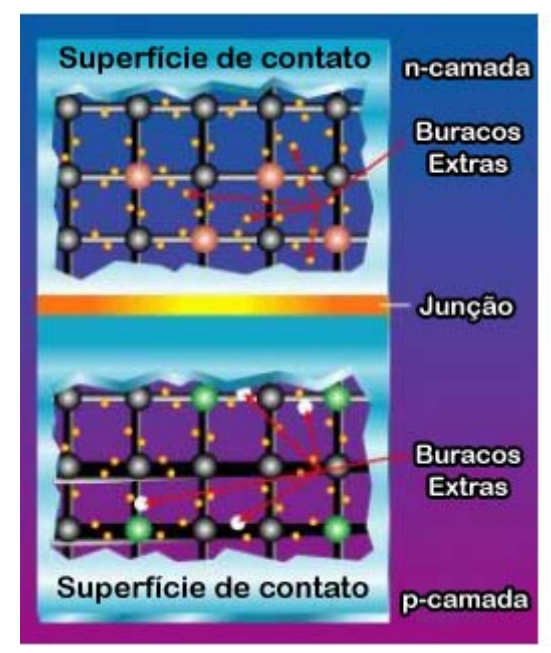

Fonte: MYERS, 2010

Figura 4: n-camada e p-camada de célula de silício

Diferentes materiais fotovoltaicos respondem com uma eficiência diferente a cada comprimento de onda da radiação. As células fotovoltaicas são apenas capazes de utilizar a radiação solar incidente em uma faixa de comprimento de onda relativamente estreita. A energia da lacuna da banda é a quantidade de energia necessária para deslocar um elétron de sua ligação covalente e permitir que ele se torne parte de um circuito elétrico (DEPARTAMENTO DE ENERGIA, SEMICONDUTORES, USA, 2009). A energia da lacuna da banda é o mínimo de energia utilizável pela célula PV. A energia da radiação incidente deve ser maior ou igual à energia da lacuna da banda do material fotovoltaico para criar elétrons livres na estrutura atômica. Silício cristalino, com energia de $1,1 \mathrm{eV}$ de lacuna da banda, pode utilizar a energia em todo o espectro visível, bem como parte do espectro infravermelho (DEPARTAMENTO DE ENERGIA, PV, USA, 2009). A 
luz vermelha tem uma energia de $1,7 \mathrm{eV}$ e energia da luz azul de 2,7 eV. Radiação abaixo da lacuna da banda de energia não é utilizável pela célula e é convertida em calor. Da mesma forma, a energia em excesso da célula, pode torna-se calor. A energia de lacuna da banda três materiais diferentes é mostrado na Fig. 5.

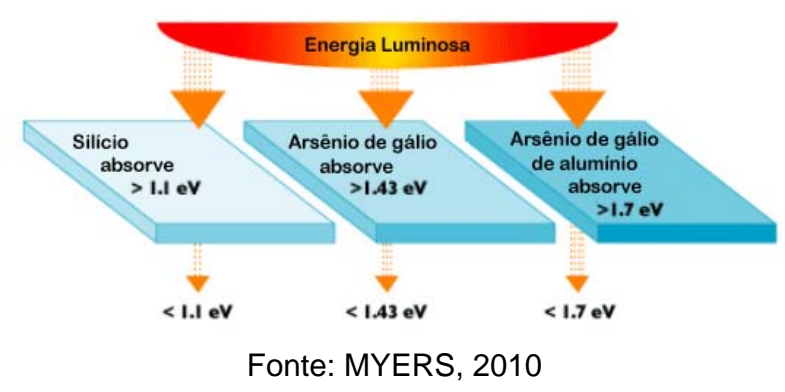

Figura 5: Materiais fotovoltaicos e faixas de absorção

Células de silício PV podem teoricamente, apenas converter cerca de $45 \%$ da energia solar, porque a diferença está fora da faixa de banda de energia (DEPARTAMENTO DE ENERGIA, SEMICONDUTORES, USA, 2009). Aproximadamente $25 \%$ da radiação solar terrestre está abaixo desta faixa de banda. A energia de radiação superior a lacuna de banda é desperdiçada, representando os outros $30 \%$ de energia da entrada. Outros materiais têm limitações semelhantes.

\section{4.}

\section{Células Fotovoltaicas}

As células solares que são utilizadas tanto em casas quanto em satélites são alinhadas de maneira a formar módulos. Esses módulos PV, por sua vez, consistem de inúmeras células PV ligadas em paralelo a fim de aumentar a corrente elétrica e em série objetivando elevar tensão. Luque (2010) exemplifica que, de maneira usual, o setor industrial PV monta um painel solar com 36 células.

Cabe aqui ressaltar que ao se referir a um painel $\mathrm{PV}$, significa um número de módulos, já a expressão "conjunto", significa um aglomerado de painéis fotovoltaicos, conforme ilustrado na Fig. 6. 


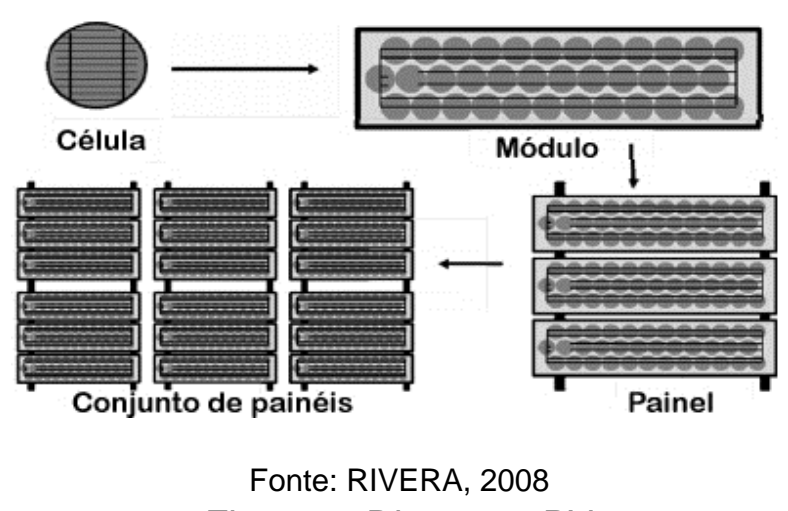

Figura 6: Diagrama PV

Atualmente, Green et al. (2000), existem cinco tecnologias comerciais para células $P V$ :

- Silício Monocristalino: Este é o produto mais antigo e mais caro tecnicamente falando, mas também é a tecnologia de conversão mais eficiente da luz solar disponível. Eficiência comercial média acima de 13,5\%.

- Silício Policristalino: Possui uma conversão um pouco mais baixa do que o monocristalino eficiência em relação a anterior e o custo, um pouco menor também. Eficiência comercial média entre $10 \%$ e $13 \%$.

- Silício Policristalino em fita: Esta é um refinamento da produção de silício policristalino. Há menos trabalho em sua produção, assim os custos são ainda mais baixos. Eficiência comercial média de $8 \%$ a $10 \%$.

- Filme Fino "cobre-índio-disseleneto": Esta é uma alternativa promissora às células de silício. Elas são muito mais resistentes ao efeito de sombreamento e altas temperaturas, e oferecem a promessa de custo muito menor. Eficiência comercial média de $9 \%$.

- Silício Amorfo: Feito de material de silício quando é vaporizado e depositado em vidro ou aço inoxidável. O custo é menor do que qualquer outro método. Eficiência comercial média de 4\% a 7\%.

A eficiência das células diminui com o aumento da temperatura. Células cristalinas são mais sensíveis ao calor do que as células de filmes finos. A produção de energia da uma célula cristalina diminui aproximadamente $0,5 \%$ com cada aumento de um grau Celsius na temperatura da célula. Por esta razão, os módulos devem ser mantidos em ambiente o mais fresco possível. Em condições muito quentes, dá-se preferência às células de silício amorfo devido a baixa redução na 
sua produção de energia, de somente $0,2 \%$ para cada grau Celsius de aumento. (ANTONY et al., 2007)

\section{5.}

\section{Módulos Fotovoltaicos}

Um módulo fotovoltaico é composto de células fotovoltaicas interligadas e encapsuladas entre uma cobertura à prova de intempéries (geralmente de vidro) e placa traseira (geralmente um plástico laminado). Ela também terá um ou mais protetores de diodos de passagem. Os terminais de saída, seja em uma caixa de junção ou em forma de cabos de saída, estarão localizados na parte de trás. A maioria tem frames e aqueles que não têm frames, são chamados laminados. Em alguns, a placa traseira também é de vidro, que dá uma maior taxa de fogo, mas quase duplica o peso (ANTONY et al., 2007).

As células nos módulos estão conectadas em uma configuração projetada para oferecer uma tensão útil e uma corrente nos terminais de saída. Células ligadas em série aumentam a tensão de saída, enquanto as células ligadas em paralelo aumentam a corrente. Um grupo de vários módulos PV que estão ligados entre si, são chamados de painel solar.

\section{6.}

\section{Potência Fotovoltaica}

Nesta dissertação, o cálculo da produção fotovoltaica dos painéis $P V$, será realizado com base no modelo king do laboratório Sandia(King, D.L.,1996), apresentado nas Eq. (2.1) - (2.11). O modelo calcula o curto-circuito atual $\left(I_{s c}\right)$, de corrente e tensão no ponto de potência máxima ( $I_{m p}$ e $V_{m p}$, respectivamente), as correntes em dois pontos intermediários $\left(I_{x}\right.$ e $\left.I_{x x}\right)$, e a tensão de circuito aberto $\left(V_{o c}\right)$.

$$
\begin{aligned}
I_{s c} & =I_{s c o} f_{1}\left(A M_{a}\right)\left[1+\alpha_{I s c}\left(T_{c}-T_{0}\right)\right]\left[\frac{E_{b} f_{2}(A O I)+f_{d} E_{\text {diff }}}{E_{0}}\right] \\
I_{m p} & =I_{m p o}\left[C_{0} E_{e}+C_{1} E_{e}^{2}\right]\left[1+\alpha_{I p m}\left(T_{c}-T_{0}\right)\right]
\end{aligned}
$$




$$
\begin{gathered}
I_{x}=I_{x o}\left[C_{4} E_{e}+C_{5} E_{e}^{2}\right]\left[1+\frac{\alpha_{I s c}+\alpha_{I m p}}{2}\left(T_{c}-T_{0}\right)\right] \\
I_{x x}=I_{x x 0}\left[C_{6} E_{e}+C_{7} E_{e}^{2}\right]\left[1+\alpha_{I p m}\left(T_{c}-T_{0}\right)\right] \\
V_{m p}=V_{m p o}+C_{2} N_{s} \delta\left(T_{c}\right) \ln E_{e}+C_{3} N_{s}\left[\delta\left(T_{c}\right) \ln E_{e}\right]^{2}+\beta_{V m p}\left(E_{e}\right)\left(T_{c}-T_{0}\right) \\
V_{o c}=V_{o c o}+N_{s} \delta\left(T_{c}\right) \ln E_{e}+\beta_{v o c}\left(E_{e}\right)\left(T_{c}-T_{0}\right) \\
E_{e}=\frac{P_{m p}=I_{m p} \cdot V_{m p}}{I_{s c o}\left\lfloor 1+\alpha_{I s c} \cdot\left(T_{c}-T_{0}\right)\right\rfloor} \\
\delta\left(T_{c}\right)=n k \frac{\left(T_{c}+273,15\right)}{q} \\
f_{1}\left(A M_{a}\right)=a_{0}+a_{1} A M_{a}+a_{2} A M_{a}^{2}+a_{3} A M_{a}^{3}+a_{4} A M_{a}^{4} \\
f_{2}(A O I)=b_{0}+b_{1} A O I+b_{2} A O I^{2}+b_{3} A O I^{3}+b_{4} A O I^{4}+b_{5} A O I^{5}
\end{gathered}
$$

A potência máxima pode ser calculada diretamente, substituindo os valores $I_{m p}$ e $V_{m p}$ das Equações (2.2) e (2.5) na Eq. (2.7).

Em resumo, as entradas:

$$
I_{s c 0}, I_{m p 0}, I_{x 0}, I_{x x 0}, V_{m p 0}, V_{o c 0}, E_{b}, E_{d i f f}, E_{0}, f_{d}, T_{c}, T_{0}, \alpha_{I s c}, \alpha_{I m p}, \beta_{V o c}, \beta_{V m p}, N_{s},
$$
$n, k, q, C_{0}, C_{1}, C_{2}, C_{3}, C_{4}, C_{5}, C_{6}, C_{7}, f_{1}\left(A M_{a}\right), f_{2}(A O I)$

Conhecido ou fornecido pelo fabricante:

$$
I_{s c 0}, I_{m p 0}, V_{m p 0}, V_{o c 0}, E_{b}, E_{d i f f}, E_{0}, f_{d}, T_{c}, T_{0}, \alpha_{I s c}, \beta_{V o c}, N_{s}, n, k, q
$$

Resultados:

$$
I_{s c}, I_{m p}, I_{x}, I_{x x}, V_{m p}, V_{o c}, P_{m p}, E_{e}, \delta\left(T_{c}\right)
$$

Se $f_{1}\left(A M_{a}\right)$ e $f_{2}(A O I)$ devem ser calculados, as equações (2.10) e (2.11) são usadas e os seguintes parâmetros são necessários:

Para $f_{1}\left(A M_{a}\right): a_{0}, a_{1}, a_{2}, a_{3}, a_{4}, A M_{a}$ 
Para $f_{2}(A O I): b_{0}, b_{1}, b_{2}, b_{3}, b_{4}, b_{5}, A O I$

Os coeficientes $\left(C_{0^{-}} C_{7}, a_{0^{-}} a_{4}, b_{0^{-}} b_{5}\right.$, etc. $)$ são determinados a partir de testes anteriores realizados nos painéis.

Equações (2.1) - (2.7) fornecem informações sobre apenas 5 pontos, correspondendo a:

$$
\begin{aligned}
& V=0 \\
& V=0.5 \quad V_{o c}=V_{x} \\
& V=V_{m p} \\
& V=0.5\left(V_{m p}+V_{o c}\right)=V_{x x} \\
& V=V_{o c}
\end{aligned}
$$

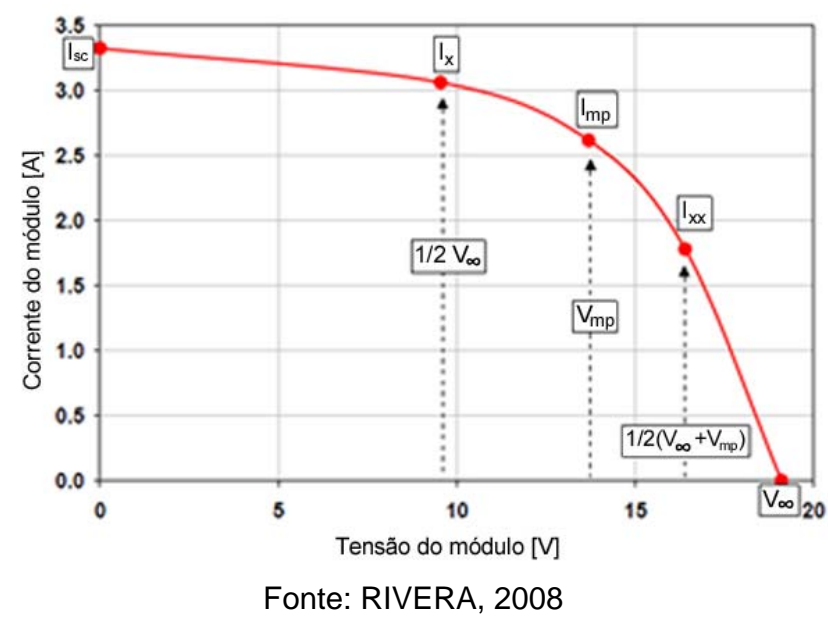

Figura 7: Cinco pontos da curva PV

A Fig. 7 objetiva expor os cinco pontos relevantes da curva PV, onde o ponto de curto-circuito $\left(I_{s c}\right)$ que é o ponto de corrente máxima e resistência zero. $\left(V_{m p}\right)$ que é ponto potência máxima e os pontos de correntes intermediários $\left(I_{x} \mathrm{e}\right.$ $\left.I_{x x}\right)$. Além do ponto de tensão máxima $\left(V_{o c}\right)$ e corrente zero.

\section{7.}

\section{Energia Fotovoltaica}

Para calcular a energia gerada em um ano $(\mathrm{kWh})$ para uma determinada localidade, utiliza-se a hora solar média de radiação de um ano médio para o determinado local, medido em $\mathrm{kW} / \mathrm{m}^{2}$. Calcula-se por hora a potência produzida 
pelo módulo usando uma fórmula simples, que é multiplicar a potência solar de entrada pela eficiência da célula.

$$
\begin{gathered}
\eta=\frac{P_{S T C}}{E_{\text {in }}} \\
P_{\text {saida }}=\eta \cdot E_{i} \cdot C_{f}
\end{gathered}
$$

Onde:

$\eta=$ Eficiência da conversão

$P_{S T C}=$ potência $25^{\circ} \mathrm{C}$ e $1000 \mathrm{~W} / \mathrm{m}^{2}$

$E_{\text {in }}=1000 \mathrm{~W} / \mathrm{m} 2(\mathrm{STC}$, condição de teste padrão)

$P_{\text {saida }}=$ Potência produzida

$E_{i}=$ Radiação solar efetiva atingindo o módulo em W/m²

$C_{f}=$ Fator de correção de $\eta$

Este método é rápido e só requer a potência produzida pelo módulo fotovoltaico a $1000 \mathrm{~W} / \mathrm{m}^{2}$, sendo este o nível de radiação atingindo pelo módulo. O método supõe que a eficiência do painel solar é constante em qualquer nível de radiação. No entanto, na prática não é assim. A eficiência é inferior para níveis baixos de radiação, como pode ser observado na Fig. 8. A Fig. 8 apresenta a eficiência de conversão fotovoltaica de um módulo solar Kyocera KC200. Visualiza-se um acréscimo de somente 5\% na eficiência do módulo para valores de radiação $600 \mathrm{~W} / \mathrm{m}^{2}$ a $1000 \mathrm{~W} / \mathrm{m}^{2}$. Isto sugere um fator de correção de $95 \%$, quando se usa este método de estimativa rápida.

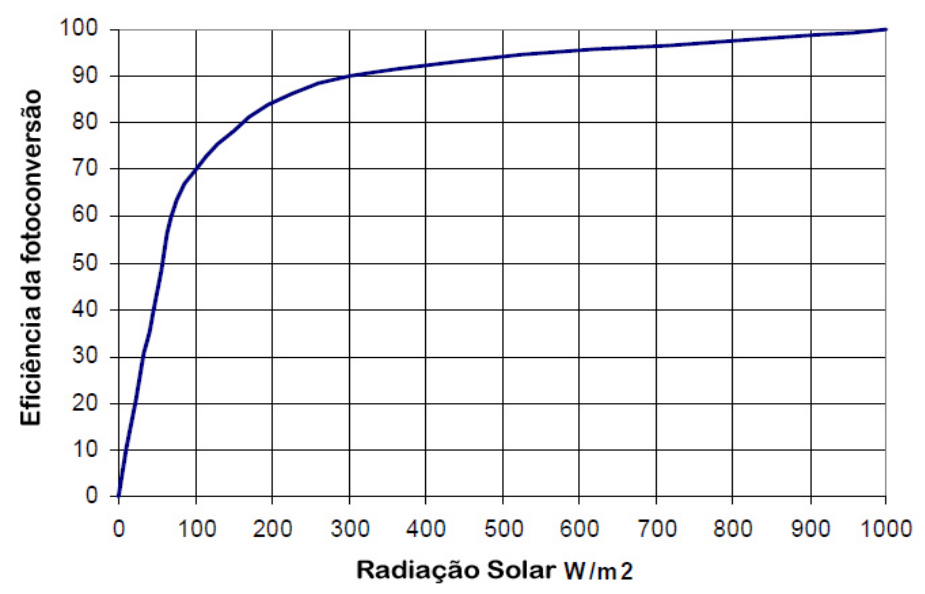

Fonte: SOTO, 2004

Figura 8: Eficiência da conversão (\%) 
Então, para calcular a produção energética disponível de um módulo fotovoltaico em uma localidade específica, utiliza-se a seguinte equação:

$$
E_{P V}=P_{\text {saida }}\left(E_{x}\right) .(\text { Janela Solar).(365) }
$$

Onde $E_{P V}$ é a produção de energia fotovoltaica anual prevista $(\mathrm{kWh})$ na localidade. A janela solar é o tempo em horas que o painel $P V$ fica exposto ao sol em um dia a uma determinada radiação média horária, como mostrado na Fig. 9.

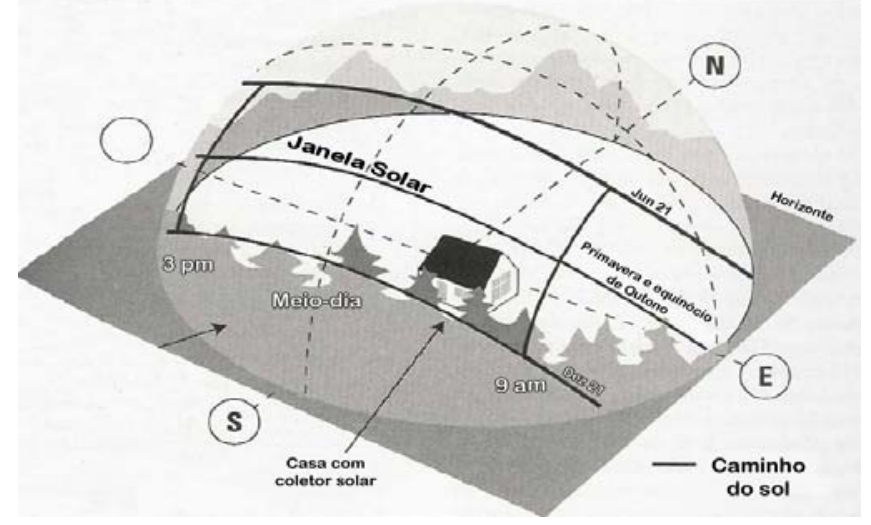

Fonte: PVDI, 2004

Figura 9: Janela solar

Para obter a potência produzida anualmente basta multiplicar o valor obtido por 365. Já a variável $P_{\text {saida }}\left(E_{x}\right)$ é a potência média produzida pelo módulo sob uma radiação solar horária média $\left(E_{x}\right)$. (RIVERA,2008)

\section{8.}

\section{Fabricantes de Painéis Fotovoltaicos}

Módulos fotovoltaicos apresentam uma variedade de tamanhos. Aqueles utilizados em grade amarrada ou sistemas autônomos variam de 80w a 300w. O desempenho de módulos $P V$ e matrizes são geralmente classificados de acordo com sua potência máxima de energia $D C$ (watts) segundo as Condições de Teste Padrão $(S T C)$. Condições de teste padrão são definidas por um módulo operacional com temperatura de $25^{\circ} \mathrm{C}$ do módulo, um nível incidente de energia solar incidente de $1000 \mathrm{~W} / \mathrm{m}^{2}$, velocidade do vento de $1 \mathrm{~m} / \mathrm{s}$ e massa de ar igual a 1,5 (relação entre a massa da atmosfera atravessada pela radiação solar e a que seria a- 
travessada com o sol ao zênite - igual à secante do ângulo de zênite). Entretanto, como estas condições não estão sempre presentes na realidade, os conjuntos de painéis em condições operacionais irão atuar com um desempenho inferior à condição padrão, sendo este desempenho, de aproximadamente, 85 a 90 por cento das condições STC. (JIMENEZ,1998)(SCHUHMACHER,1993).

Conforme Rivera (2008), os módulos fotovoltaicos utilizados atualmente são produtos seguros e confiáveis, com uma taxa de insucesso mínima e vida útil projetada de serviço de 25 a 30 anos. Os principais fabricantes garantem que a potência nas condições STC não é menor do que $90 \%$ do valor inicial até 10 anos de operação, e $80 \%$ entre 10 e 25 anos.

\section{9 .}

\section{Recursos Solares}

A radiação solar que alcança nosso planeta é abundante. A quantidade total de energia, que é irradiada do sol para a superfície terrestre, equivale a aproximadamente 10.000 vezes o consumo anual de energia global. Em média, 1.700 kWh por metro quadrado é a insolação a cada ano (PATEL, 2006).

A radiação solar que atinge a superfície terrestre possui principalmente dois componentes: radiação solar direta e difusa. A radiação solar direta é o feixe de raios que atinge o solo sem nenhum desvio e a luz difusa é o somatório de todos os raios solares que se desviaram, espalhados por partículas de poeira e água na atmosfera. (Fig. 10).

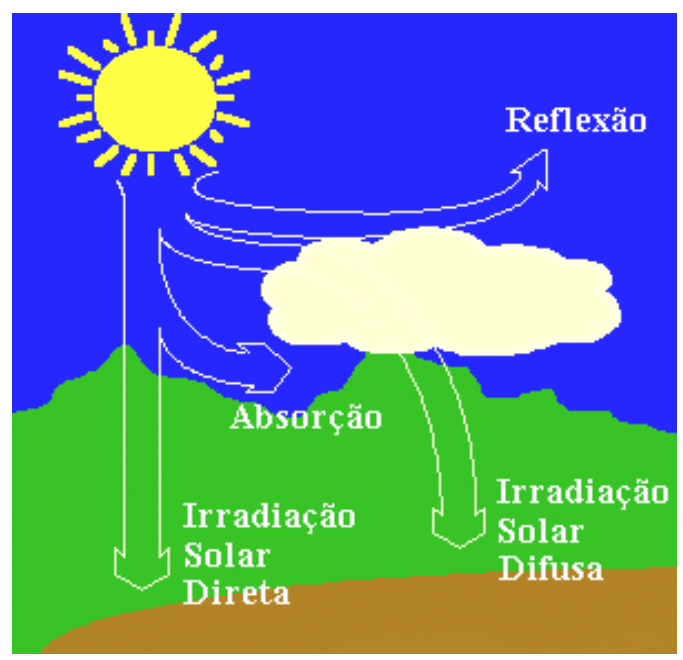

Fonte: CRESESB.CEPEL,2003

Figura 10: Irradiação direta e difusa 
Células fotovoltaicas não só utilizam a componente direta da luz, mas também podem produzir eletricidade quando o céu está nublado, apesar de seu baixo desempenho. Quando se quer avaliar o potencial de geração de eletricidade PV para um determinado lugar, é importante avaliar a energia solar total média recebida durante o ano, ao invés de referir-se a radiação instantânea. Um bom exemplo disso é a média de radiação solar anual do Brasil. A radiação solar média anual é mostrada na Fig. 11.

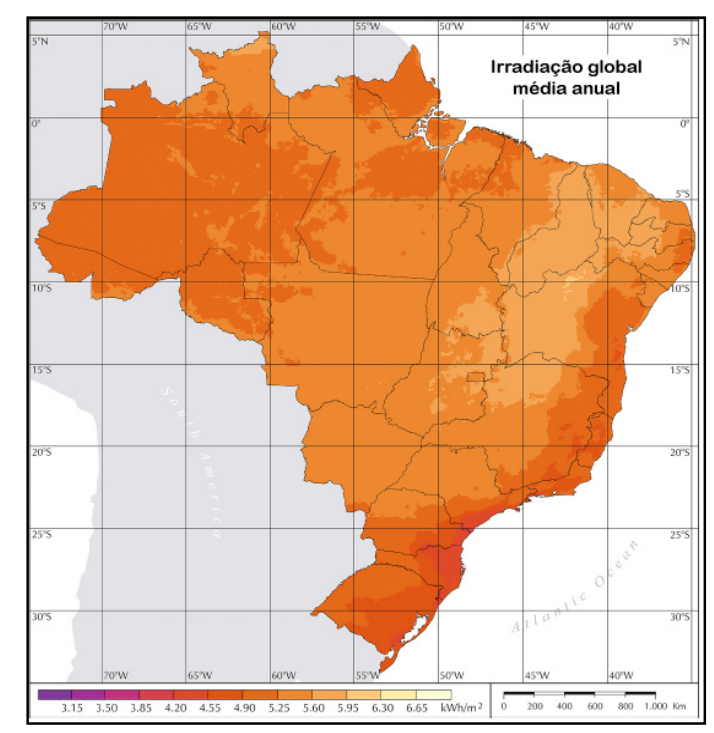

Fonte: Atlas Solarimétrico do Brasil (2000)

Figura 11: Média anual diária de radiação solar global

Por meio do uso das células fotovoltaicas, esta radiação pode ser transformada e gerar eletricidade. Quando a radiação atinge uma célula fotovoltaica, uma diferença de potencial é criada. Assim, este fluxo elétrico percorre através da célula podendo ser coletado. Nem toda a radiação pode ser convertida em eletricidade; as células $P V$ utilizam, principalmente, a luz visível. A maior parte da energia solar é em infravermelho ou calor e radiação ultravioleta, o que explica a eficiência de conversão teórica ser tão baixa (20\% a 30\%). Deficiências práticas, tais como impurezas podem diminuir o desempenho de uma célula fotovoltaica ainda mais (Luque et al. 2003). Conforme pode ser visto na Fig. 10, a quantidade de eletricidade útil gerada por um módulo $P V$ está diretamente relacionada com a intensidade de radiação solar, que incide sobre a área de conversão. Em outras palavras, quanto maior for o recurso solar disponível, maior será o potencial de geração de eletricidade. Por exemplo, as regiões com baixa latitude, localizadas 
entre os trópicos, podem dispor de uma maior capacidade de geração de energia elétrica, pois nelas os dias tendem a ser mais longos. Porém, nos trópicos a radiação difusa será maior, dado que a umidade do ar também é maior devido à evaporação. (Luque et al. (2003)) salienta também que um sistema $P V$ não irá gerar eletricidade à noite, e é importante evitar que os módulos estejam em local totalmente ou parcialmente sombreado, pois nesta situação, se terá uma menor produção elétrica.

Caso haja demanda de por energia elétrica em horário noturno, bem como em dias contendo nebulosidade, haverá necessidade de um sistema de armazenamento de energia como, por exemplo, um banco de baterias. Outra solução possível seria a utilização de outras fontes energéticas; um sistema híbrido com geração diesel em backup se encaixaria nesta situação.

A célula fotovoltaica deve estar orientada o máximo de tempo para o sol. Se os painéis fotovoltaicos têm uma posição fixa, a sua orientação será para o norte (hemisfério sul) e a inclinação dos painéis em relação ao plano horizontal será igual a latitude do local. Já nas regiões mais próximas ao equador, este ângulo de inclinação será menor ou mesmo zero, uma vez os feixes solares incidem de maneira mais perpendicular nos painéis. Um desvio do ângulo de inclinação do ângulo ótimo resultará em uma menor conversão fotovoltaica. Com isto, quanto maior for à radiação direta, maior será o resultado obtido. Por exemplo, conforme ilustrado nas Fig. 11 e 12 a cidade de Manaus está localizada na Latitude $03^{\circ} 06^{\prime} 0^{\prime \prime} \mathrm{S}$ e longitude $60^{\circ} 01^{\prime} 0^{\prime \prime} \mathrm{W}$, o que significa que o ângulo de inclinação para a cidade deve ser baixo.

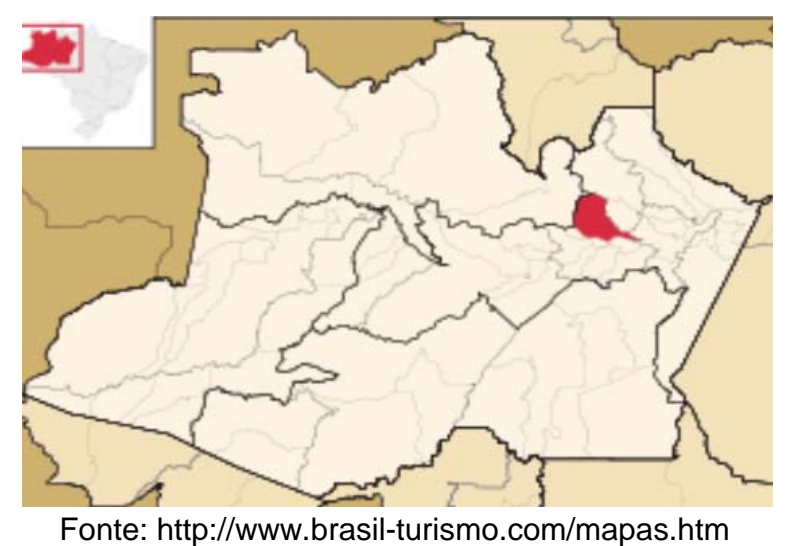

Figura 12: Localização de Manaus no Amazonas 


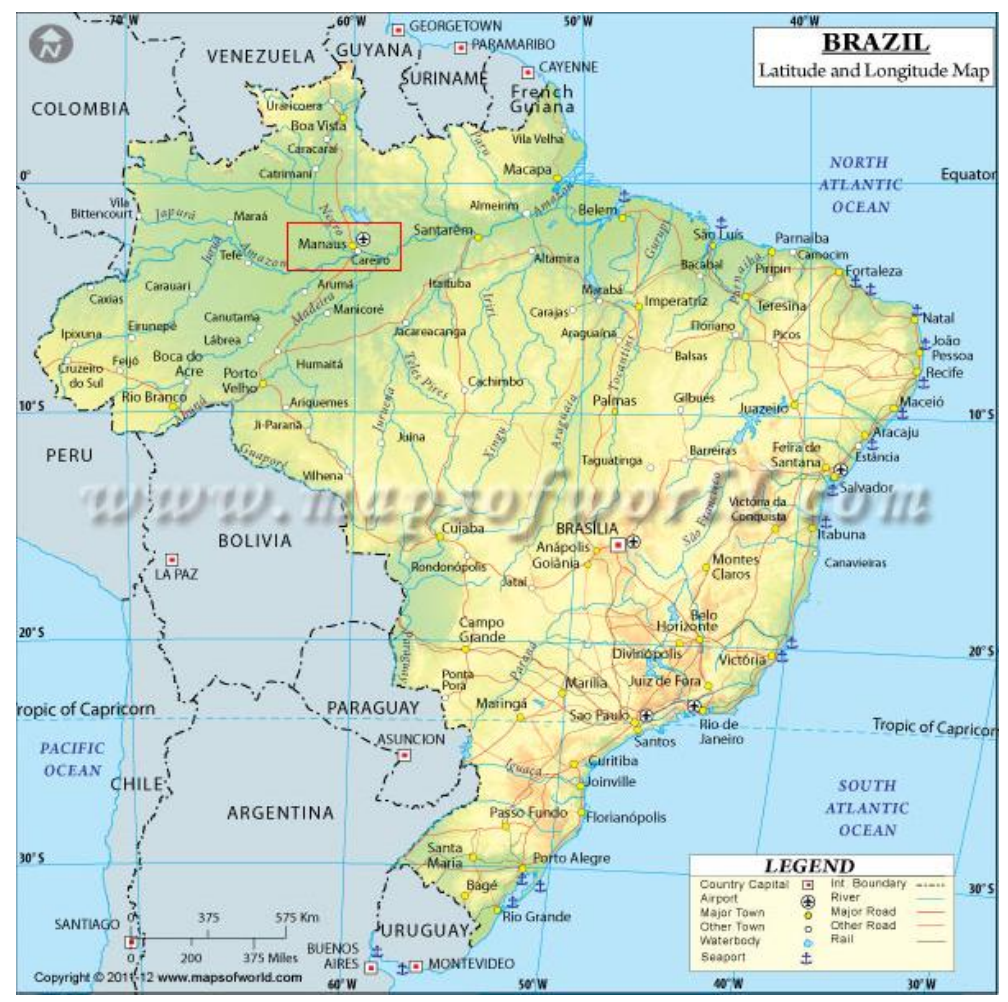

Fonte: www.mapsofworld.com

Figura 13: Localização de Manaus no Brasil

Módulos fotovoltaicos são realmente mais eficientes em temperaturas mais amenas; por isso, é importante garantir que eles não se superaqueçam, sendo essencial que a instalação seja efetuada de uma maneira que permita que o ar se mova livremente ao seu redor. Este fato deve ser observado principalmente em localidades que possuem propensão a elevadas temperaturas no meio do dia. Conforme o IEA (2006), as condições de geração $P V$ ideais, podem ser sintetizadas da seguinte maneira: temperaturas amenas, ar limpo, baixa umidade, dias ensolarados e sem a presença de nuvens.

\subsection{0 .}

\section{Recursos Solares de Manaus}

O recurso solar é um fator determinante do quanto será a produção de energia a partir de um sistema fotovoltaico. Na Tab. 1 apresenta-se um ano médio de radiação solar que mostra médias diárias e mensais em $\mathrm{kWh} /\left(\mathrm{m}^{2}\right.$.dia). Para efeitos do presente estudo, a temperatura média diária para a cidade em questão 
será $32,5^{\circ} \mathrm{C}$. Esta é a temperatura média horas por dia de radiação solar em Manaus.

Os dados solares médios diários foram obtidos junto a Eletrobras Amazonas Energia, sendo utilizados na presente dissertação para a realização das simulações diárias. No caso das simulações horárias, os dados são provenientes do Projeto Swera ${ }^{1}$. O banco de dados do projeto contém 29 anos de dados climáticos e solarimétricos e estão disponíveis na internet sem nenhum custo.

Tabela 1: Médias Diárias Solarimétricas

\begin{tabular}{|c|c|c|c|c|c|c|c|c|c|c|c|c|}
\hline Dia & Jan. & Fev. & Mar. & Abr. & Mai. & Jun. & Jul. & Ago. & Set. & Out. & Nov. & Dez \\
\hline 1 & 3,12 & 6,43 & 2,17 & 3,78 & 5,16 & 4,49 & 3,24 & 6,16 & 7,36 & 3,8 & 6,18 & 4,42 \\
\hline 2 & 7,25 & 2,02 & 6,88 & 1,85 & 4,91 & 4,62 & 4,40 & 6,06 & 7,30 & 5,30 & 7,43 & 5,12 \\
\hline 3 & 6,36 & 3,80 & 3,50 & 1,66 & 4,93 & 5,01 & 3,06 & 6,49 & 7,43 & 6,15 & 3,87 & 5,56 \\
\hline 4 & 7,30 & 6,29 & 6,15 & 3,68 & 2,19 & 6,25 & 5,58 & 5,30 & 5,30 & 4,12 & 5,02 & 2,50 \\
\hline 5 & 5,30 & 2,16 & 6,80 & 4,93 & 6,28 & 6,43 & 5,90 & 6,75 & 7,36 & 7,49 & 4,62 & 3,93 \\
\hline 6 & 4,49 & 4,09 & 6,76 & 6,75 & 5,68 & 5,95 & 6,47 & 6,84 & 7,49 & 4,69 & 5,3 & 4,42 \\
\hline 7 & 6,43 & 7,71 & 2,91 & 4,87 & 5,19 & 4,91 & 6,08 & 7,27 & 7,30 & 4,87 & 1,56 & 3,50 \\
\hline 8 & 2,80 & 5,87 & 5,21 & 5,23 & 5,78 & 3,47 & 5,71 & 6,34 & 6,86 & 4,75 & 1,37 & 4,42 \\
\hline 9 & 7,93 & 4,29 & 4,41 & 6,86 & 6,14 & 5,65 & 3,78 & 6,86 & 7,30 & 2,56 & 5,07 & 6,86 \\
\hline 10 & 5,25 & 5,28 & 2,40 & 5,58 & 5,85 & 2,06 & 5,93 & 5,86 & 6,86 & 6,62 & 5,30 & 6,95 \\
\hline 11 & 4,37 & 4,94 & 3,91 & 6,02 & 4,08 & 2,93 & 5,73 & 6,66 & 7,30 & 3,80 & 1,50 & 6,49 \\
\hline 12 & 6,80 & 3,73 & 3,91 & 3,84 & 6,18 & 4,24 & 3,65 & 6,56 & 7,51 & 3,93 & 5,87 & 5,47 \\
\hline 13 & 6,12 & 4,42 & 3,91 & 1,86 & 3,74 & 2,37 & 5,68 & 6,75 & 7,12 & 5,68 & 5,75 & 7,36 \\
\hline 14 & 3,80 & 2,37 & 3,91 & 4,86 & 3,40 & 6,37 & 4,65 & 6,65 & 7,05 & 7,36 & 5,25 & 5,80 \\
\hline 15 & 2,21 & 7,57 & 5,43 & 3,01 & 3,93 & 5,99 & 6,34 & 6,68 & 7,49 & 5,49 & 6,25 & 4,62 \\
\hline 16 & 5,05 & 4,66 & 6,04 & 1,16 & 4,64 & 5,19 & 6,25 & 6,63 & 7,05 & 5,34 & 5,68 & 4,87 \\
\hline 17 & 5,38 & 2,04 & 3,44 & 3,77 & 3,30 & 4,06 & 6,15 & 6,34 & 5,75 & 5,34 & 5,12 & 4,62 \\
\hline 18 & 4,22 & 1,57 & 2,43 & 1,28 & 5,43 & 5,93 & 6,58 & 6,54 & 6,68 & 5,37 & 7,79 & 1,87 \\
\hline 19 & 4,81 & 2,71 & 3,15 & 3,73 & 5,30 & 6,55 & 5,99 & 6,75 & 6,75 & 5,34 & 4,56 & 3,99 \\
\hline 20 & 5,69 & 1,88 & 1,87 & 1,34 & 5,87 & 4,75 & 6,49 & 6,28 & 6,68 & 4,49 & 6,62 & 2,31 \\
\hline 21 & 3,65 & 3,77 & 3,41 & 4,09 & 5,59 & 3,30 & 6,56 & 3,56 & 6,52 & 5,34 & 5,02 & 3,19 \\
\hline 22 & 6,22 & 3,02 & 2,83 & 2,99 & 4,09 & 3,43 & 6,58 & 6,16 & 4,56 & 2,69 & 1,62 & 3,30 \\
\hline 23 & 4,66 & 3,63 & 1,42 & 4,63 & 3,69 & 5,68 & 6,79 & 2,06 & 6,93 & 5,12 & 7,55 & 5,65 \\
\hline 24 & 5,26 & 4,16 & 2,90 & 2,54 & 6,56 & 6,33 & 4,30 & 2,93 & 5,30 & 4,30 & 6,36 & 2,29 \\
\hline 25 & 4,77 & 2,72 & 3,49 & 4,18 & 6,18 & 4,93 & 7,09 & 7,30 & 4,56 & 7,36 & 5,06 & 2,65 \\
\hline 26 & 7,84 & 2,86 & 5,70 & 1,99 & 1,83 & 5,30 & 6,86 & 6,79 & 7,05 & 7,18 & 5,02 & 4,95 \\
\hline 27 & 6,62 & 6,27 & 3,62 & 4,06 & 5,93 & 5,93 & 6,49 & 6,75 & 5,25 & 5,93 & 5,02 & 5,65 \\
\hline 28 & 5,75 & 4,52 & 5,97 & 3,62 & 4,06 & 5,30 & 4,69 & 5,77 & 6,18 & 7,18 & 5,02 & 1,91 \\
\hline 29 & 5,57 & - & 2,93 & 4,36 & 6,83 & 5,43 & 6,06 & 6,16 & 4,99 & 5,99 & 5,02 & 4,28 \\
\hline 30 & 4,75 & - & 0,63 & 3,20 & 2,83 & 4,62 & 7,12 & 6,06 & 4,06 & 5,34 & 5,02 & 5,08 \\
\hline 31 & 5,33 & - & 3,12 & - & 5,09 & - & 7,48 & 6,51 & - & 6,62 & - & 3,06 \\
\hline$\mu$ & 5,33 & 4,11 & 3,91 & 3,72 & 4,86 & 4,92 & 5,73 & 6,12 & 6,51 & 5,34 & 5,03 & 4,42 \\
\hline
\end{tabular}

Fonte: Eletrobras Amazonas Energia (1993)

\footnotetext{
${ }^{1}$ Projeto que auxilia paíss em desenvolvimento a alcançar uma matriz energética mais sustentável.
} 


\subsection{1.}

\section{Programa Solar (SAM)}

O modelo Solar (SAM) é uma ferramenta de software desenvolvido pelo Laboratório Nacional de Energia Renovável (NREL) e Laboratório Nacional Sandia (SNL), em parceria com o Departamento de Energia dos EUA do Programa de Tecnologias de Energia Solar (SETP). O SAM fornece um quadro coerente para analisar e comparar os custos do sistema de potência, desempenho e economia em toda a gama de tecnologias de energia solar e mercados. A versão 2011.12 do SAM foi usada nas simulações para este projeto de pesquisa. A versão 2011.12 tem a capacidade de modelar tecnologias fotovoltaicas de energia solar para aplicações elétricas em uma ampla gama de mercados, incluindo residencial, comercial e utilitário de propriedade sistemas. A versão utilizada do programa foi lançada em 2011 e inclui atualizações, como por exemplo, o banco de dados da Comissão de Energia da Califórnia (CEC), o banco de dados de inversor do Sandia e outras melhorias.

Modelos de desempenho do sistema do SAM utilizam o software TRNSYS desenvolvido na Universidade de Wisconsin combinados com componentes personalizados.

Nesta dissertação, o referido programa foi usado para simular a contribuição fotovoltaica com o modelo Sandia.

\subsection{2.}

\section{Ano meteorológico típico (TMY)}

Ano meteorológico típico (TMY) é um conjunto de dados de radiação solar horária e dados meteorológicos para um período de um ano. O TMY representa no longo prazo as médias meteorológicas para cada determinado local. Os dados são derivados a partir de medições de terra tomadas em locais específicos no mundo todo, e servem para serem utilizados em simulações de conversões de energia solar e sistemas de construção de carga de energia. Os mesmos não são apropriados para simulação de sistemas eólicos devido à prioridade dada as informações de radiação. Os dados do TMY não tem como finalidade a previsão da 
radiação solar ou tempo em um dado ano ou mesmo no horizonte de cinco anos, e sim tem como objetivo a previsão da média durante um longo período de tempo (30 anos), representando o longo prazo típico, ao invés de pontos extremos.

O TMY foi desenvolvido pelo Laboratório Nacional (NREL) e hoje já existem atualizações como os TMY2 e TMY3 (Hall I, Prairie R, Anderson H, Boes E.,1978). Os TMY2 e TMY3 são baseados na metodologia original, tendo sido atualizados os dados de origem e a ponderação dos fatores importantes (Marion W, Urban K.,1995). O método seleciona meses individuais de diferentes anos, que são considerados como os mais típicos. Ou seja, cada conjunto de dados para cada mês é julgado individualmente. Um mês típico é selecionado a partir de cada conjunto de meses sendo ele o que melhor representa a média em longo prazo. Por exemplo, em um conjunto de dados de 30 anos, cada mês tem 30 meses possíveis dos quais um será selecionado o mês mais típico. Este processo é repetido para cada mês até a obtenção de um ano completo. As descontinuidades nas interfaces do mês são suavizadas durante 6 horas em cada lado para permitir a um conjunto contínuo de dados. As ponderações para os dados de radiação solar (radiação global e radiação direta) têm prioridade sobre todas as outras medidas, respeitando o método original que é do laboratório Sandia.

O SAM utiliza o formato TMY para fazer sua predição.

\subsection{3.}

\section{Cálculo da energia gerada por um módulo solar}

Esta seção quer exemplificar o dimensionamento da quantidade de módulos necessários para o fornecimento de energia elétrica a uma demanda de $4000 \mathrm{~W}$ na cidade de Manaus, Amazonas. O passo a passo para o cálculo da energia gerada é o que segue:

1. Obtenção do dado representativo do valor do recurso solar da localidade. A título de exemplo, tem-se que a radiação solar média durante o mês de fevereiro em Manaus, conforme Tab. 1, é 4,11 k$\mathrm{Wh} / \mathrm{m}^{2}$ por dia.

2. Cálculo da janela solar de 12,1 horas (duração do dia a partir de latitude e declinação) obtendo $\left(4,11 \mathrm{kWh} / \mathrm{m}^{2}\right) /(12,1 \mathrm{~h})=340 \mathrm{~W} / \mathrm{m}^{2}$ 
de radiação solar média durante este período. Supondo uma temperatura de $32,5{ }^{\circ} \mathrm{C}$ e com o módulo da marca Kyocera Solar (KC200) que produz $200 \mathrm{~W}$ de potência a $1000 \mathrm{~W} / \mathrm{m}^{2}$ e $25^{\circ} \mathrm{C}$.

3. Com base nas Eq. (2.1) a (2.11) do modelo King (2006), calcula-se a potência gerada pelo módulo fotovoltaico. A Fig. 14 mostra a potência versus tensão PV e a Fig. 15 corrente versus tensão. Como especificado pelo fabricante, o módulo PV produz $200 \mathrm{~W}$ a 1000 $\mathrm{W} / \mathrm{m}^{2}$ e com uma radiação menor, a produção cai. A Fig. 15 expõe uma queda da corrente de 30\% com um nível de radiação menor.

4. Para atender uma carga de $4000 \mathrm{~W}$, basta dividir a carga pela energia gerada de um módulo, que é de $(4000 \mathrm{~W}) /(132 \mathrm{~W})=30,3$. Para tanto, com uma carga de $4000 \mathrm{~W}$, necessita-se de 31 módulos Kyocera.

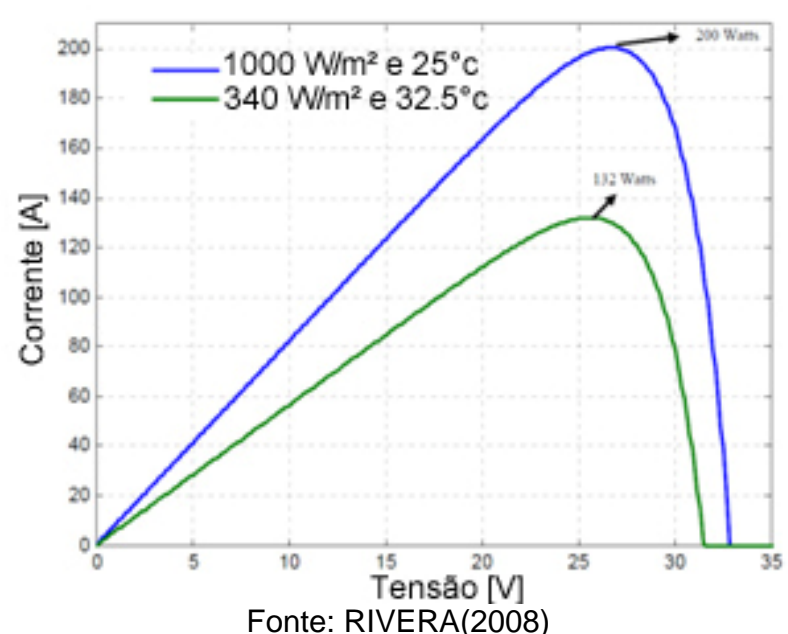

Figura 14: Módulo Kyocera em $1000 \mathrm{~W} / \mathrm{m}^{2}$ e $340 \mathrm{~W} / \mathrm{m}^{2}$

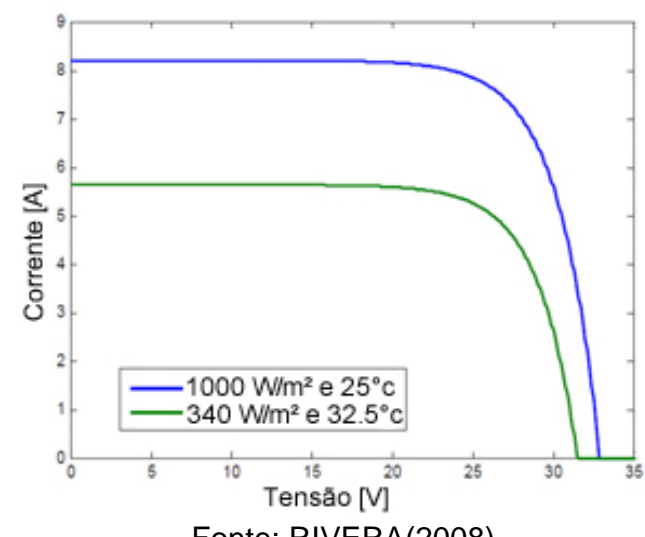

Fonte: RIVERA(2008)

Figura 15: Módulo Kyocera em $1000 \mathrm{~W} / \mathrm{m}^{2}$ e $340 \mathrm{~W} / \mathrm{m}^{2}$ 


\section{3}

\section{Baterias, Gerador, Controladores PV e Inversores}

\section{1.}

\section{Introdução}

A bateria é um dispositivo que armazena energia elétrica em corrente direta $(D C)$ numa forma eletroquímica para uso posterior. A quantidade de energia que será armazenada na bateria é gerenciada pelo controlador de carga e o inversor objetiva converter a energia elétrica $(D C)$ para corrente alternada $(A C)$, que é a forma de energia que a maioria dos aparelhos usa.

\section{2. \\ Baterias}

Nos dias atuais, as baterias possuem papel crucial no mundo por conta da sua extensa aplicabilidade, podendo ser utilizada em simples computadores desktop ou até mesmo em submarinos de últimas gerações. Entretanto, a eficiência de conversão das baterias não é perfeita, pois parte considerável da energia é perdida na forma de calor ou na reação química, durante a descarga.

Nem todas as baterias podem ser recarregadas, sendo, por isso, divididas em dois grupos. O primeiro grupo é o das pilhas, que apenas converte energia química em energia elétrica, não sendo recarregável. Já o segundo grupo contempla as baterias recarregáveis às quais são empregadas no sistema PV e em outras aplicações.

Conforme Luque et al. (2003) o componente interno de uma célula eletroquímica típica é o eletrodo. Dentro da bateria existem os eletrodos positivos e negativos com separadores de placas isolantes e um eletrólito químico entre eles. As células armazenam energia eletroquímica em um baixo potencial elétrico, tipicamente alguns volts. A capacidade da célula é medida em amperes-hora $(A h)$, que é uma medida da quantidade de carga que uma bateria pode fornecer por uma 
unidade de tempo. Um ampère é um fluxo de carga a uma taxa de um coulomb por segundo. Portanto, um número de ampère multiplicado por um tempo, fornece uma quantidade de carga. Da mesma forma, o watt-hora é uma medida da quantidade de energia que uma bateria pode fornecer: um watt é o fornecimento de energia a uma taxa de um joule por segundo. Assim, um número de watts multiplicados por um determinado período de tempo produz uma quantidade de energia.

\subsection{1.}

\section{Fabricantes de baterias}

Segundo Patel (2006), atualmente uma grande variedade de baterias estão disponíveis no mercado como, por exemplo: chumbo-ácido, níquel-cadmium, de níquel-metal, lítio-íon, de lítio-polímero e zinco-ar. As baterias de chumbo-ácido são recarregáveis e continuam a ser as mais usadas em aplicações de reserva de energia, já que uma tecnologia madura e alto desempenho considerando seu custo. Estas baterias de chumbo ácido vêm em duas versões mais usuais. A versão rasa do ciclo, que é a verificada em automóveis, em que uma pequena explosão de energia é extraída da bateria para iniciar o motor. Já a versão do ciclo de profundo, mostra-se adequada para ciclos de carga e de descarga completos repetidamente. Por fim, o autor ressalta que as baterias de ciclo profundo também são as requeridas para produção de energia intermitente.

\subsection{2.}

\section{Dimensionamento do banco de baterias}

O dimensionamento da capacidade do banco de baterias consiste em calcular o número de baterias necessárias para o sistema que está sendo simulado. Para isso precisa-se definir a quantidade de dias de autonomia que se deseja alcançar, sendo dois dias o mínimo para se atender a regulação vigente. Ou seja, é o número de dias que um banco de baterias vai suportar uma determinada carga sem ter sido recarregado. Se a carga a ser fornecida não é crítica, dois ou três dias de autonomia são normalmente necessários. Para cargas críticas, de cinco a sete dias de autonomia são recomendados. A carga crítica é aquela que tem ser contínua. 
Outro fator importante é a profundidade máxima de descarga da bateria. A profundidade de descarga está relacionada em como se utiliza a bateria e quanto de energia, será retirada dela. A maioria dos sistemas é projetada para descargas regulares de até $40 \%$, no entanto, a vida útil da bateria está diretamente relacionada em como ela é usada e também em como ela é mantida. Em outras palavras, é possível dizer que a vida útil da bateria está atrelada a quanto de profundidade de retirada de energia ela irá suportar e em quanto tempo ela voltará a ser recarregada, além é claro de como ela será mantida. Por exemplo, se uma bateria é descarregada em $50 \%$ a cada dia, ela irá durar em média, duas vezes mais do que se ela fosse submetida a uma profundidade de descarga de 80\% (PVDI, 2007).

Na Fig. 16 a seguir, se apresenta a relação entre profundidade de descarga e quantidade de ciclos. Considera-se um ciclo como sendo uma descarga e uma recarga, sempre retornando ao estado de $100 \%$ carregado. A troca do banco de baterias deve ocorrer seguindo a referida tabela ou cada 4 anos por questão de segurança.

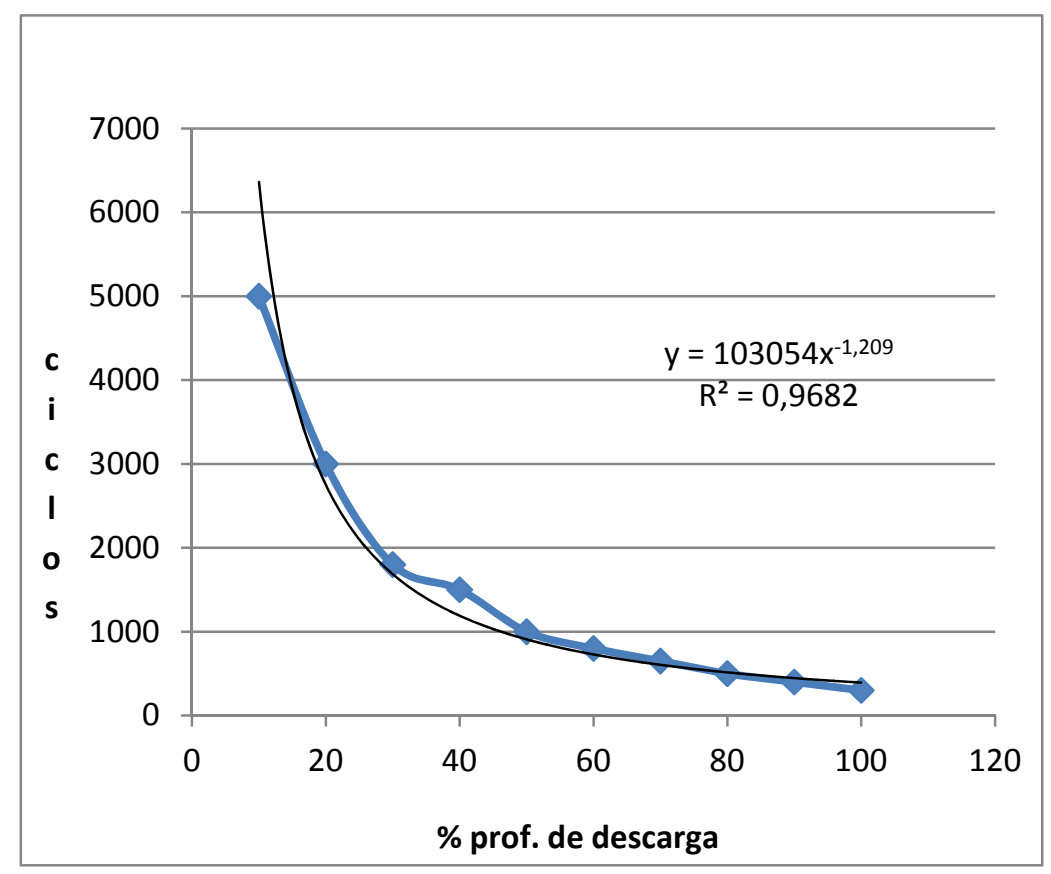

Fonte: www.batteryuniversity.com

Figura 16: Ciclos X profundidade de descarga 
A temperatura do ambiente é outro fator que afeta o desempenho das baterias. Os fabricantes geralmente recomendam que sejam armazenadas a uma temperatura de $25^{\circ} \mathrm{C}$, dado que a capacidade da bateria diminui em baixa temperatura e aumenta em temperatura mais alta. Ou seja a vida útil da bateria, se eleva com temperaturas menores e diminui à medida que esta aumenta. É importante salientar que a região Amazônica é bastante quente e úmida, portanto isto compromete bastante o banco de baterias.O procedimento a seguir mostra como calcular o número de baterias necessárias para um sistema de energia híbrido, Sandia (2004).

A Eq. 3.1 mostra como calcular o exigido de capacidade do banco de baterias para um sistema de energia híbrido renovável.

$$
B_{r}=\frac{L_{A h / D i a} \cdot D_{s t}}{M_{d d} \cdot D_{f}}
$$

onde,

$B_{r}$ é a requerida capacidade do banco de baterias $(A h)$

$L_{A h / D i a}$ é o consumo ampère-hora pela carga em um dia (Ah/dia);

$D_{s t}$ é o número de dias de autonomia;

$M_{d d}$ é a profundidade máxima de descarga;

$D_{f}$ é o fator de redução.

Equação 3.2 apresenta como calcular o número de baterias a ser conectado em paralelo para atingir a quantidade de ampère-hora requerida pelo sistema.

$$
B_{p}=\frac{B_{R}}{B_{C}}
$$

Onde $B_{R}$ é a capacidade requerida do banco $(A h)$. $B_{C}$ é a capacidade da bateria selecionada em $(A h)$ e $B_{p}$ é o número de baterias que são necessárias em paralelo.

Já a Eq. 3.3 é utilizada para calcular o número de baterias para ser conectado em série para alcançar a tensão requerida pelo sistema. 


$$
B_{S}=\frac{V_{n}}{V_{b}}
$$

Em que, $V_{n}$ é a tensão do sistema $D_{C}($ Volt $), V_{B}$ é a tensão da bateria (Volt) e $B_{S}$ é o número de bateria que precisa ser em série. O número total de baterias que são necessárias: é obtido multiplicando o número total de baterias em série com número total em paralelo, como mostrado na Eq. 3.4.

$$
N_{b}=B_{s} \cdot B_{p}
$$

$B_{s}$ é o número de baterias em série. $B_{p}$ é o número de baterias em paralelo. $N_{b}$ é o número total de baterias necessárias.

\subsection{3.}

\section{Exemplo do dimensionamento de um banco de baterias}

Para demonstrar o dimensionamento de um banco de baterias capaz de suprir uma carga elétrica DC de $4000 \mathrm{Wh} /$ dia, são necessários os seguintes dados: a tensão DC do sistema de bateria será de 48 volts, a autonomia será de três dias e a profundidade máxima de descarga será de 50 por cento. Como isto é um exemplo, será considerado que a temperatura das baterias permanecerá em $25^{\circ} \mathrm{C}$, deste jeito não ocorrerá nenhuma alteração na vida útil como também na sua capacidade de 357 Ah com 12 volts. O primeiro passo é dividir a carga do sistema que é de $4000 \mathrm{Wh} /$ dia por $48 \mathrm{v}$, que dá $83.3 \mathrm{Ah} /$ dia. Em seguida, usando as Eq. (3.1) até a (3.4), tem-se a quantidade de baterias exigidas pelo sistema.

$$
\begin{gathered}
\text { Capacidade requerida das baterias }=\frac{L_{A h / d i a} \cdot D_{S T}}{M_{D D} \cdot D_{f}}=\frac{(83,3) \cdot(3)}{(0,5) \cdot(1)}=499,8 \mathrm{Ah} \\
\text { Baterias em paralelo }=\frac{B_{R}}{B_{C}}=\frac{(499,8)}{(357)}=1,5 \rightarrow 2 \\
\text { Baterias em série }=\frac{V_{N}}{V_{B}}=\frac{48}{12}=4
\end{gathered}
$$$$
\text { Número total de baterias }=B_{S} \cdot B_{P}=(2) \cdot(4)=8
$$ 


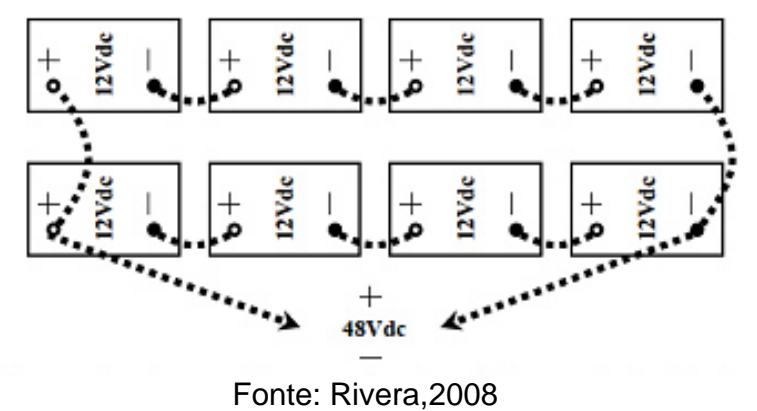

Figura 17: Exemplo de configuração de sistema de baterias

\section{3.}

\section{PV controladores}

O controlador tem a função de regular a tensão, evitando que o banco de baterias seja sobrecarregado por um excesso de energia produzida. O controlador de carga monitora constantemente a tensão da bateria. Quando as baterias estão totalmente carregadas, o controlador irá parar ou diminuir a quantidade de corrente que flui a partir do conjunto de placas fotovoltaicas para a bateria, sendo sua eficiência média de $95 \%$ a 98\%. Nesta dissertação, a eficiência que será utilizada é de 95\% (LUQUE et al., 2003).

Controladores de carga para sistemas $P V$ possuem o mais diverso tamanho (potência), geralmente a partir de apenas uns poucos amperes até de 80 amperes. Se for necessária uma corrente alta, dois ou mais controladores poderão ser usados. Ao usar mais de um controlador, é necessário dividir o conjunto em subconjuntos. Cada subconjunto será conectado ao banco de baterias. Existem cinco tipos diferentes de $P V$ controladores: controlador de fechamento, controlador de série fase única, controlador de desvio, controlador de modulação da largura de pulso $(P W M)$ e os controladores de monitoramento de máximo de potência $(M P P T)^{2}$.

\footnotetext{
${ }^{2}$ Para mais informações sobre esses controladores ver PVDI (2007).
} 


\subsection{1.}

\section{Controladores de Carga - MPPT}

O controlador de rastreamento do ponto de máxima potência de carga (MPPT) é o mais adequado para uso em sistemas de PV (Rivera, 2008). Este dispositivo permite que o controlador persiga eletronicamente o ponto de máxima potência, garantindo assim que o sistema terá o máximo de potência elétrica independente das circunstâncias climáticas. Esta capacidade de perseguir constantemente o ponto de máxima potência é crucial nos dias em que as condições climáticas estão variando muito, uma vez que produz o máximo de energia solar disponível para a rede ou um banco de baterias. O resultado chega a patamares de 15$30 \%$ superiores quando comparados com a produção de energia de um sistema com controlador PWM. Antes do MPPT estar disponível como uma opção de controladores, a tensão de um sistema de painéis era puxada para baixo ligeiramente acima da tensão da bateria durante o seu carregamento. Por exemplo, em um sistema de bateria de $12 \mathrm{~V}$ de tensão, o pico de tensão de um conjunto no ponto de alimentação é de cerca de 17 a 18V. Sem MPPT, o conjunto seria forçado a operar em torno da tensão da bateria resultando em uma perda de potência para o conjunto. Além disso, qualquer variação de tensão em um sistema elétrico pode produzir danos.

\subsection{2.}

\section{Dimensionamento do controlador - MPPT}

Para o dimensionamento de um controlador (MPPT) calcula-se o número de controladores necessários no sistema PV. Num sistema PV pequeno, um único controlador pode ser suficiente para suprir a demanda elétrica. No entanto, em sistemas de maior capacidade, mais controladores serão necessários para suprir sua necessidade. Quando for selecionado um controlador deve-se assegurar de que a tensão de saída seja igual à tensão nominal do banco de baterias. Deve-se também, verificar a tensão máxima $\mathrm{PV}$, devendo esta ser inferior à tensão máxima nominal do controlador. 
A tensão máxima PV pode ser obtida utilizando a Eq. 3.6:

Tensão PV máxima = (Módulo $\left.V_{o c}\right)$ x (n Número de Módulos em série)

$V_{o c}$ é a tensão de circuito aberto do módulo e o $n$ representa o número de módulos conectados em série. A tensão aumenta, à medida que os módulos fotovoltaicos são conectados em série. O número de controladores necessários para um sistema de painel fotovoltaico, PVDI (2007) é calculado usando a equação abaixo:

Potência Máxima Fotovoltaica $S T C=P_{p v s t c} \times N_{p v}$

Potência Máxima do Controlador $=V_{\text {banco de baterias }} x I_{\text {controlador }}$

Número de Controladores Requerido $=\frac{\text { Potência Máxima Fotovoltaica STC }}{\text { Potência Máxima do Controlador }}$

Onde $P_{p v s t c}$ representa o poder de classificação $S T C$ do módulo fotovoltaico que se escolher. $\mathrm{O} N_{p v}$ variável representa o número de módulos $P V$ em seu sistema. $V_{\text {Banco de baterias }}$ é a tensão do seu banco de baterias. $I_{\text {controlador }}$ é a máxima corrente que o controlador consegue manusear vinda do sistema PV para o banco de baterias.

\subsection{3.}

\section{Exemplo do dimensionamento de um controlador}

Assim como na subseção 3.2.3., aqui se apresenta um exemplo de dimensionamento da quantidade de controladores necessários a um sistema com produção de 4000 W DC ligado a um banco de baterias com uma tensão de 48 V. Como outrora mencionado, a energia é gerada por um módulo solar Kyocera (KC200). Na subseção 3.2.3. foi dimensionado a necessidade de 31 módulos solares Kyocera $K C 200$ para gerar os $4000 \mathrm{~W}$. Este módulo possui uma $V_{o c}$ de $32.9 \mathrm{~V}$ e uma potência de saída de 200 Watts na STC, sendo todos os módulos conectados em paralelo e divididos em subconjuntos como necessário. O modelo de controlador escolhido para o exemplo foi o Outback Flaxman 80, que possui corrente máxima de 80 ampères de saída e tensão máxima de $150 \mathrm{~V}$, sendo com base na Eq.(3.9), 
sendo necessário 2 controladores para o sistema, como representado pelo cálculo abaixo:

$$
\text { Número de controladores requerido }=\frac{P_{p v s t c} \cdot N_{p v}}{V_{\text {banco de baterias }} \cdot I_{\text {controlador }}}=\frac{(200) \cdot(31)}{(48) \cdot(80)}=1,6 \rightarrow 2
$$

Com isso, sendo um sistema composto por 31 módulos fotovoltaicos conectados, a configuração será de: um subconjunto de 16 módulos e outro subconjunto de 15 módulos PV. Entretanto, existe a necessidade dos painéis estarem ligados em paralelo a cada um dos controladores. Outra restrição é que tensão PV máxima deve ser menor do que a classificação máxima de tensão do controlador. O $V_{o c}$ do $K C 200$ é $32,9 \mathrm{~V}$, portanto é menor do que a tensão máxima do controlador que é de 150 V. Desejando-se conectar dois ou três módulos em série, isto pode ser feito, entretanto, dependerá de como se deseja configurá-lo. Cabe ressaltar que, para esse exemplo, os módulos foram dispostos em paralelo.

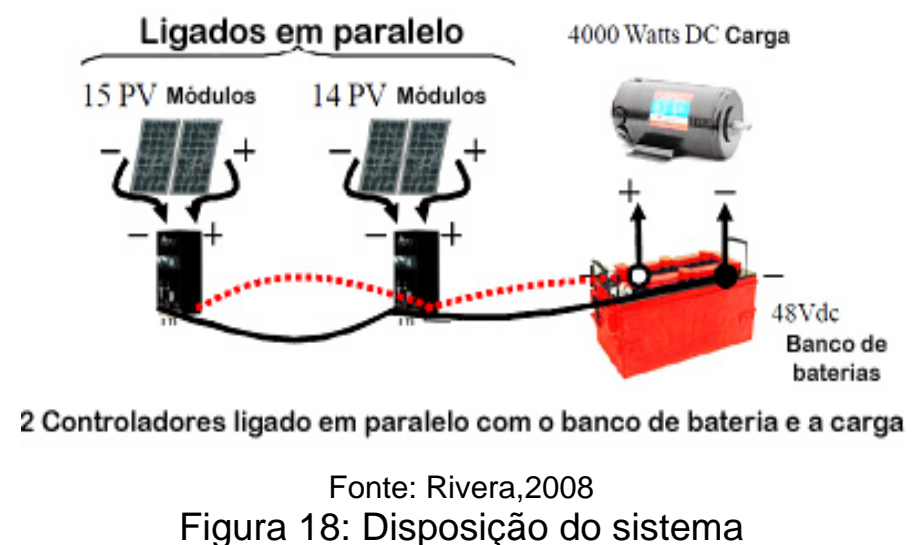

\section{4 .}

\section{Inversores}

Um inversor converte a corrente elétrica direta (DC) oriunda de fontes tais como banco de baterias, conjunto de módulos solares e turbinas eólicas para corrente alternada (AC). Assim a eletricidade pode ser usada para operar um equipamento que necessita de corrente (AC) como os que estão na maioria das casas. A forma da onda normal de saída (AC) de um inversor é uma onda senoidal com uma frequência de $60 \mathrm{~Hz}$ (para o Brasil). Inversores estão disponíveis em três diferentes categorias: menor bateria ligada a rede, back-up de bateria ligada a rede e 
sistema isolado. A menor bateria ligada à rede são os inversores mais populares hoje (Rivera, 2008). Estes inversores conectam diretamente à rede, utilizando a energia elétrica como uma bateria de armazenamento. Quando a radiação solar incidente é maior do que a demanda, a eletricidade vem do sistema $P V$ através do inversor. Neste caso é possível armazenar o excesso no sistema de baterias para posterior consumo. Caso, a necessidade de energia seja superior à produzida pelo sistema $P V$, a diferença será requerida das baterias ou então do gerador. (PVDI, 2007)

De acordo com Patel (2006) os inversores devem ter uma alta capacidade para suportar um pulso mais forte do que eles suportam normalmente. Isto significa ser capaz de atender a uma situação onde ocorre a ultrapassagem de sua potência nominal por períodos limitados de tempo. Isto é importante porque a potência de ignição de um gerador pode ser de até sete vezes a sua potência nominal durante a inicialização.

Os inversores para sistemas isolados são projetados para serem independentes dos utilitários do sistema e apropriados também para um sistema remoto híbrido. Estes inversores alimentam a carga utilizando-se da energia proveniente dos painéis $P V$ ou então de outra fonte, quando não há produção solar. Tal fato mostra-se importante para o fornecimento de energia do sistema, sendo hibrido. Estes conversores devem possuir uma capacidade elevada para suportar variações da demanda.

A eficiência de conversão da corrente contínua para corrente alternada, hoje na maioria dos inversores, é de $95 \%$ ou mais. Muitos inversores afirmam ter maior eficiência, mas para esta dissertação a eficiência utilizada é de 95\% (Pinho et al., 2008).

Todos os inversores têm tensão de saída de $120 \mathrm{~V}$ e produzem uma onda senoidal de saída $A C$ de $60 \mathrm{~Hz}$. Os mesmos estão ligados a um banco de baterias estando aptos a trabalhar de maneira autônoma ou conectada a rede. 


\subsection{1.}

\section{Dimensionamento do inversor}

Para o dimensionamento são calculados quantos inversores são necessários para o sistema PV. Em pequenos sistemas híbridos um inversor será suficiente para suprir a carga. Em sistemas maiores, mais de um é necessário. Quando se seleciona um inversor, deve-se observar se a tensão $D C$ do sistema é igual à tensão $D C$ de entrada do inversor. E também se a tensão de saída $A C$ é coerente com seus aparelhos e a rede, uma vez que qualquer sobrecarga poderá acarretar uma perda dos aparelhos e prejuízos.

A Eq. (3.10) mostra como calcular o número de conversores necessários para um sistema híbrido isolado:

$$
\text { Número de inversores requerido }=\frac{P_{\text {carga }}}{P_{\text {inversor }}}
$$

Onde $P_{\text {carga }}$ representa a potência máxima contínua que sua rede consome. $P_{\text {inversor }}$ é a potência máxima de saída do inversor. Se o sistema estiver ligado à rede, utiliza-se a equação (3.11).

$$
N \text { úmero de inversores requerido }=\frac{P_{\text {produzido }}}{P_{\text {inversor }}}
$$

Onde $P_{\text {produzido }}$ representa a potência máxima gerada pelo seu sistema híbrido. $P_{\text {inversor }}$ é a potência máxima que pode ser fornecida pelo seu inversor.

\subsection{2.}

\section{Exemplo de dimensionamento do inversor}

Aqui será calculada a quantidade de inversores necessários em um sistema autônomo com carga AC de 3600 W. O modelo de inversor com potência de saída de $3600 \mathrm{~W}$ ou mais foi o XW4048 Xantrex, que possui uma saída de $4000 \mathrm{~W}$ em 120 V. Com isso usando a Eq. (3.11) observa-se a necessidade de somente um inversor no sistema:

$$
\text { Número de inversores }=\frac{P_{\text {carga }}}{P_{\text {inversor }}}=\frac{3600}{4000}=0,9 \rightarrow 1
$$


Para o cálculo da potência de entrada do inversor, divide-se a potência da carga de entrada pela eficiência do inversor. Supondo que a eficiência do inversor seja de 0,90, a potência total de entrada que o inversor precisa ter do lado DC para fornecer a carga necessária no lado AC é de 4000 watts. (3600/0.9).

\section{5 .}

\section{Gerador Diesel}

Jimenez (1998) salienta que geradores funcionam com uma gama de combustíveis, dentre eles: diesel, gasolina, propano, metano e biocombustíveis. Comparando-o com o sistema de energia renovável, o gerador diesel exige baixo investimento na sua instalação, tecnologia madura, confiabilidade, fácil instalação e ampla disponibilidade de combustível, além de ser encontrado com uma ampla variedade de tamanhos e modelos. Além disso, se ajustam bem a qualquer carga de energia (Jimenez, 1998). Por outro lado o mesmo autor aponta as seguintes desvantagens: dependência do combustível, transporte e armazenamento; bem como o alto custo de manutenção, poluição sonora e ambiental.

O gerador diesel é muito comum, estando amplamente disseminado por todo o mundo e em grande quantidade. Nos lugares remotos é um grande facilitador para a produção de eletricidade, mas também é muito dispendioso por causa do transporte, armazenamento, operação e manutenção do combustível.

A vida útil usual de um gerador diesel é de 25.000 a 30.000 horas operacional e para os grandes geradores: revisões bem antes disso segundo Jimenez (1998).

Para uma alta carga elétrica, a eficiência de um gerador a diesel gira em torno de 2,5 a $3 \mathrm{Wh} / \mathrm{L}$. Caso a carga seja baixa sua eficiência diminui. Assim, existem pequenos geradores que se ajustam a uma pequena carga. São específicos para lugares remotos e localidades que raramente são atendidos pela rede de energia elétrica. 


\subsection{1.}

\section{Trabalhos Gerais}

O Gerador é composto por um motor e um gerador elétrico que geralmente trabalha para atender uma baixa carga elétrica com baixa eficiência. Por isto, podem ter seus custos de manutenção elevados e ocorrer uma grande variação de consumo de combustível de um modelo para outro (SIABBERT SEELINGHOCHMUTH, 1997). A Fig. 19 mostra uma curva de consumo comum de combustível para um gerador refrigerado a água:
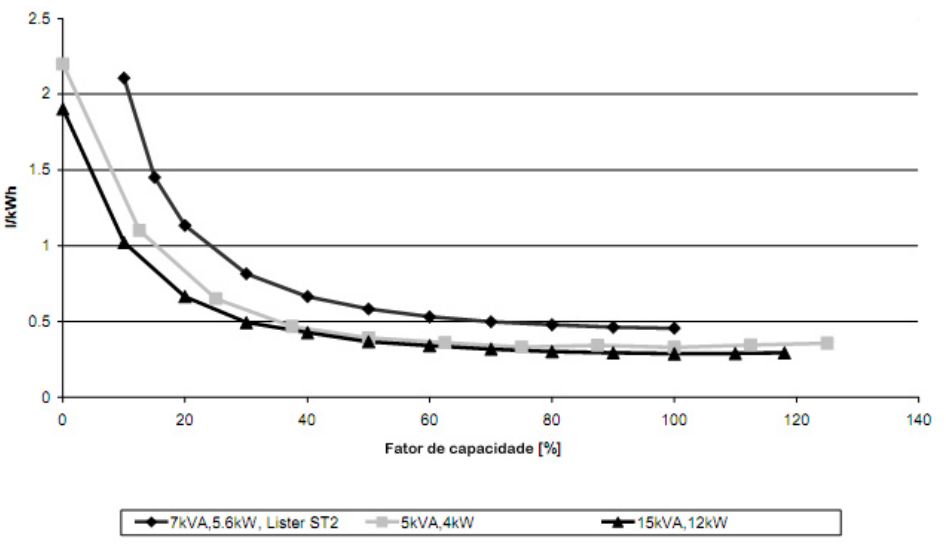

Nota: 15kVA gerador [Remmer \& Dymond, 1991], um 5kVA gerador [Jennings, 1996] e um 7kVA gerador [Morris, 1988]

Fonte: Hochmuth, 1998

Figura 19: O uso de combustível diesel em função do fator de capacidade de gerador

\subsection{2.}

\section{Questões Operacionais}

O gerador deve trabalhar a plena carga, só assim poderá maximizar sua eficiência e minimizar seu custo. Baixa carga operacional resulta em aumento da fragilidade do cilindro, alta perda por fricção, aumento da viscosidade do óleo, baixa temperatura de combustão e deposição de combustível o que resultará em gastos maiores de manutenção e baixa eficiência do combustível e do gerador. (HOCHMUTH,1998)

Conforme pontuado por Slabbert, Seeling-Hochmuth (1997) e Jimenez (1998) frequentes ignições aumentam o desgaste porque o óleo se torna mais viscoso, aumentando assim a pressão do cilindro e maior desgaste em pontos de con- 
tato. Por isso, é comum instalar um dissipador para dissipar a energia quando a carga útil é baixa, protegendo o gerador. Melhorias funcionais poderiam aumentar a prevenção contra o aquecimento, diminuindo a pressão nos momentos de ignição e evitando condições de carga parciais.

\subsection{3.}

\section{Ignição-Parada em Motores Diesel}

O gerador diesel deve ser usado mesmo em meses com alta incidência solar. Ele não pode ficar grandes períodos de tempo parado como, por exemplo, três meses. A regra de ouro é que o motor a diesel deve ser acionado uma ou duas vezes ao dia (SEELING-HOCHMUTH, 1996). Além de afirmar também que o motor a diesel deve ser ligado para altas cargas, mas cedo o suficiente para o inversor não se sobrecarregar. O motor a diesel deve se aquecer por 20 a 30 segundos, a menos que a carga aumente dramaticamente.

O motor se resfria dentro de uma hora. Manter o motor aquecido para futuras partidas é caro, mas permite uma rápida ignição com um desgaste mínimo. Isto é uma boa prática para um sistema múltiplo de motores em que um sempre deve estar ligado. Se a temperatura exterior estiver muito baixa, deve-se então ligar o motor em curtos intervalos de tempo. Num período de 2 a 4 minutos, o aquecimento começa a desgastar o motor e uma falha de ignição pode ocorrer a cada 100 partidas, sendo o principal problema a falha de ignição e não o desgaste da partida. (SEELING-HOCHMUTH, 1996)

\subsection{4.}

\section{Manutenção do Gerador}

A experiência demonstra que o número de intervalos de manutenção por ano vai depender do nível de confiança do cliente. (SEELING-HOCHMUTH, 1996). Sistemas automáticos podem apresentar 2 a 4 intervalos de manutenção por ano. Num exemplo que foi mencionado na África do Sul, um motor precisava a cada 500 horas de uso, de um serviço básico de manutenção e cada 15000 horas de uma revisão completa. (HOCHMUTH, 1998) A quantidade de manutenção 
também depende do tamanho do cárter de óleo. Uma troca de óleo é necessária a cada $250 \mathrm{~h}$ de funcionamento. Portanto, para reduzir a frequência de paradas com menor tempo de manutenção, é recomendado mais trocas de óleo.

\subsection{5.}

\section{Escolha do gerador}

O gerador diesel deve ser escolhido de forma a atender a uma carga com confiabilidade e por isto, a média das cargas mais altas deve ser usada como limite mínimo. (HOCHMUTH, 1998)

Se o sistema de baterias está instalado com o gerador, isto pode ajudar a superar as cargas mais altas fazendo com que se diminua a potência do gerador e também seu custo, caso o inversor seja adequado. O gerador diesel poderá carregar as baterias através do conversor $A C / D C$. Isto permitirá que, o gerador diesel funcione com uma eficiência maior e ainda ajudará a diminuir a quantidade de ciclos de acionamento e parada. Resultando em menor consumo de combustível e manutenção. (HOCHMUTH, 1998)

A desvantagem é que o gerador quando está em operação, deverá atender a uma alta carga para ser econômico. As baterias quando estão próximas do estado de plena carga, precisam de uma taxa de carregamento baixa para evitar os efeitos negativos do sobrecarregamento.

O carregador das baterias deve ser instalado para que possa ir diminuindo a corrente do gerador. Isto provavelmente produzirá perda de energia. Portanto, qualquer gerador só deve distribuir energia para as baterias quando elas estiverem suficientemente descarregadas permitindo que o gerador trabalhe com maior eficiência.

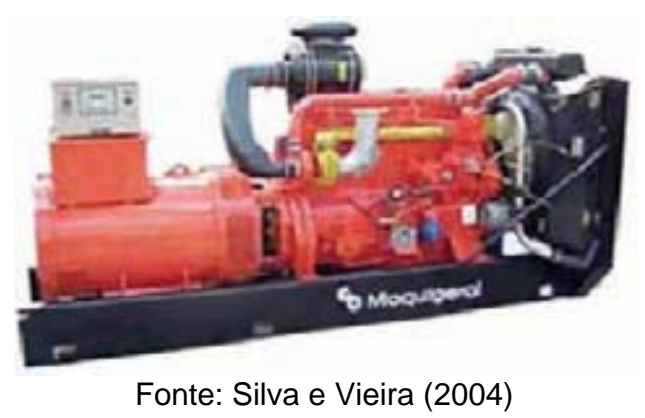

Figura 20: Grupo gerador diesel de 450 kVA 


\subsection{6.}

\section{Gerador Diesel num Sistema Híbrido}

De acordo com Hochmuth (1998) a integração de um gerador com um sistema renovável de energia está longe de ser simples. Especialmente quando se espera altas contribuições da fonte renovável. Dependendo da estratégia de controle escolhida, é possível ter alguns problemas:

- Ciclos de acionamento e parada inaceitáveis, principalmente quando este funciona como um dispositivo de reserva. Isto se deve a variabilidade das fontes de energia renováveis e também a carga do sistema.

- Prolongada subutilização do gerador. Assim aumentaremos o desgaste e manutenção, além da redução do tempo de vida do gerador. Este é o caso em que o gerador foi superdimensionado ou o sistema $P V /$ baterias é que foi superdimensionado para atender a carga.

- Tudo isto fará aumentar o consumo de combustível para uma baixa carga, diminuindo a eficiência do sistema.

Escolher um gerador exige critério e isto pode incluir alguns pontos a serem recomendados a seguir:

- O gerador é acionado por uma ou duas razões. Primeiro, se o sistema renovável ou as baterias não estão atendendo a carga. Segundo, se o estado de carga das baterias está no limite da profundidade de descarga.

- Geralmente os geradores podem ser desligados se há suficiente energia disponível do sistema $P V /$ baterias para atender a carga. (SLABBERT.SEELING-HOCHMUTH, 1997).

Muitos destes pontos podem ser alcançados com um bom projeto de sistema híbrido, sendo assim, o gerador diesel será acionado poucas vezes. Sempre atendendo a algum pico da carga e atendendo a uma alta carga, terá um melhor desempenho e uma diminuição dos custos. Poderá também desligá-lo durante certos períodos, como por exemplo, durante o período noturno já que outras fontes de energia estarão disponíveis, eólica ou as baterias. É importante também que se tenha algum sistema de destinação para o excesso de energia. Isto dará mais segurança ao sistema que em algumas vezes funcionará com baixa potência. 
Um gerador a diesel num sistema híbrido renovável, frequentemente, elimina a necessidade de se ter um sistema unicamente $P V$, além de adicionar confiabilidade ao sistema. A capacidade do sistema renovável com um gerador a diesel será minimizada quando comparada a um sistema renovável projetado para atender a carga sozinha. (HOCHMUTH, 1998) 


\section{Consumo de Energia}

\section{1. \\ Introdução}

Consumo de energia é a potência elétrica consumida com suas devidas cargas em um período de tempo. A carga é geralmente a que tem a maior influência sobre o tamanho e o custo de um sistema $P V$ e por sua vez, pode ser medido em Wh ou kWh.

A fim de reduzir o custo do sistema $P V$, é necessário o uso mais eficiente da energia, usar aparelhos que apresente menor demanda e eliminar parcial ou completamente o uso de outras cargas.

\section{2. \\ Consumo das cargas de energia}

De acordo com PVDI (2007), normalmente, é possível encontrar o valor do consumo de energia ou a "potência" dos aparelhos na parte inferior ou posterior dos mesmos. Este consumo de energia representa a máxima potência que o aparelho pode necessitar. Uma vez que muitos aparelhos têm uma gama de definições como, por exemplo: o tamanho de uma televisão, a quantidade real de potência consumida depende da configuração usada a qualquer momento.

Caso o consumo de energia não esteja impresso no aparelho é possível estimá-lo através da medição do consumo de corrente (em ampères) e posterior multiplicação dessa pela tensão nominal do aparelho. A maioria dos aparelhos nos Brasil é classificada em 120 volts. Outros aparelhos podem ser classificados em 240 volts.

Conforme Rivera (2008) alguns aparelhos continuam a consumir uma pequena quantidade de energia quando está ligada a tomada. Estas cargas fantasmas ocorrem em aparelhos como televisores, aparelhos de som, computadores e aparelhos de cozinha. A maioria das cargas fantasma irá aumentar a energia consumida 
do aparelho (watt-hora), no entanto, tais perdas podem ser evitadas desligando-se o aparelho ou usando um filtro de linha de modo a cortar toda a energia do aparelho.

A Tab. 2 mostra alguns exemplos de consumo de energia para diversos aparelhos domésticos.

Tabela 2: Potência Típica dos Aparelhos

\begin{tabular}{|l|l|l|l|}
\hline APARELHO & WATT & APARELHO & WATT \\
\hline Rádio Relógio & 10 & Computador pessoal & 120 \\
\hline \hline Máquina de Café & $900-1200$ & Monitor & 150 \\
\hline \hline Lavadora de Roupa & $350-500$ & Notebook & 50 \\
\hline Lava-Louça & 1200 & Aparelho de Som & $70-400$ \\
\hline \hline Ventilador de teto & $65-175$ & Refrigerador & 127 \\
\hline Ventilador de mesa & $55-250$ & Televisão 19" & $65-110$ \\
\hline Ferro de passar & $1000-1800$ & Televisão 27" & 113 \\
\hline \hline Forno de microondas & $750-1100$ & DVD & $20-25$ \\
\hline \hline Lâmpada fluorescente equiv. 60W & 16 & Secador de cabelo & $1200-1875$ \\
\hline Fonte: NREL, 2007 & \multicolumn{3}{|l}{} \\
\hline
\end{tabular}

4.3.

\section{Estimativa do Consumo de Energia}

Objetivando o uso mais eficiente e racional da energia, mostra-se essencial realizar uma estimativa do consumo. Necessitando-se calcular a média diária e o consumo total. Assim o sistema será mais econômico e eficiente, porque a produção de energia será ajustada ao consumo.

De acordo com PVDI (2007), uma vez que o consumo de energia por aparelho é conhecido ou estimado, adota-se a equação (4.1) para calcular em kWh quanto de carga é consumida em um dia.

$$
K W h / \text { dia }=\frac{n \cdot P_{\text {carga }} \cdot H_{\text {dia }} \cdot D_{\text {semana }}}{7}
$$

Onde $n$ representa a quantidade desse tipo de carga. $P_{\text {carga }}$ é o consumo de energia do tipo de carga. $H_{d i a}$ é o número de horas em que este utilitário é acionado por dia, consumindo carga. $D_{\text {semana }}$ é número de dias em que esta carga é usada durante uma semana. O total de $\mathrm{kWh} /$ dia de todas as cargas é obtido pelo somatório do consumo das cargas individuais como na equação (4.2).

$$
\text { Total } K W h / d i a=\sum_{i} K W h / d i a
$$


Onde kWh Total/dia é o somatório dos consumos individuais com um consumo de carga em $\mathrm{kWh} /$ dia e para calcular a carga anual, aplica-se a fórmula a seguir:

$$
\text { Carga anual }=(\text { KWh total } / \text { dia }) .365
$$

Objetivando calcular a potência total instalada ou, em outras palavras, a potência máxima consumida se todos os aparelhos elétricos fossem ligados ao mesmo tempo, aplica-se o somatório de todos os $P_{\text {carga }}$ de todas as cargas i.

$$
\text { Potência máxima } K W=\sum_{i} P_{\text {carga }} a_{i}
$$

\section{4.}

\section{Exemplo de estimação do consumo de energia}

Buscando estimar o consumo de energia de uma casa hipotética que contenha dois quartos, dois banheiros, uma sala de estar, um escritório e uma cozinha. Assumindo que o fogão e o forno de cozinha vão usar gás (GLP); a água quente da casa será oriunda de um aquecedor de água térmica solar e a Tab. 3 mostra as cargas elétricas em watt e kWh total que a casa irá consumir. 
Tabela 3: Cálculo da estimativa de consumo de energia

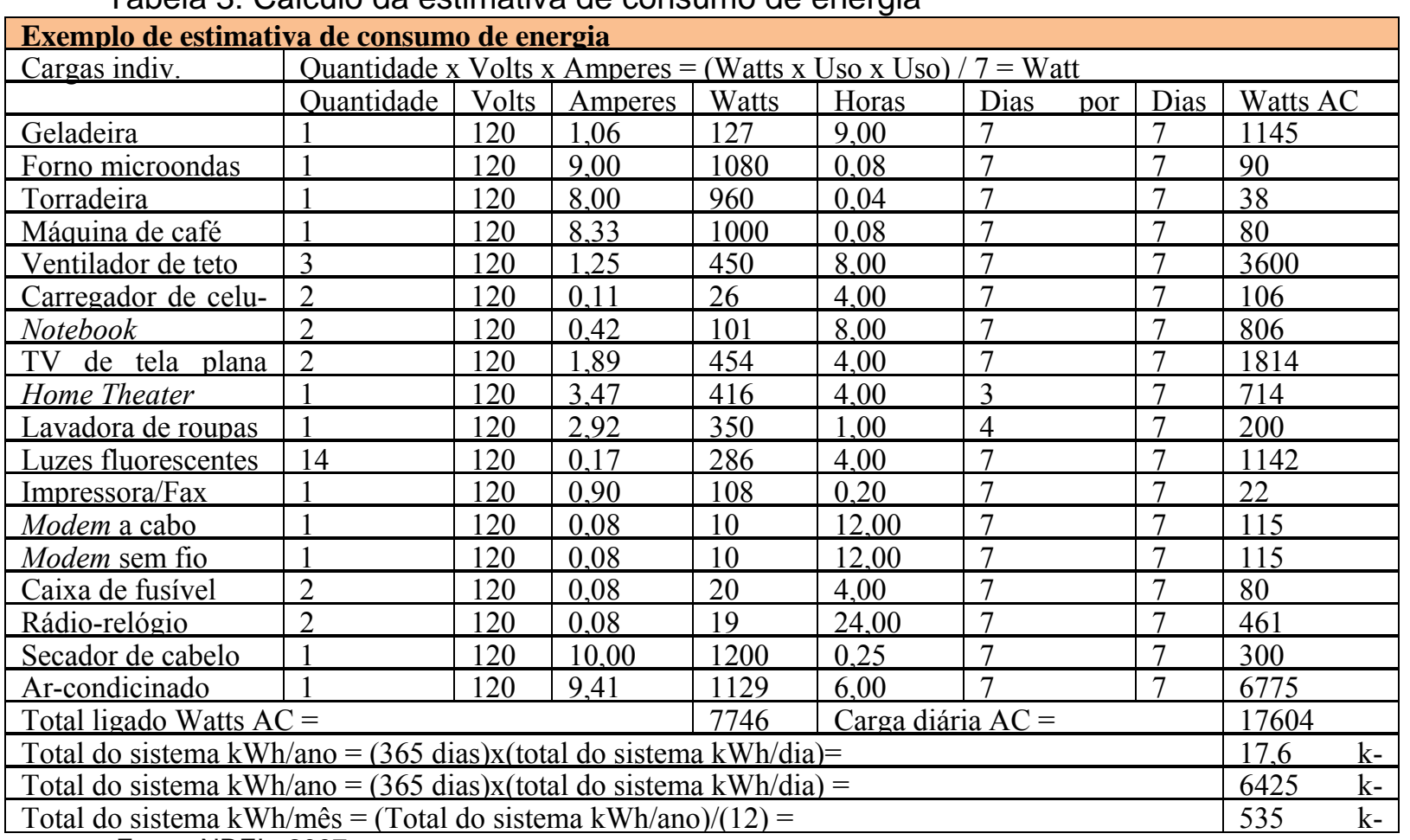
Fonte: NREL, 2007

Consumo total de energia AC na casa é 7746 W e a média diária é de carga $A C 17.6 \mathrm{kWh}$.

\section{5.}

\section{Consumo de energia da agrovila}

No tabela 4, apresenta-se a demanda de energia mensal da agrovila e por último o consumo total anual que é de $70507 \mathrm{kWh}$.

Tabela 4: Consumo mensal da agrovila

\begin{tabular}{|l|l|l|l|l|l|l|l|l|l|l|l|l|}
\hline \multicolumn{2}{|c|}{ Carga kWh/mês } \\
\hline Jan & Fev & Mar & Abr & Mai & Jun & Jul & Ago & Set & Out & Nov & Dez & Total \\
\hline 5617 & 7130 & 4847 & 5265 & 5248 & 7562 & 4024 & 4448 & 8056 & 4298 & 8136 & 5876 & 70507 \\
\hline
\end{tabular}

Fonte: Eletrobrás Amazonas Energia,1993

Na figura 21, é mostrado o perfil de consumo médio de um morador da agrovila durante as 24 horas, perfazendo o total de um dia. A demanda é em unidades básicas e o procedimento para se calcular, é mostrado a seguir: 


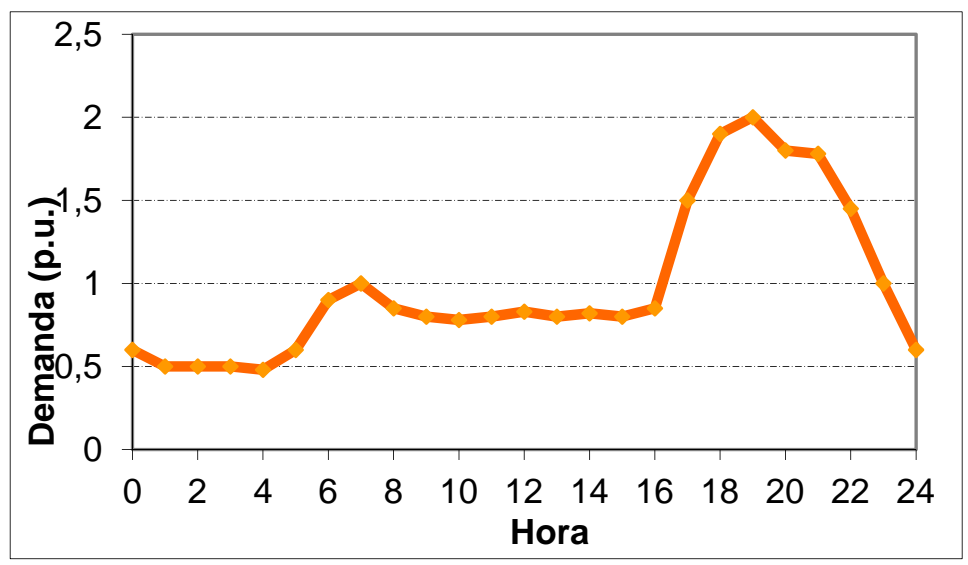

Fonte: Sousa et al, 2010

Figura 21: Consumo de energia de uma residência

A unidade básica é simplesmente a parte que é consumida naquela hora referente a média horária do consumo de um mês. Na Tab. 5 abaixo, foi usado o mês de outubro como exemplo e o cálculo das unidades básicas se procede da seguinte forma:

a) Somatório do consumo de um mês.

b) Cálculo da média de consumo horário.

c) Cálculo da participação horária referente a média.

Tabela 5: Consumo horário em p.u e em kWh do mês de outubro da agrovila

\begin{tabular}{|l|l|l|}
\hline \multicolumn{1}{|l|}{ Hora } & \multicolumn{1}{l}{ Demanda (kW) } & (p.u.) \\
\hline 0 & 108,17 & 0,60 \\
\hline 1 & 90,14 & 0,50 \\
\hline 2 & 90,14 & 0,50 \\
\hline 3 & 90,14 & 0,50 \\
\hline 4 & 86,54 & 0,48 \\
\hline 5 & 108,17 & 0,60 \\
\hline 6 & 162,26 & 0,90 \\
\hline 7 & 180,29 & 1,00 \\
\hline 8 & 153,24 & 0,85 \\
\hline 9 & 144,23 & 0,80 \\
\hline 10 & 140,62 & 0,78 \\
\hline 11 & 144,23 & 0,80 \\
\hline 12 & 149,64 & 0,83 \\
\hline 13 & 144,23 & 0,80 \\
\hline 14 & 147,83 & 0,82 \\
\hline 15 & 144,23 & 0,80 \\
\hline 16 & 153,24 & 0,85 \\
\hline 17 & 270,43 & 1,50 \\
\hline 18 & 342,54 & 1,90 \\
\hline 19 & 360,57 & 2,00 \\
\hline 20 & 324,51 & 1,80 \\
\hline 21 & 320,91 & 1,78 \\
\hline 22 & 261,41 & 1,45 \\
\hline 23 & 180,29 & 1,00 \\
\hline Total & 4298,00 & \\
\hline
\end{tabular}

Fonte: Eletrobrás Amazonas Energia, 1993 


\section{Sistema Híbrido de Energia}

\section{1.}

Introdução: o contexto rural

Conforme Barreto et. al., (2008), "a energia é fundamental para qualquer ser vivo, pois é utilizada no atendimento de suas necessidades básicas como a locomoção, a alimentação e a própria manutenção da vida. O homem, de modo especial dentre todos os seres vivos, é o mais dependente da energia em suas diversas formas, pois desenvolveu ao longo da história, máquinas, usos e costumes que demandam cada vez mais de energia, principalmente a elétrica. No entanto, tais serviços nos dias atuais ainda não são fornecidos a muitas das vilas rurais localizadas em partes remotas do nosso país. A energia elétrica possui papel desencadeador do desenvolvimento econômico e melhoria de qualidade de vida, e além alavancar esses processos, funciona também como pré-condição essencial a sua evolução. Contudo, Barreto et al (2008), salienta que isoladamente a eletricidade não propicia o desenvolvimento, sendo necessária a adoção de um leque de ações e medidas para que se alcance melhorias de condições de vida e aumento da oportunidade de geração de renda e emprego nessas comunidade.

O preço da energia de fontes convencionais em áreas remotas, tal como velas, parafina, gás, baterias é, em geral, mais elevado do que nas áreas urbanas, devido à distância entre a indústria e mercado consumidor, a quantidade comercializada e a menor concorrência. Além disso, o custo da iluminação nas áreas rurais também se mostra superior da área urbana, que possui acesso à rede elétrica e encontra-se densamente povoada. Ou seja, existe ganho de escala no aumento do quilometro de rede em área urbana, fato que não ocorre em boa parte das áreas isoladas/remotas. E em alguns casos a rede realmente não pode chegar devido a questões ambientais. Com isso, o investimento na eletrificação das cidades ocorre em ritmo muito mais acelerado quando comparada com o da eletrificação das áreas rurais, sendo os custos envolvidos para a realização do investimento nas áreas urbanas, muito mais diluído devido ao elevado número de clientes. Em contrapar- 
tida, nas áreas rurais a referida diluição não pode ser constada tornando pouco interessante economicamente esse investimento.

Hochmuth (1998) destaca que há outros problemas associados com o suprimento de energia convencional em áreas remotas como, por exemplo, o transporte requerido para se obter o mesmo, bem como os perigos do uso e/ou armazenamento.

Segundo NER (1997) apud Patel (2006), milhões de pessoas vivem em aldeias que não são ainda ligadas à rede pública ao redor do mundo. Estas aldeias são o maior mercado potencial para o fornecimento de energia elétrica com sistemas híbridos. Além disso, Patel (2006) salienta que as turbinas eólicas e os sistemas de módulos PV podem criar uma grande quantidade de empregos por cada real investido, uma vez que, nestas áreas, verifica-se uma grande demanda reprimida, mas por outro lado, deve-se observar também a capacidade de pagamento desta demanda. $\mathrm{O}$ autor destaca ainda que a instalação de fontes alternativas de energia elétrica nas áreas rurais pode ajudar a reduzir o êxodo rural e aliviar o “inchaço” das grandes cidades, já tão populosas na maioria dos países.

Apesar dos avanços dos sistemas híbridos, aumentando o seu grau de confiabilidade e a redução do tamanho do sistema de potência, os custos iniciais permanecem ainda relativamente elevados.

Avanços na eficiência do uso da energia permitem que os usuários possam atender suas necessidades de energia com menor potência, sendo menos dispendioso possível. O desenvolvimento de lâmpadas fluorescentes compactas e aparelhos que economizam energia, podem agora tornar isto possível com pouco sacrifício no estilo de vida. (GIPE, 2004)

\section{2.}

\section{Acesso à eletricidade em áreas rurais}

Conforme Pinho et al. (2008), em virtude do programa do governo federal "Luz para Todos", há a obrigatoriedade de atendimento à todos os cidadãos brasileiros com energia elétrica, bem como da necessidade cada vez maior da produção de eletricidade com a mínima degradação ambiental possível. Assim sendo, o em- 
prego de recursos renováveis como fontes primárias de energia tornam-se cada vez mais importante.

O autor destaca ainda que sistemas híbridos são definidos como aqueles que utilizam mais de uma fonte energética, de pequeno e médio porte para geração de eletricidade apresentam-se como uma forma importante do uso das energias renováveis. Sendo de disponibilidade local e para um atendimento descentralizado de pequenas demandas pelo Brasil através de minirredes de distribuição, sobretudo, na Região Amazônica, uma vez que nesta região é possível verificar um grande número de localidades isoladas, sem perspectivas de atendimento pela rede elétrica convencional.

Áreas rurais no estado do Amazonas sofrem de altos níveis de pobreza e desemprego conforme dados do IDH e tendo $72 \%$ das pessoas vivendo com uma renda mensal abaixo de $\mathrm{R} \$ 75,50$. O nível de desemprego nas áreas rurais é significativamente mais alto do que as áreas urbanas (IDH, 2005). Obter serviços para contribuir com o desenvolvimento e melhorar as condições sociais da população é uma função de qualquer governo. A população rural e, em particular a população feminina, suportam uma grande carga de pobreza no estado do Amazonas.

Segundo Texeira e Cavaliero (2010) opções de tecnologia fora da rede e sistemas híbridos poderiam, em alguns casos, se apresentar como uma opção econômica rentável, uma vez que o Estado do Amazonas possui regiões com abundância de recursos solares, estando acima de $5000 \mathrm{Wh} / \mathrm{m}^{2} \cdot$ dia (ver seção 2.10 , recursos solares de Manaus).

\section{3.}

\section{Produção elétrica auxiliar do sistema híbrido}

Produção de energia elétrica pode ser atendida por uma única fonte como, por exemplo: painéis solares, micro turbinas de vento, micro barragens e geradores a combustão. Conforme Pinho et. al, (2008), o objetivo é ser mais rentável e eficiente valorizando as potencialidades regionais e a opção híbrida ou não híbrida que atenda a esses requisitos (ver Fig. 22). O sistema geralmente inclui armazenamento de energia na forma de baterias e pode fornecer a carga em $A C$ ou $D C$. 
Isto pode requerer dispositivos elétricos para corrente $A C$ e $D C$. Componentes ou sistemas de controle para ambos, regulando toda a operação do sistema.

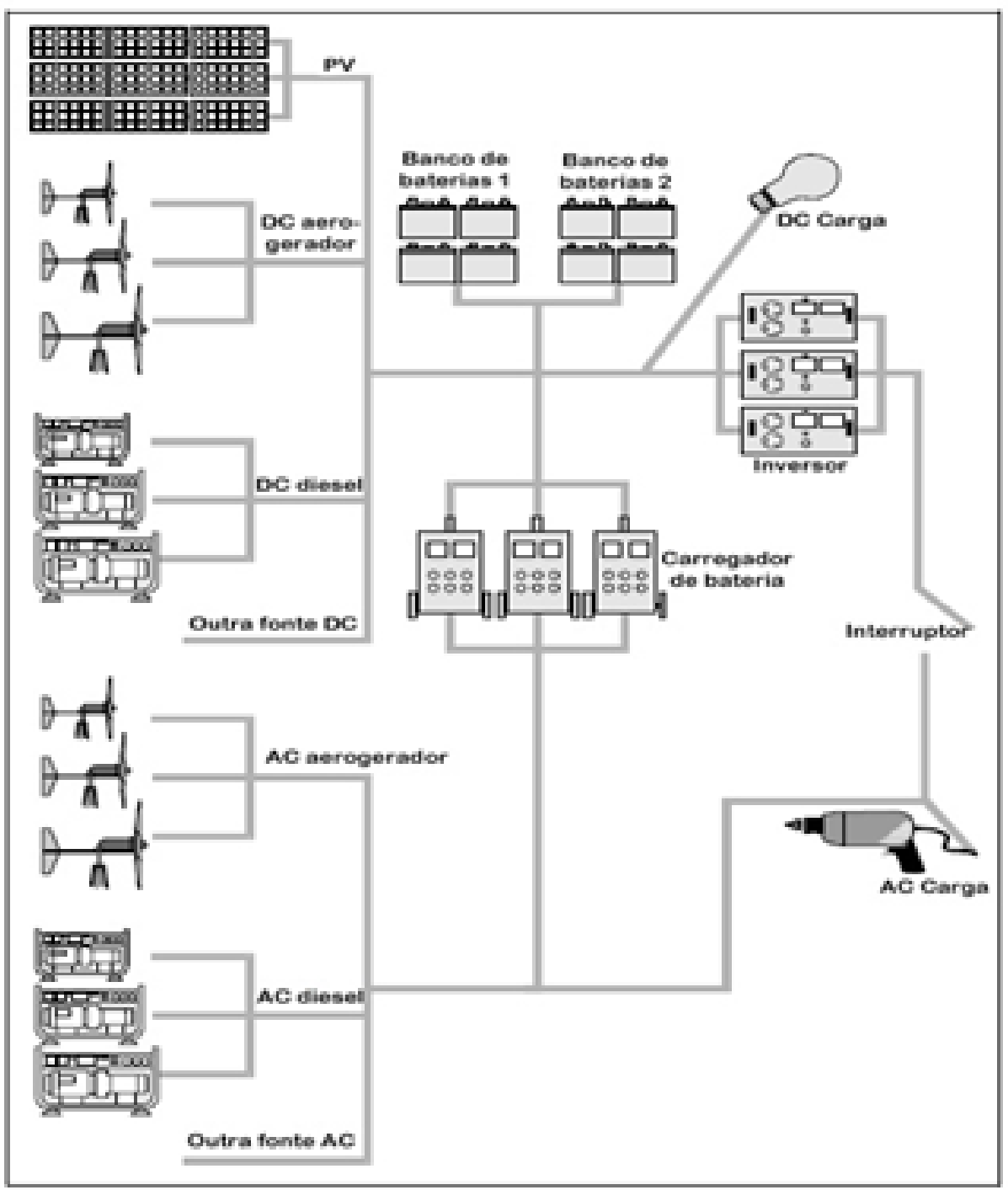

Fonte: Hochmuth (1998)

Figura 22: Configuração dos componentes de um sistema híbrido

\section{4.}

\section{Aplicações e potencial para o sistema híbrido instalado e planejado}

Alguns exemplos de sistemas híbridos (conforme figuras 23 e 24), principalmente, PV/eólico/diesel podem ser encontrados instalados em fazendas, clínicas, para provisão elétrica de telecomunicações e instalações de pesquisa e turismo, bem como em algumas unidades remotas. Isto demonstra a grande versatilidade e potencial de aplicações. Por outro lado, este sistema é um grande facilita- 
dor de inclusão de novas fontes de energia renováveis como, por exemplo: pequenas barragens hidrelétricas, biogás, briquetes de madeira e outros mais.
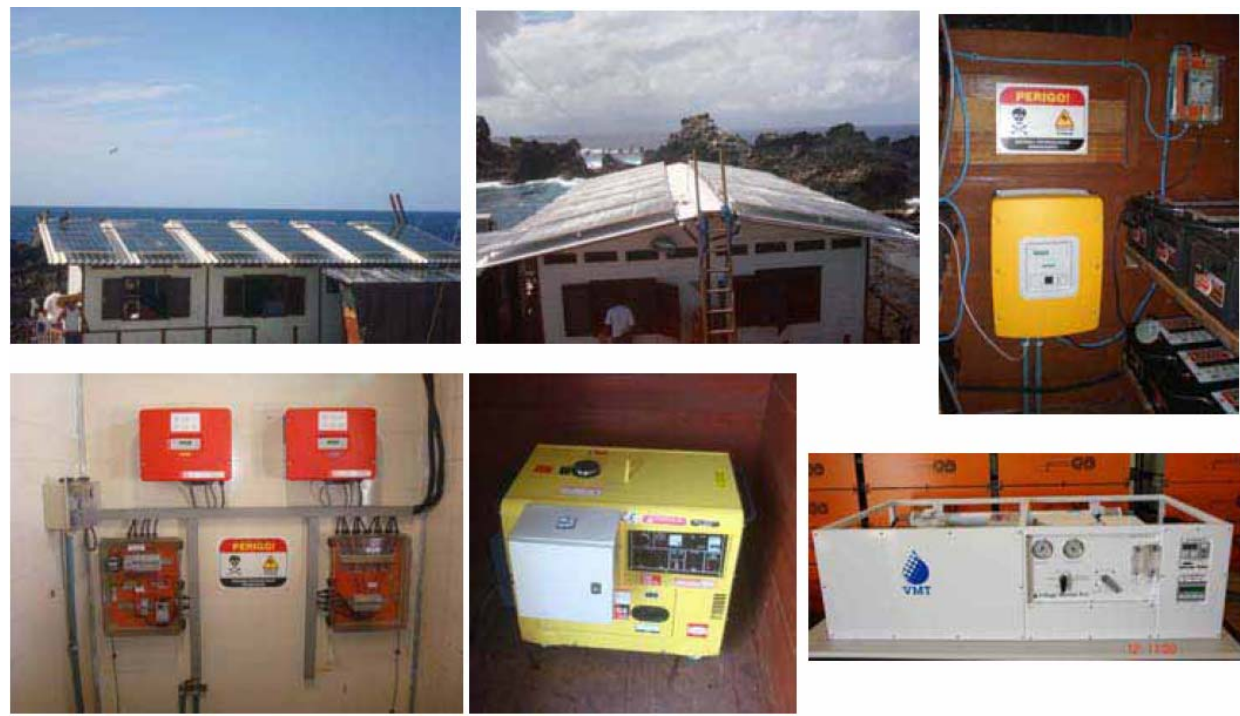

Fonte: CEPEL,2011

Figura 23: Sistema híbrido no arquipélago de São Pedro e São Paulo

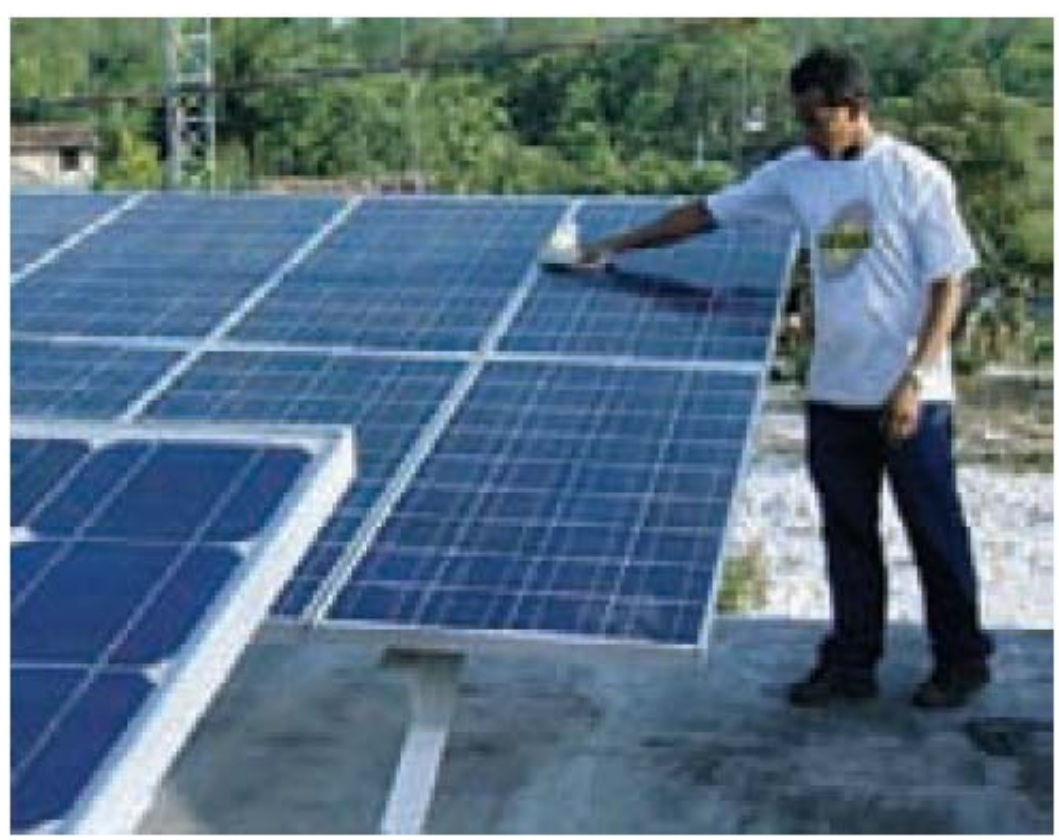

Fonte: Pinho et. al. (2008)

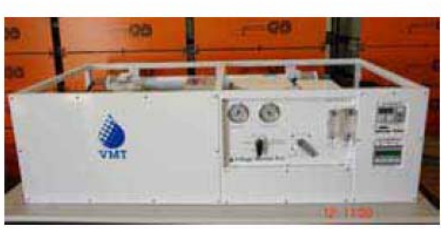

.

Figura 24: Limpeza dos módulos fotovoltaicos 


\section{5 .}

\section{Potencial para adaptação de sistemas diesel para sistemas híbridos}

Hochmuth (1998) destaca que uma grande quantidade de geradores a diesel se encontra instalado em fazendas, hotéis, vilarejos, próprios ou públicos. Segundo o autor uma das vantagens da utilização de geradores a diesel consiste no fato destes sistemas suprirem eletricidade à carga. Contudo, algumas das desvantagens são: manutenção intensiva, operação ineficiente de energia e um alto consumo de combustível com baixa eficiência. Tais desvantagens conduzem a um desgaste do gerador acarretando, consequentemente, a diminuição da sua vida útil. Entretanto, em muitos casos pode-se promover uma modernização do sistema a fim de torná-lo mais eficiente através da implantação de um sistema hibrido como, por exemplo, aliando a geração solar com o diesel.

Hochmuth (1998) salienta ainda que um sistema renovável único para atender uma carga, também não seria interessante, uma vez que o sistema seria superdimensionado para ser seguro e confiável. Seeling e Hochmuth, (1997c) também ressalta que objetivando atender todo um vilarejo, só poderia ser viável adicionando outra fonte renovável ou um gerador diesel, uma vez que este conjunto se mostra mais promissor porque torna o desempenho melhor, ou seja, permite um ajuste fino entre a produção e a demanda.

Contudo, para os supracitados autores, para necessidades básicas tais como iluminação e acionamento de bombas de água, um sistema renovável único atenderia de maneira adequada.

Nas figuras seguintes são expostos alguns sistemas híbridos renováveis. 


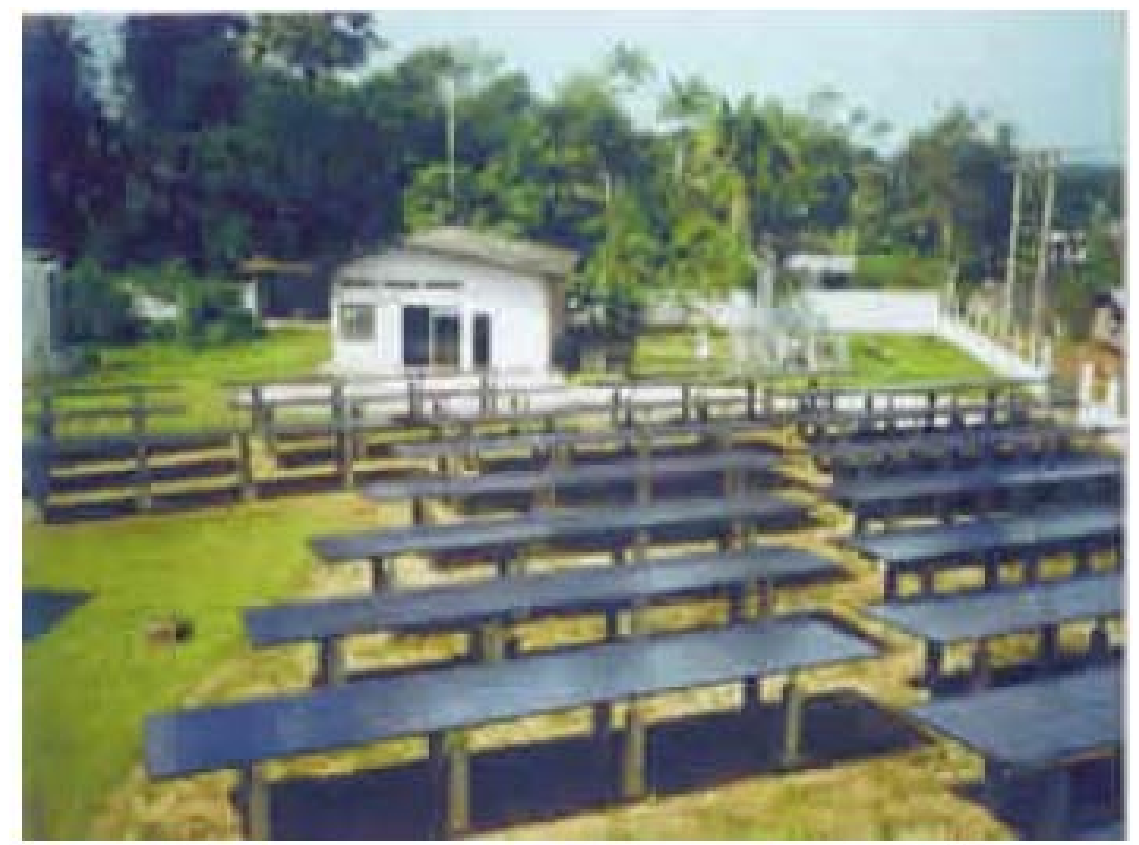

Fonte: Barbosa et. al. (2012)

Figura 25: Arranjo solar fotovoltaico de vila Campinas

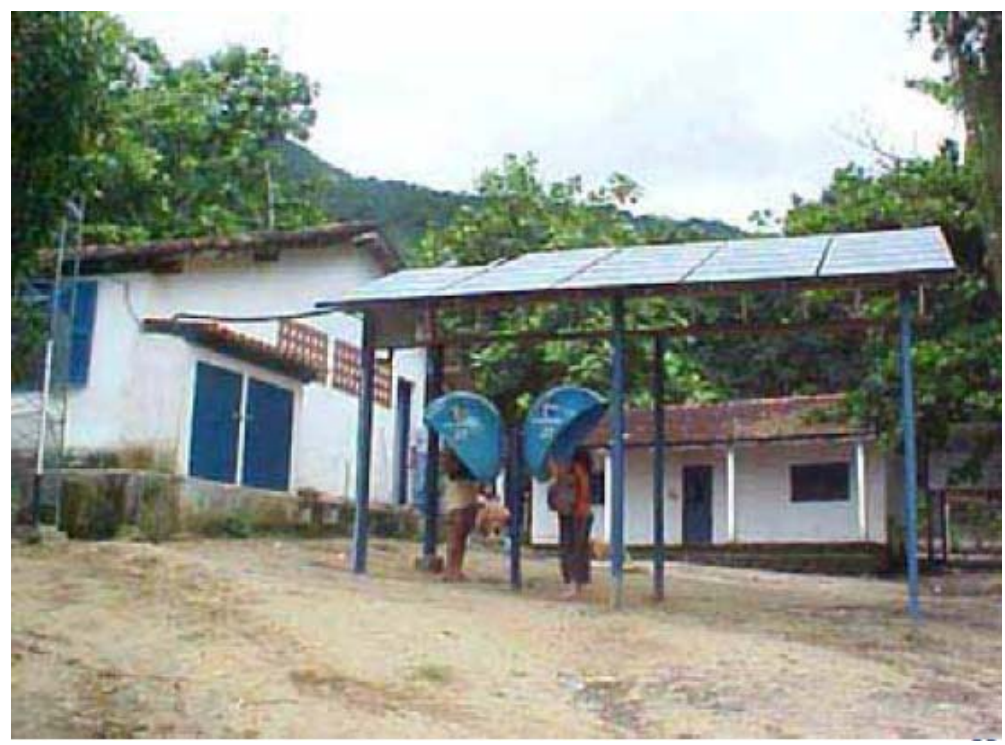

Fonte: CEPEL (2011)

Figura 26: Comunidade de Pouso da Cajaíba: E.M. Pouso da Cajíba, Centro Comunitário, Posto de Saúde, Sistema Telefônico 


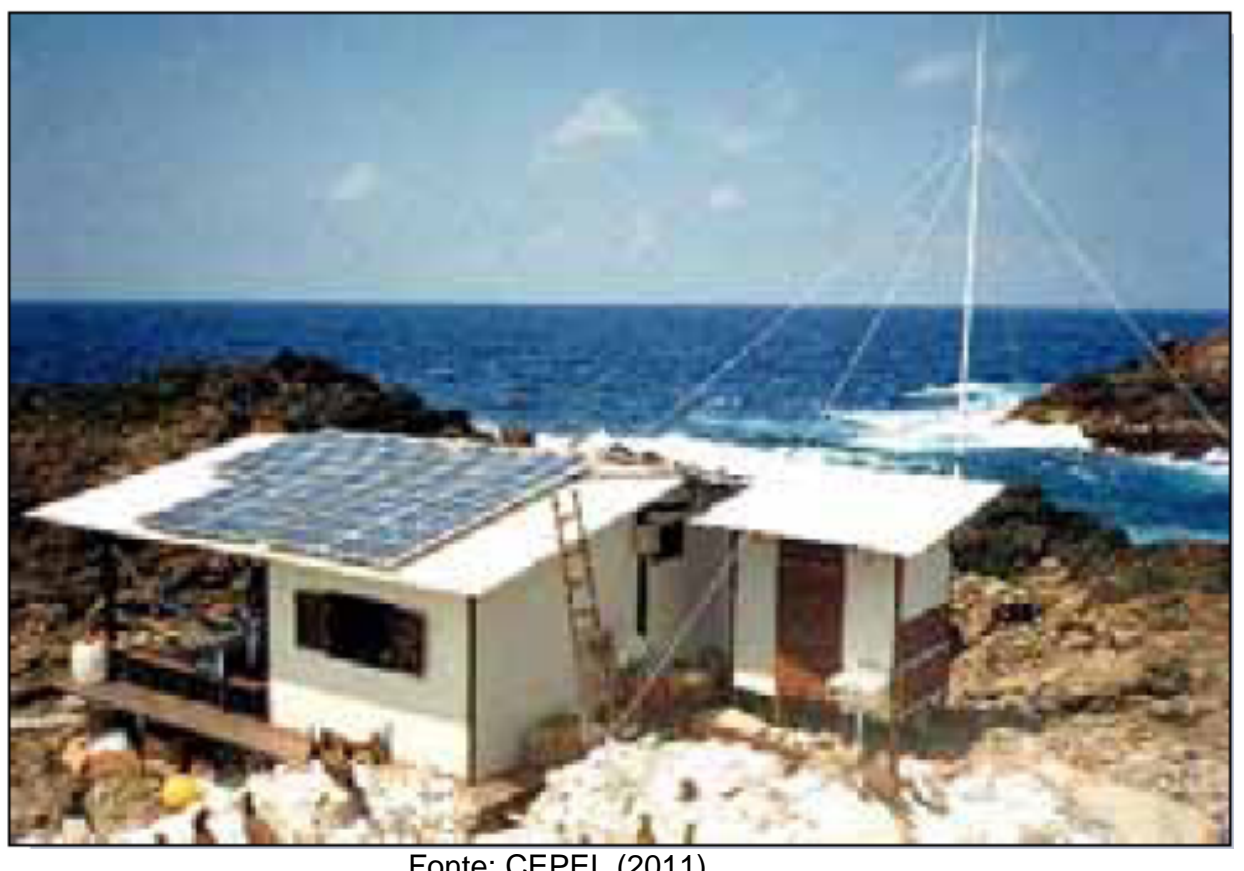

Fonte: CEPEL (2011)

Figura 27: Estação Científica do Arquipélago de São Pedro e São Paulo (Painel fotovoltaico de 3,6 kWp fornecendo energia a dessalinização de água)

\section{6.}

Sistema isolado típico e a eficiência de cada componente

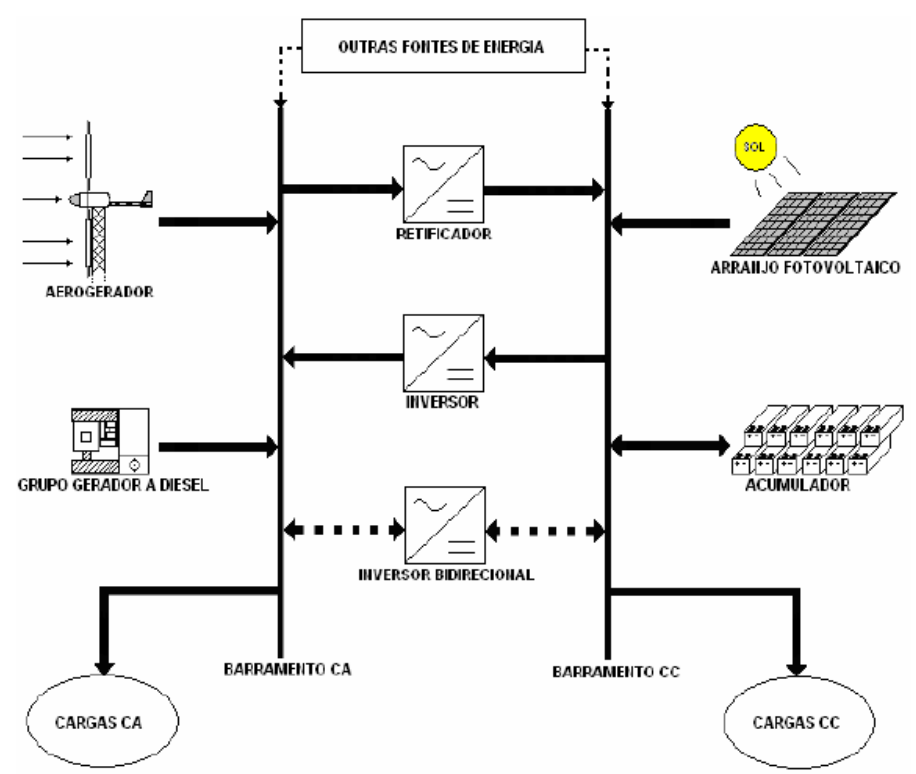

Fonte: Barbosa et. al. (2012)

Figura 28: Configuração geral de um sistema isolado 
Componentes típicos de um sistema isolado híbrido são:

- Painéis Solares: Transformam radiação solar em eletricidade.

- Controladores (MPPT): Mantém as baterias livres de sobrecarga e fazem os painéis solares estarem sempre no ponto máxima potência. Sua eficiência média é de $95 \%$

- Inversor: é um dispositivo com circuitos eletrônicos que convertem a corrente contínua (DC) em corrente alternada (AC). Sua eficiência média é de 95\%.

- Baterias: Armazenam o excesso de energia produzida e fornecem energia ao sistema quando necessário. Sua eficiência média é de $85 \%$.

- Fios: conectam eletricamente os equipamentos, transformando-os em um sistema. Sua eficiência média é de 98\%.

- Carga: Energia consumida pelos aparelhos.

Uma vez que o subsistema ou os componentes são sequenciais em relação ao fluxo de energia. A eficiência global do sistema é o produto das eficiências dos componentes individuais.

$\eta_{\text {sa }}=$

(eficiência do inversor) · (eficiência do controlador) ·

(eficiência da fiação) $\cdot($ eficiência da bateria)

Onde $\eta_{s a}$ é a eficiência total do sistema isolado. A Tab. 6 mostra a eficiência média para o inversor, controladores, baterias e fios usados neste trabalho.

Tabela 6: Listas das Eficiências

\begin{tabular}{|l|c|}
\hline Inversor & 0,95 \\
\hline \hline Controlador & 0,95 \\
\hline \hline Fiação & 0,98 \\
\hline \hline Baterias & 0,85 \\
\hline
\end{tabular}

Usando os valores da Tab. 6 acima e Eq. (5.1), a eficiência total do sistema é:

$$
\eta_{s a}=(0,95) \cdot(0,95) \cdot(0,98) \cdot(0,85) \cong 0,75
$$


A eficiência total do sistema é de aproximadamente $75 \%$. Em outras palavras é possível dizer que $75 \%$ de toda a eletricidade produzida são empregadas para suprir a carga e $25 \%$ é consumida pelos fios e os componentes internos, inversores, controladores e baterias. 


\section{Metodologia}

Este processo inicia-se pelo cálculo da fração solar e como já foi mencionado na seção 2.11, usou-se o programa SAM para calcular a fração solar da energia produzida, depois se usou o programa MATLAB para calcular os balanços diários e horários.

\section{1.}

\section{Procedimento proposto para a otimização do sistema isolado}

O procedimento básico para a otimização de um sistema é mostrar qual a situação em que apresenta um menor custo ou uma maior eficiência. Já o interesse deste estudo, concerne verificar qual arranjo possui maior viabilidade econômica.

Como os dados solares e de carga elétrica são considerados estáveis será simulada uma planta híbrida de $10 \mathbf{k W p}$ até $100 \mathbf{~ k W p}$ com variações na capacidade operacional das baterias e profundidade de descarga. Será calculado assim o custo da energia $(\mathrm{R} \$ / \mathrm{kWh})$ nas diversas situações e será determinado qual é o melhor arranjo, dentro destas variações.

Dados do problema:

Tabela 7: Dados de carga e de consumo diesel e lubrificante

\begin{tabular}{|l|l|l|l|}
\hline Mês & Carqa elétrica $\quad$ (k- & Consumo diesel & Consumo oléo (I/mês) \\
\hline \hline Janeiro & $5617 \quad 1904$ & 19 \\
\hline \hline Fevereiro & 7130 & 2410 & 23 \\
\hline \hline Marco & 4847 & 1643 & 19 \\
\hline \hline Abril & 5265 & 1785 & 19 \\
\hline \hline Maio & 5248 & 1779 & 17 \\
\hline \hline Junho & 7562 & 2556 & 50 \\
\hline \hline Julho & 4024 & 1564 & 18 \\
\hline \hline Aqosto & 4448 & 1508 & 4 \\
\hline \hline Setembro & 8056 & 2723 & 38 \\
\hline \hline Outubro & 4298 & 1457 & 29 \\
\hline \hline Novembro & 8136 & 2750 & 37 \\
\hline \hline dezembro & 5876 & 1989 & 25 \\
\hline \hline Total & 24068 & 298 \\
\hline
\end{tabular}

Os dados diários são gerados pela divisão dos dados mensais pela quantidade de dias. 


\section{2.}

\section{Análise de custo do gerador}

Na Tab. 8 são apresentados os custos médios de um gerador diesel com base nas condições operacionais do Brasil. Dados da demanda de eletricidade e consumo de diesel e lubrificante são fornecidos pela Eletrobras Amazonas Energia.

Atualmente, o município de Campinas possui 2 geradores de $48 \mathrm{~kW}$, funcionando 6 horas por dia para atender a 65 usuários. Na Tab. 7 já foi mostrado os dados de carga e de consumo para o vilarejo atualmente. O combustível é fornecido para atender dois meses de consumo e é armazenado em lugar próprio no local.

Tabela 8: Dados do sistema

\begin{tabular}{|l|c|l|l|}
\hline Parâmetro & Símbolo & Unidade & Valor \\
\hline \hline Potência instalada & $P$ & $\mathrm{~kW}$ & 96 \\
\hline \hline Vida útil & $V$ & anos & 25 \\
\hline Consumo específico de com- & SFC & l/kWh & 0,341 \\
\hline Demanda de energia & $e$ & $\mathrm{kWh} /$ ano & 70507 \\
\hline Consumo de diesel & $d$ & $\mathrm{l} / \mathrm{ano}$ & 24068 \\
\hline Consumo de lubrificante & $I$ & $\mathrm{l} / \mathrm{ano}$ & 298 \\
\hline \hline Custo do gerador & $C_{g}$ & $\$ / \mathrm{kW}$ & 1000 \\
\hline \hline Custo do diesel & $C_{d}$ & $\$ / l$ & 2,2 \\
\hline \hline Custo do lubrificante & $C_{i}$ & $\$ / /$ & 10 \\
\hline Custo de manutenção & $C_{m}$ & $\$ / \mathrm{kW}$. ano & 500 \\
\hline
\end{tabular}

Fonte: Eletrobras Amazonas Energia,1993

Cálculo do custo da geração diesel:

a) Custo de manutenção durante sua vida útil:

$$
C_{m}=c_{m} \cdot P \cdot V
$$

b) Custo do diesel durante sua vida útil:

$$
C_{d}=c_{d} \cdot d \cdot V
$$

c) Custo do lubrificante durante sua vida útil:

$$
C_{i}=c_{i} \cdot I \cdot V
$$


Assim, o custo operacional durante a vida útil do gerador é:

$$
C_{0}=C_{m}+C_{d}+C_{i}
$$

A geração elétrica durante a vida útil é:

$$
E=e \cdot V
$$

O custo da eletricidade $(\$ / \mathrm{kWh})$ é:

$$
C=C_{0} / E
$$

O investimento inicial para a compra do gerador diesel não foi computado para esta análise. Substituindo os dados da Tab. 7 nas Eq. (6.1) a (6.6), o seguinte valor é obtido.

$$
C=R \$ 1,4740 / k W h
$$

\section{3.}

\section{Custos do sistema (painéis, inversores, baterias e instalação)}

Tabela 9: Dados do sistema

\begin{tabular}{|l|l|c|l|l|}
\hline Componente & & Símbolo & Unidade & Valor \\
\hline$P V$ & Vida útil & $V$ & anos & 25 \\
\hline & Custo & $C_{p v}$ & $\$ / \mathrm{kWp}$ & 5330 \\
\hline Bateria & \% da capacidade removida & $r$ & $\%$ & 40 \\
\hline & Eficiência & $\eta_{b}$ & $\%$ & 85 \\
\hline & Capacidade operacional & $d i a s$ & dias & 2 \\
\hline & custo & $C_{b}$ & $\$$ & 400 \\
\hline Inversor & eficiência & $\eta_{i}$ & $\%$ & 95 \\
\hline & custo & $C_{i}$ & $\$$ & 10067,84 \\
\hline Instalação & \% do total do custo & mont & $\%$ & 30 \\
\hline
\end{tabular}

Fonte: www.buscape.com.br

A potência de pico $\left(P_{p v}\right)$ é definida quando o painel é atingido por uma radiação solar de $1 \mathrm{~kW} / \mathrm{m}^{2}$, temperatura da célula a $25^{\circ}$ Celsius, velocidade do vento a $1 \mathrm{~m} / \mathrm{s}$ e massa de ar de 1,5 . O cálculo da contribuição solar para o sistema com dados diários, é feito multiplicando a intensidade de energia solar $\left(I_{t}\right)$ sobre o plano do painel pela potência instalada, utilizando a devida fórmula.

$$
E_{s}=P_{p v} \cdot I_{t}
$$


A eficiência da bateria é definida como a fração entre a energia retirada das baterias e a injetada nelas. Existe uma perda devido à ineficiência da reação química. A capacidade de estocagem $\left(E_{b}\right)$ é definida como a quantidade que pode ser estocada no sistema e é medido em (kWh). Entretanto, só uma parcela $(r)$ pode ser removida no processo de descarga, definida pela profundidade de descarga. A capacidade de estocagem operacional das baterias é definida por $\left(R_{b}\right)$, em $\mathrm{kWh}$.

$$
R_{b}=E_{b} \cdot\left(\frac{r}{100}\right)
$$

A autonomia operacional é o parâmetro que define quantos dias sem produção fotovoltaica, o sistema poderá ser atendido pelas baterias sem o acionamento do gerador.

$$
R_{s}=\left(\frac{e}{365}\right) \cdot \operatorname{dias}
$$

A vida útil das baterias é função do número de ciclos de carga e descarga, ocorridos ao longo de sua vida útil. Na seção 3.2.2, na Fig. 13, mostra-se o gráfico em relação ao desgaste e troca das baterias. É importante salientar que num período máximo de 12 anos, as baterias dever ser trocadas por uma questão de segurança.

O inversor utilizado neste trabalho possui capacidade de $10 \mathrm{~kW}$ e foram $\mathrm{u}-$ tilizados dois por questão de segurança e também porque em certas ocasiões a carga horária ultrapassa a capacidade de um inversor. O custo de instalação foi considerado nesta análise e foi adotado o valor de $30 \%$ sobre o total do sistema, sendo considerado para este tipo de análise como um valor médio. O custo de sistema solar $\left(C_{s}\right)$ é composto pelos seguintes parâmetros:

a) Painéis PV, baterias, inversores: $C_{e q}$

b) Custo de instalação: $C_{m o n t}$

c) Custo das baterias considerando toda a vida útil, quer dizer que o custo da reposição das baterias deve ser considerado: $C_{b}$

As seguintes equações devem ser usadas:

$$
C_{\text {mont }}=C_{e q} \cdot 0,3
$$




$$
C_{s}=C_{e q}+C_{m o n t}+C_{b}
$$

Metodologia para o cálculo da contribuição solar e diesel no atendimento a carga:

Esta metodologia será aplicada tanto no cálculo diário quanto no horário. Por isto, a cada dia e hora é feito um balanço de energia para mensurar o quanto foi produzido na parte fotovoltaica, quanto foi armazenado ou retirado das baterias e por último quanto o gerador produziu para atender a carga. Começando com as baterias carregadas, os seguintes passos devem ser seguidos, tanto para o balanço horário quanto para o diário:

1) Calcula-se para cada área instalada de painéis, a produção fotovoltaica $\left(E_{S}\right)$ :

2) Calcula-se a diferença $(D I F)$ entre o produzido $\left(E_{S}\right)$ pela parte fotovoltaica e o que é necessário para atender a carga $\left(E_{l}\right)$.

$$
D I F=E_{S}-E_{l}
$$

3) Se a DIF $>0$, a produção fotovoltaica foi suficiente para atender a carga e ainda sobrou energia para ser estocada nas baterias. Caso as baterias estiverem completamente carregadas. Esta sobra de energia será desperdiçada para o meio ambiente por dissipação térmica.

4) Se a DIF $=0$, não haverá estocagem de energia, nem o gerador será acionado. A produção fotovoltaica foi suficiente para atender a carga.

5) Se a DIF $<0$, toda energia solar produzida será enviada para o consumo e esta diferença será atendida pelas baterias, observando que ao descarregá-las, ocorre uma perda devido à ineficiência da mesma (DIF $\left.\cdot\left(\frac{100}{\eta_{\mathrm{b}}}\right)\right)$.

6) O balanço de energia ocorre até o término da capacidade operacional das baterias $\left(\mathrm{R}_{\mathrm{b}}\right)$. Deste ponto em diante, o gerador é acionado para atender a carga diretamente sem passar pelo inversor, devido ao fato do gerador produzir em AC.

7) O número de vezes que o gerador é acionado durante um ano, é a mesma quantidade de vezes em que a capacidade operacional das baterias é zerada.

8) O número de ciclos das baterias é a contagem de vezes, durante o ano em que o sistema partindo da capacidade máxima é plenamente descarregado até no- 
vamente estar na posição de carga máxima. Esta contagem permite que calculemos a duração do banco de baterias e sua devida reposição.

9) Finalizado o ano, poderemos calcular a fração energética da carga atendida pela solar $\left(F_{s}\right)$, a fração do gerador $\left(F_{d}\right)$ e o excesso dissipado no meio ambiente $\left(\mathrm{F}_{\text {diss }}\right)$.

\section{4.}

\section{Custo da energia do sistema híbrido diesel-solar:}

$$
C=\frac{C_{s}+C_{d} \times F_{d}}{E}=R \$ / k W h
$$

É suposto que a vida útil do gerador é proporcional ao seu uso.

Custo inicial do sistema $\left(C_{s i}\right)$ :

$$
C_{s i}=C_{e q}+C_{m o n t}
$$

\section{5 .}

\section{Avaliação estocástica}

A metodologia descrita nas seções 6.1 a 6.4 realiza a avaliação econômica sob a hipótese implícita de que os 25 anos de duração do projeto são iguais. A realidade, no entanto, será certamente diferente. Haverá anos com mais radiação e outros com menos. Assim, devido às não linearidades implícitas ao modo de operação do sistema híbrido, onde o gerador a diesel apenas funciona quando as baterias estão descarregadas, o custo médio anual que vai se revelar ao fim dos 25 anos será certamente diferente daquele calculado supondo-se que os anos se repetem.

De acordo com Street (2009) para captar o efeito da incerteza a respeito da radiação dos anos futuros sobre o custo médio anual, foi implementada uma metodologia de avaliação estocástica. No enfoque estocástico, o modelo fornece como resultado uma distribuição de probabilidades do custo médio anual, ao invés de um só valor como no enfoque determinístico apresentado nas seções anteriores.

Para obter a distribuição de probabilidades empírica do custo médio anual, utilizou-se uma técnica chamada "bootstrap" para criar cenários de radiação solar 
para os 25 anos de duração do projeto. Para cada cenário, simulou-se o comportamento do sistema considerando cada uma das configurações possíveis de número de placas e capacidade total das baterias. Foi mantida constante a capacidade do gerador e profundidade de descarga em $40 \%$. Para cada cenário e para cada configuração, pode-se então obter um valor para o custo médio anual. Ao final do processo, obtém-se a chamada "amostra bootstrap" com um grande número de valores possíveis para o custo médio anual representando a sua distribuição empírica. (Street, 2009)

A metodologia "bootstrap" implementada no exercício apresentado no capítulo 7, constrói os cenários futuros de 25 anos de radiação sorteando repetidamente, e com reposição, anos que estão presentes no histórico. Na realidade, o sorteio já foi realizado diretamente sobre o custo associado à operação do sistema durante aquele ano. Esta estratégia foi adotada para reduzir a complexidade computacional, mas pode gerar uma pequena diferença com relação a que se teria obtido através do sorteio da radiação ao invés do sorteio do custo, como foi realizado, devido a diferenças no estado das baterias na virada do ano. Da forma que foi feito, as baterias estariam sempre carregadas no início do ano.

A otimização no enfoque estocástico se dá de uma forma um pouco mais complexa que no enfoque determinístico, pois para cada configuração há toda uma distribuição de valores para o custo, ao invés de um só valor como no caso determinístico. Para se extrair apenas um valor da distribuição de custos, e assim poder comparar as diferentes configurações, o tomador de decisão deve selecionar o seu 'perfil de risco' representado pelo quantil da distribuição. Por exemplo, o tomador de decisão pode definir que o custo que vale para ele, dentre todos aqueles produzidos pelos cenários, é décimo maior custo. Neste caso, se houver 100 cenários, este seria o quantil de $90 \%$ da distribuição empírica. Sendo assim, no enfoque estocástico, haverá uma configuração ótima para cada quantil selecionado pelo tomador de decisão. As Fig. 43, 45 e 46 apresentam o custo associado a cada quantil e a configuração ótima correspondente.

Procedimento matemático utilizado:

Seja $I$ o número de painéis, $J$ o número de baterias, $K$ o número de simulações e T o número de anos. Seja também a matriz chamada MatrizDados de di- 
mensões $(I, J, T)$, contendo o preço de cada combinação de painel e bateria para cada ano. $\mathrm{O}$ algoritmo para encontrar os quantis de $1 \%$ a $100 \%$ segue abaixo:

Para todo painel $_{i}, i=1 . . I$, faça

$$
\begin{aligned}
& \text { Para toda } \text { bateria }_{j}, j=1 . . J, \text { faça } \\
& \qquad \begin{array}{r}
\text { Para toda } \text { simulação }_{k}, k=1, \ldots, K, \text { faça } \\
\text { VariavelAuxiliar }_{1}=0 \\
\text { VariavelAuxiliar }_{2}=0 \\
\text { Para todo } l=1, \ldots, 25, \text { faça } \\
\text { VariavelAuxiliar }_{1}=
\end{array}
\end{aligned}
$$

Variável Uniforme entre 1 e 29

$$
\text { VariavelAuxiliar }_{2}=
$$

VariavelAuxiliar $_{2}+$ MatrizDados $\left(i\right.$, VariavelAuxiliar $\left._{1}, j\right)$

Fim-faça

$$
\text { VariavelAuxiliar }_{2}=\text { VariavelAuxiliar }_{2} / 25
$$

$$
\begin{aligned}
& \text { Fim-faça } \\
& \text { Para todo } m=1, \ldots, 100 \\
& \qquad \operatorname{Quantil}(m)=\operatorname{menor}(\boldsymbol{c u s t o}(i, j), m)
\end{aligned}
$$

Fim-faça

Fim-faça

Fim-faça

Onde a função menor $(A, m)$ retorna o $m$-ésimo menor valor do vetor $A$ e $\boldsymbol{c u s t o}(i, j)$ é um vetor contendo os K custos médios simulados para o painel $i$ e a bateria $j$. 


\section{Resultados}

\section{1.}

Simulações do sistema solar híbrido com dados solarimétricos diários e horários

As tabelas apresentam simulações do sistema híbrido para atender a comunidade 24 horas por dia, incluindo a fração atendida pela energia solar, diesel, total de energia desperdiçado e o custo por kWh. Os parâmetros técnico e econômico representam condições operacionais médias e com alta probabilidade de ocorrência.

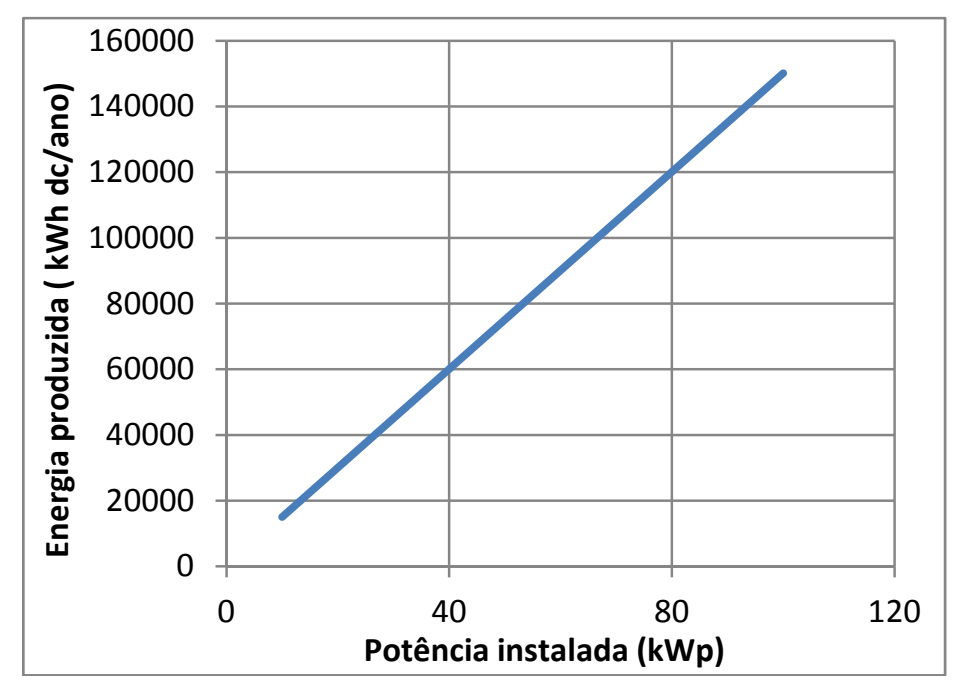

Figura 29: Relação entre potência instalada $\left(\mathrm{kW}_{\mathrm{p}}\right)$ versus energia produzida (kWh)

Na Fig. 29, pode-se visualizar uma relação linear entre a potência instalada dos painéis fotovoltaicos $(\mathrm{kWp})$ e a energia produzida que é dependente das condições climáticas ( ex: vento, poluição, temperatura, massa de ar e etc) e solarimétricas (ex: incidência solar e inclinação do raio entrante). 


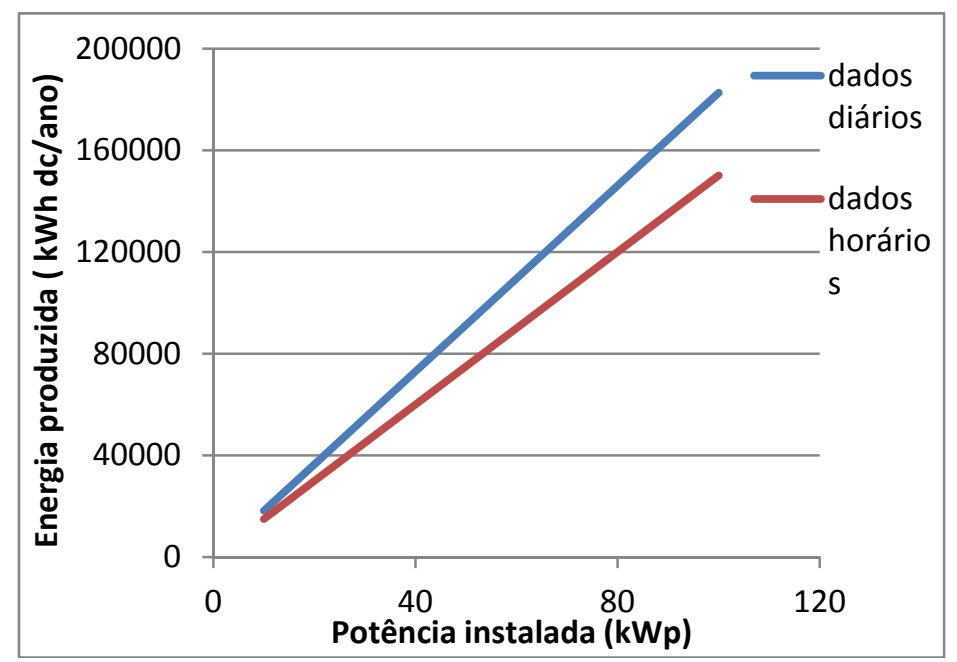

Figura 30: Relação entre potência instalada $(\mathrm{kWp})$ versus produção fotovoltaica

A Fig. 30 mostra os resultados da simulação da produção de energia fotovoltaica $(\mathrm{kWh}$ dc/ano) como função da potência nominal do sistema $(\mathrm{kWp})$ em duas situações, (a) dados médios diários de radição e temperatura, e, (b) dados horários de radiação e temperatura. Como a temperatura média diária é inferior à temperatura horária no período de produção, valores mais baixos de temperatura dos módulos são calculados na primeira situação, resultando em uma eficiência de conversão mais elevada e portanto uma maior produção de energia.

\subsection{1.}

Variação da capacidade total de armazenamento das baterias

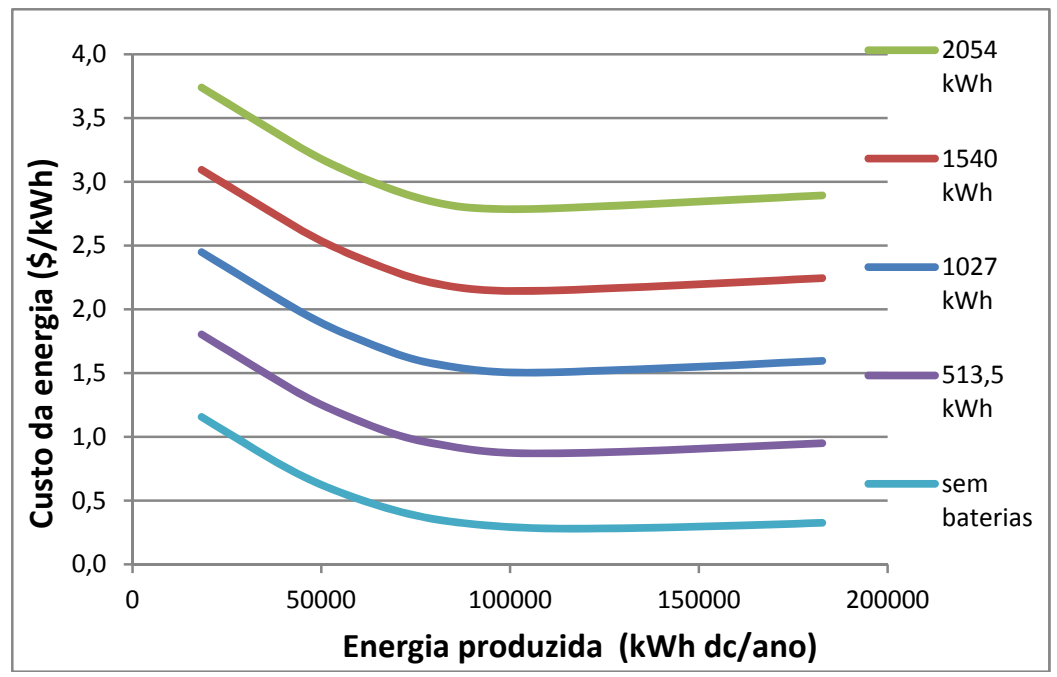

Figura 31: Variação do custo da energia e da capacidade total de armazenamento das baterias com a mesma profundidade de descarga, usando-se dados diários. 


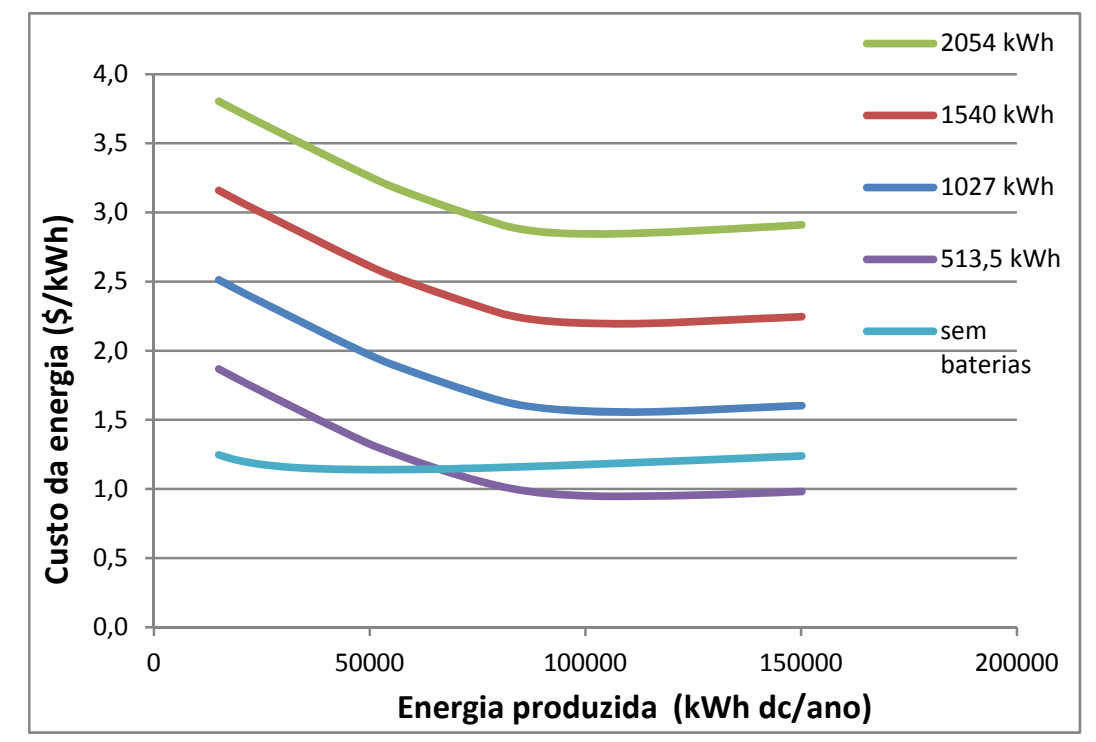

Figura 32: Variação do custo da energia e da capacidade total de armazenamento das baterias com a mesma profundidade de descarga, usando-se dados horários.

Usando-se a metodologia descrita, foi simulado o custo da energia ( $\mathrm{R} \$ / \mathrm{kWh}$ ) como função da energia produzida (kWh dc/ano), relacionada com a potência instalada pela Fig. 31, para diferentes valores da capacidade total de armazenamento das baterias e mesma profundidade de descarga (40\%), considerando-se valores médios diários (Fig. 31) e horários (Fig. 32) de radiação e temperatura. A capacidade total de armazenamento das baterias foi calculada a partir da demanda de energia elétrica pelo usuário e considerando-se de 0 a 4 dias de autonomia, quando a energia seria fornecida apenas pelas baterias devido à ausência de incidência solar (1 dia de autonomia é equivalente a 513,5 kWh). Pode-se observar que o custo da energia aumenta com a capacidade de armazenamento. Para um dado valor desta última, o custo da energia passa por um valor mínimo.

Pode-se observar que a diferença é pequena entre os resultados com dados diários e horários, com exceção da opção sem baterias, que requer dados horários para confiabilidade dos valores obtidos.

Nos sistemas fotovoltaicos de menor tamanho, pode-se ver que a opção sem baterias apresenta um custo sempre menor, tanto para a simulação diária e como para horária. A energia produzida é logo consumida e o banco de baterias fica subutilizado. Em sistemas maiores, demonstra-se pelas simulações a necessidade de um sistema de baterias. Elas agregam valor aumentando a fração solar, possibilitando um maior encontro da produção solar que é durante o dia com o 
pico da demanda que é à noite. Na simulação horária fica visível esta análise enquanto na diária, ela fica mascarada. O menor custo foi alcançado para um dia de autonomia $(513,5 \mathrm{kWh})$ e potência instalada de $74 \mathrm{kWp}$ na simulação horária como pode ser visto nas Tab. 10 e 11 .

Tabela 10: Dados do sistema

\begin{tabular}{|l|l|l|}
\hline Painel fotovoltaico & Vida útil & $\mathbf{2 5}$ anos \\
\hline & Custo médio & $\mathrm{R} \$ 5247.38 / \mathrm{kWp}$ \\
\hline \hline baterias & Profundidade de descarga & $40 \%$ \\
\hline & Eficiência & $85 \%$ \\
\hline & Autonomia operacional & $\mathbf{1}$ dia \\
\hline & Capacidade total & $\mathbf{5 1 3}, 5 \mathrm{kWh}$ \\
\hline \hline & Custo & $\mathrm{R} \$ 356.51 / \mathrm{kWh}$ \\
\hline 2 inversores de 10kW & Eficiência & $95 \%$ \\
\hline & Custo & $\mathrm{R} \$ 20135.68$ \\
\hline Custo de instalacão & & $30 \%$ sobre valor total \\
\hline Gerador diesel & Vida útil & 5 anos \\
\hline & Potência de nico & $96 \mathrm{~kW}$ \\
\hline \hline & Custo & $1000 \mathrm{RS} / \mathrm{kW}$ \\
\hline & Consumo específico & $0.341 / \mathrm{kWh}$ \\
\hline & Demanda elétrica & $70507 \mathrm{kWh} / \mathrm{ano}$ \\
\hline & Consumo anual de diesel & 240681 \\
\hline \hline & Consumo de lubrificante anual & 2981 \\
\hline & Custo da energia elétrica & $1,4740 \mathrm{R} \$ / \mathrm{kWh}$ \\
\hline
\end{tabular}

Tabela 11: Valores da fração solar, diesel e o custo da energia

\begin{tabular}{|c|c|c|c|c|c|c|c|}
\hline$P V$ & kWh & ciclos & vida útil & ñ usada \% & solar \% & diesel \% & \$/kWh \\
\hline 10 & 15015,2 & 0 & 12,00 & 0,00 & 20,22 & 79,78 & 1,8675 \\
\hline 12 & 18018.2 & 0 & 12,00 & 0.00 & 24.20 & 75.80 & 1,8176 \\
\hline 14 & 21021,3 & 0 & 12,00 & 0,00 & 28,14 & 71,86 & 1,7688 \\
\hline 16 & 24024,3 & 0 & 12,00 & 0,00 & 32,04 & 67,96 & 1.7208 \\
\hline 18 & 27027,3 & 0 & 12,00 & 0.00 & 35,89 & 64.11 & 1,6734 \\
\hline 20 & 30030.4 & 0 & 12.00 & 0.00 & 39.70 & 60.30 & 1.6264 \\
\hline 22 & 33033,4 & 0 & 12.00 & 0.00 & 43,47 & 56.53 & 1.5797 \\
\hline 24 & 36036.5 & 0 & 12.00 & 0.00 & 47.19 & 52.81 & 1.5333 \\
\hline 26 & 39039.5 & 0 & 12.00 & 0.00 & 50.87 & 49.13 & 1.4871 \\
\hline 28 & 42042.5 & 0 & 12.00 & 0.00 & 54.51 & 45,49 & 1.4411 \\
\hline 30 & 45045.6 & 1 & 12.00 & 0.01 & 58.10 & 41.90 & 1.3952 \\
\hline 32 & 48048.6 & 1 & 12.00 & 0.15 & 61.53 & 38,47 & 1.3512 \\
\hline 34 & 51051.7 & 2 & 12.00 & 0.56 & 64.69 & 35,31 & 1,3105 \\
\hline 36 & 54054.7 & 2 & 12.00 & 1.32 & 67.52 & 32.48 & 1.2743 \\
\hline 38 & 57057.7 & 2 & 12.00 & 2.23 & 70.18 & 29.82 & 1.2402 \\
\hline 40 & 60060,8 & 3 & 12,00 & 3,17 & 72.79 & 27,21 & 1,2066 \\
\hline 42 & 63063,8 & 3 & 12,00 & 4,14 & 75,35 & 24,65 & 1,1735 \\
\hline 44 & 66066,9 & 3 & 12,00 & 5,26 & 77,76 & 22,24 & 1,1425 \\
\hline 46 & 69069,9 & 3 & 12,00 & 6,51 & 80,04 & 19,96 & 1,1131 \\
\hline 48 & 72072,9 & 3 & 12,00 & 7,86 & 82,21 & 17,79 & 1,0852 \\
\hline 50 & 75076.0 & 3 & 12.00 & 9.31 & 84.28 & 15,72 & 1.0586 \\
\hline 52 & 78079.0 & 5 & 12.00 & 10.94 & 86.19 & 13.81 & 1.0344 \\
\hline 54 & 81082,0 & 5 & 12,00 & 12,81 & 87,88 & 12,12 & 1,0134 \\
\hline 56 & 84085.1 & 5 & 12.00 & 14.92 & 89.35 & 10.65 & 0.9958 \\
\hline 58 & 87088.1 & 5 & 12.00 & 17.21 & 90,66 & 9.34 & 0.9807 \\
\hline 60 & 90091.2 & 5 & 12.00 & 19.86 & 91.69 & 8.31 & 0,9698 \\
\hline 62 & 93094.2 & 5 & 12.00 & 22.73 & 92.55 & 7.45 & 0,9617 \\
\hline 64 & 96097.2 & 4 & 12.00 & 25,75 & 93.29 & 6.71 & 0,9554 \\
\hline 66 & 99100.3 & 4 & 12.00 & 28.88 & 93.95 & 6.05 & 0.9504 \\
\hline 68 & 102103.3 & 4 & 12.00 & 32.20 & 94.46 & 5.54 & 0,9478 \\
\hline 70 & 105106.4 & 4 & 12.00 & 35,66 & 94.87 & 5.13 & 0.9466 \\
\hline 72 & 108109,4 & 4 & 12,00 & 39,22 & 95,23 & 4.77 & 0,946434 \\
\hline 74 & 111112,4 & 4 & 12,00 & 42,80 & 95,57 & 4,43 & 0,946487 \\
\hline 76 & 114115,5 & 4 & 12,00 & 46,45 & 95,87 & 4,13 & 0,9471 \\
\hline 78 & 117118,5 & 3 & 12,00 & 50,17 & 96,11 & 3,89 & 0,9487 \\
\hline 80 & 120121,5 & 2 & 12,00 & 53,95 & 96,33 & 3,67 & 0,9506 \\
\hline 82 & 123124,6 & 2 & 12,00 & 57,76 & 96,54 & 3,46 & 0,9527 \\
\hline 84 & 126127,6 & 2 & 12,00 & 61,60 & 96,73 & 3,27 & 0,9551 \\
\hline 86 & 129130,7 & 2 & 12.00 & 65,48 & 96.91 & 3.09 & 0.9577 \\
\hline 88 & 132133,7 & 2 & 12.00 & 69,40 & 97.06 & 2,94 & 0,9606 \\
\hline 90 & 135136.7 & 2 & 12.00 & 73.34 & 97.21 & 2.79 & 0,9636 \\
\hline 92 & 138139.8 & 2 & 12.00 & 77.32 & 97.34 & 2.66 & 0.9669 \\
\hline 94 & 141142.8 & 2 & 12.00 & 81.34 & 97.46 & 2.54 & 0,9704 \\
\hline 96 & 144145.9 & 2 & 12.00 & 85.38 & 97.57 & 2,43 & 0,9740 \\
\hline 98 & 147148.9 & 2 & 12.00 & 89.45 & 97.67 & 2.33 & 0.9776 \\
\hline 100 & 150151,9 & 2 & 12,00 & 93,53 & 97,78 & 2,22 & 0,9813 \\
\hline
\end{tabular}




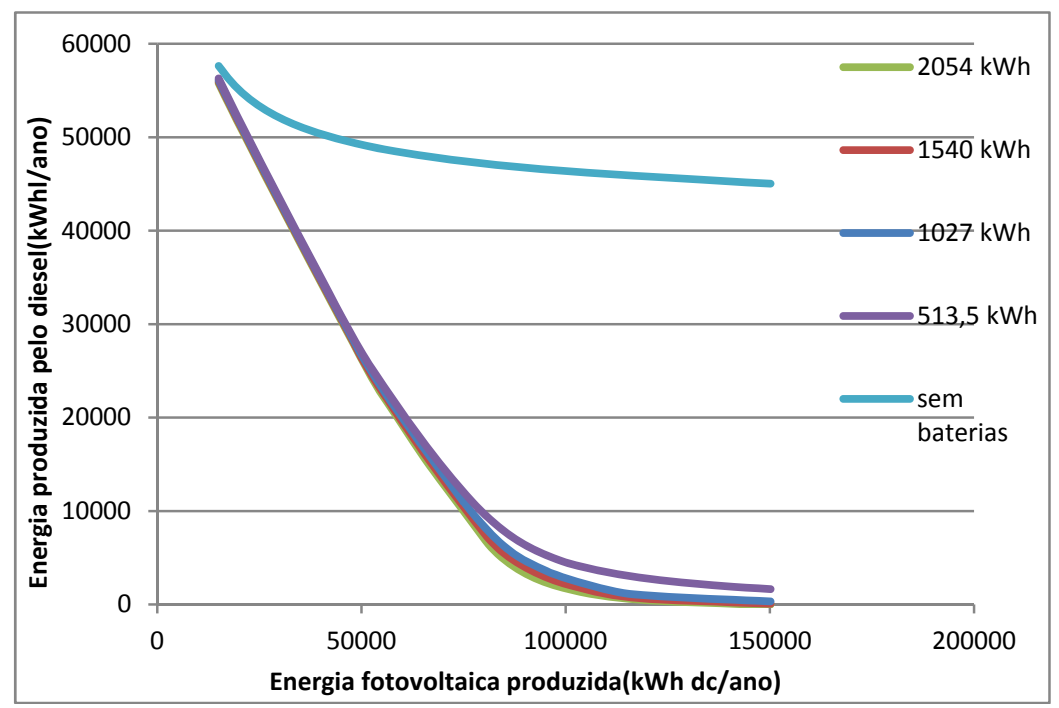

Figura 33: Variação da energia produzida pelo gerador versus energia fotovoltaica com a capacidade total de armazenamento das baterias para a mesma profundidade de descarga (40\%).

Na Fig. 33, pode-se observar a participação do diesel como função da energia fotovoltaica produzida. Como era de se esperar, quanto maior é fração de energia solar, menor é a geração de energia pelo diesel. Novamente é visível que o sistema funciona bem com um dia de autonomia para as baterias, mas deve-se prestar atenção no uso do gerador. Como já foi dito anteriormente, ele não pode ficar longos períodos parado, deve-se ter uma escala de acionamento dele mesmo que não seja necessária a produção de energia.

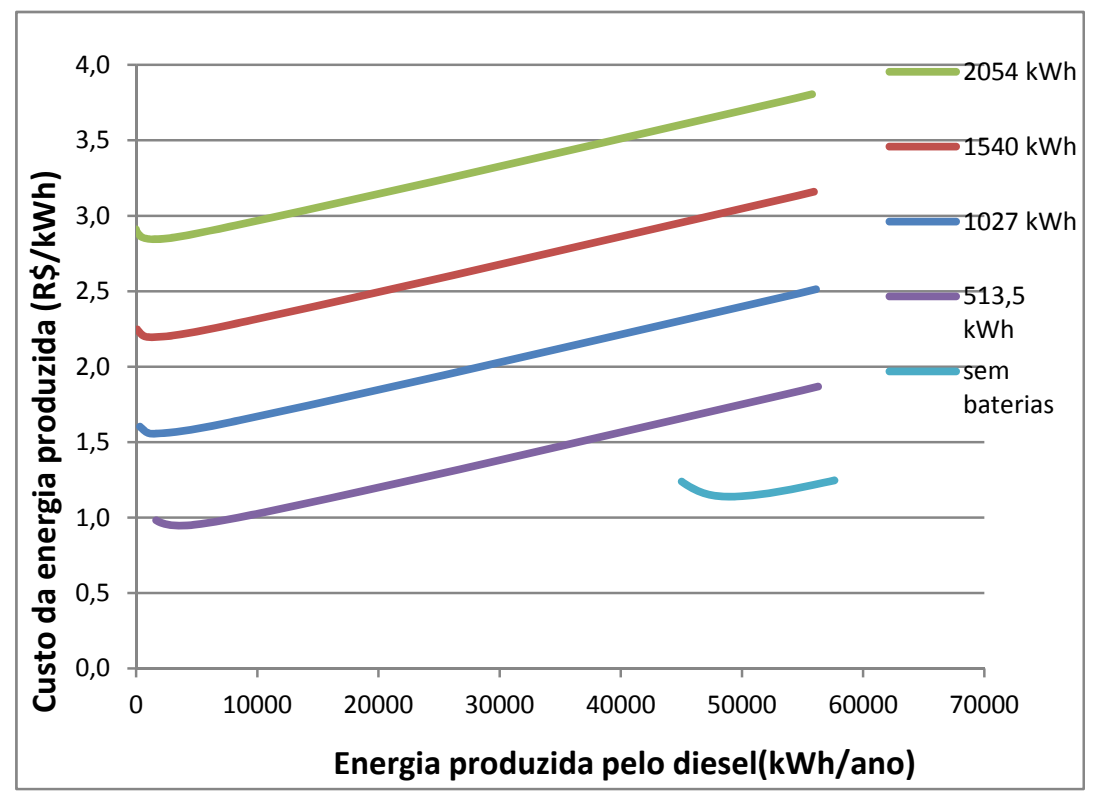

Figura 34: Variação do custo da energia versus energia produzida pelo gerador diesel com a capacidade total de armazenamento das baterias para a mesma profundidade de descarga (40\%). 
Na Fig. 34 pode-se ver que o menor custo da energia é alcançado pela opção sem baterias. E isto acontece porque, como já foi explicado anteriormente, esta opção é mais vantajosa para sistemas menores. Entretanto para sistemas maiores, a opção com um dia de autonomia das baterias é a melhor.

\subsection{2.}

\section{Influência da demanda elétrica no custo da energia}

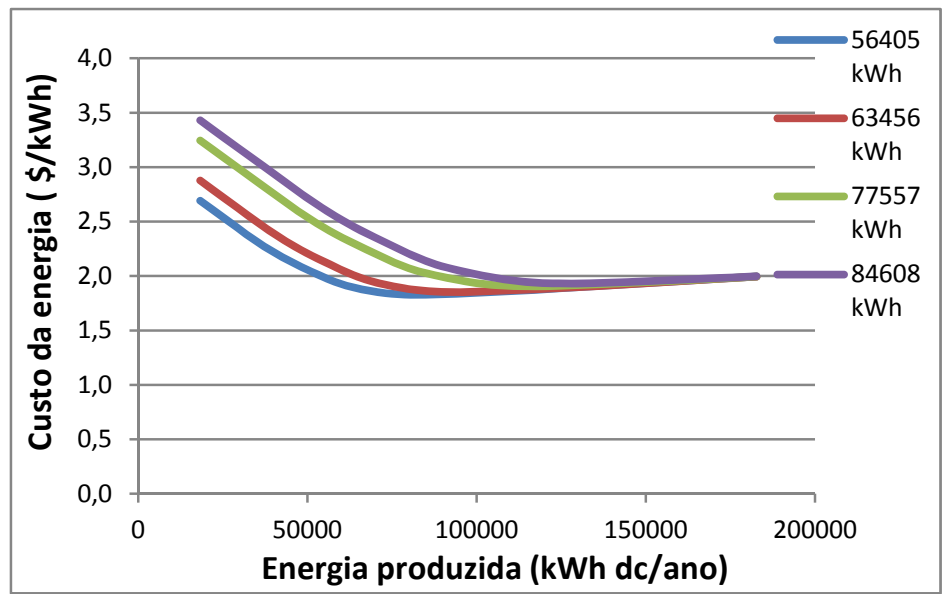

Figura 35: Influência da demanda elétrica no custo da energia, usando-se dados diários

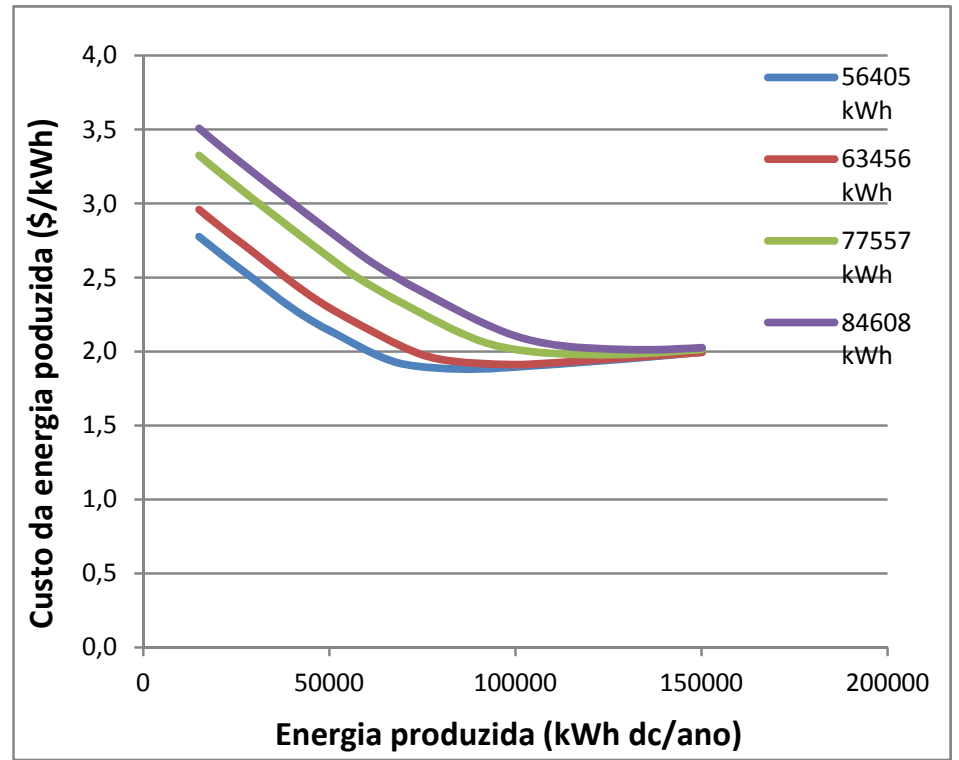

Figura 36: Influência da demanda elétrica no custo da energia, usando-se dados horários 
Para investigar a influência da demanda elétrica sobre o custo da energia, foram feitas simulações multiplicando-se os valores diários e horários de demanda elétrica por um coeficiente, maior ou menor do que 1, resultando em diferentes valores para a mesma .

Nas Fig. 35 e 36, pode-se ver como a variação de demanda elétrica (56405; 63456; 77557; $84608 \mathrm{kWh} / \mathrm{ano})$ influencia no custo da energia, principalmente em sistemas solares menores no qual a produção solar de energia elétrica é logo consumida. Assim o banco de baterias fica subutilizado e no horário de pico de consumo da agrovila, o gerador precisa ser acionado aumentando o custo da energia. Isto pode-se visto principalmente com a simulação da energia de $84608 \mathrm{kWh} /$ ano, tanto com dados diários como com dados horários. Já em sistemas maiores, a produção solar horária é maior do que a demanda horária e, assim, há sobra de energia para ser consumida a noite. Isto afetará diretamente o custo da energia através do menor uso do gerador. Percebese a importância do projeto para que o sistema seja bem dimensionado e opere de forma econômica. Nas Fig. 36 e 37, mostra-se que com o aumento da produção solar de energia elétrica, a demanda vai influenciando cada vez menos e os custos da energia tendem para um mesmo valor. Caso ocorresse um aumento da capacidade instalada solar em todas as simulações, mas mantendo as mesmas demandas elétricas, seria observado um aumento do custo da energia com a diminuição da demanda elétrica. Isto porque, existiria um superdimensionamento do sistema resultando em aumento de energia não utilizada que deveria ser dissipada. Outra fato interessante de se observar, é que o custo da energia com dados diários é menor do que com dados horários. Isto porque, a produção fotovoltaica calculada com dados diários é maior. 


\subsection{3.}

\section{Dissipação da produção solar de energia elétrica}

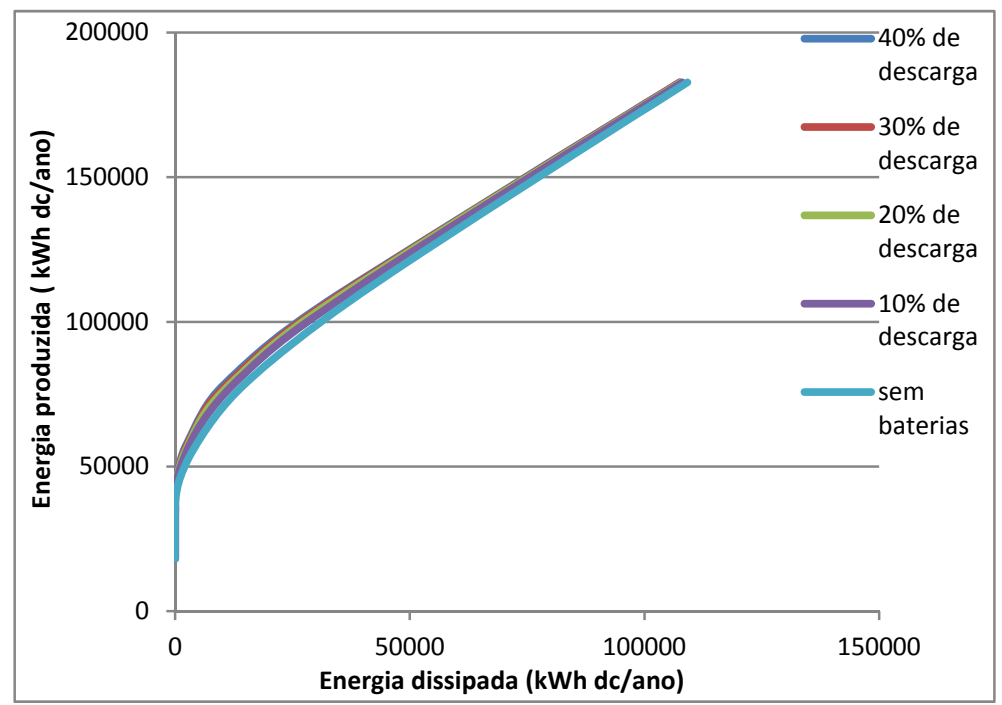

Figura 37: Dissipação (kWh dc) da produção solar da energia elétrica, para diferentes profundidades de descarga, capacidade total de $1027 \mathrm{kWh}$, usando-se dados diários

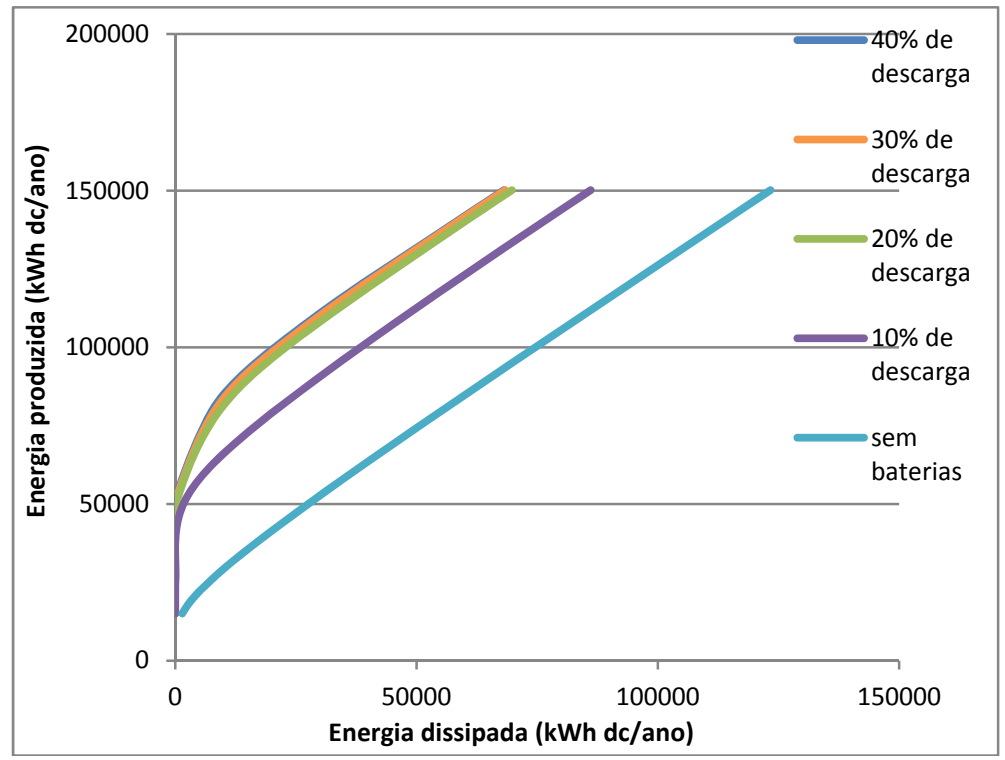

Figura 38: Dissipação (kWh dc) da produção solar da energia elétrica, para diferentes profundidades de descarga, capacidade total de $1027 \mathrm{kWh}$, usando-se dados horários

A dissipação da produção solar de energia elétrica ocorre ocorre quando o excesso de produção em relação à necessidade de consumo não pode ser 
armazenado porque as baterias já se encontram com sua carga plena. Ela também pode ser denominada de perda.

Pode-se perceber nas Fig. 37 e 38, que a simulação com dados diários produz resultados menos confiáveis. É possível ver que com o aumento da produção de energia fotovoltaica, ocorre um aumento das perdas. Para a mesma produção solar de energia elétrica, quanto maior a profundidade de descarga, menores são as perdas. O banco com a maior profundidade de descarga (40\%) está dentro do limite de segurança e portanto apresenta as menores perdas, aproveitando o máximo de sua capacidade operacional.

\subsection{4.}

\section{Variação da capacidade operacional e total}

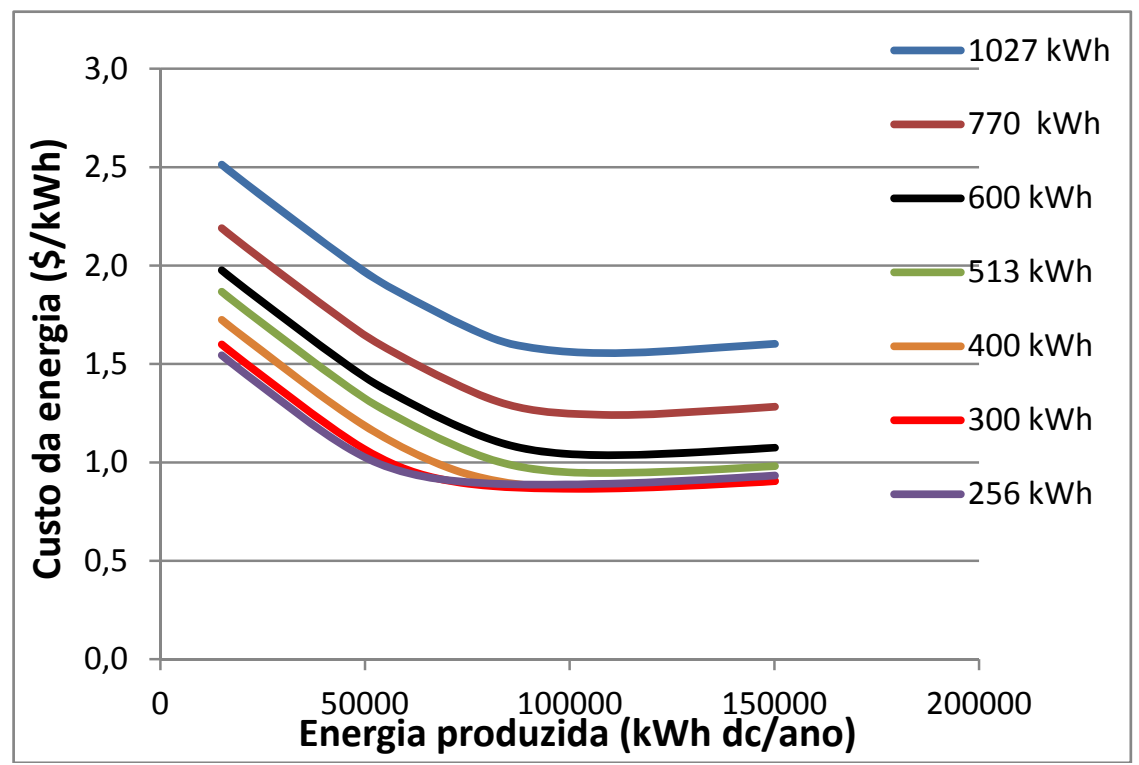

Figura 39: Simulação horária com $40 \%$ de profundidade de descarga e variação da capacidade total e operacional

Na Fig. 39 é possível ver que mantida a mesma profundidade de descarga para todas as simulações e variando somente a capacidade total do sistema de baterias, pode-se encontrar os melhores custos da energia para esta agrovila. $\mathrm{O}$ custo da energia está intimamente ligado com o melhor aproveitamento do banco de baterias e portanto menor será o seu custo. Assim, deve-se procurar o melhor 
projeto, quer dizer, o melhor ajuste entre a produção e a demanda. Portanto menores perdas ocorrerão, menor gasto de manutenção por potência produzida e uma consequente economia de capital investido.

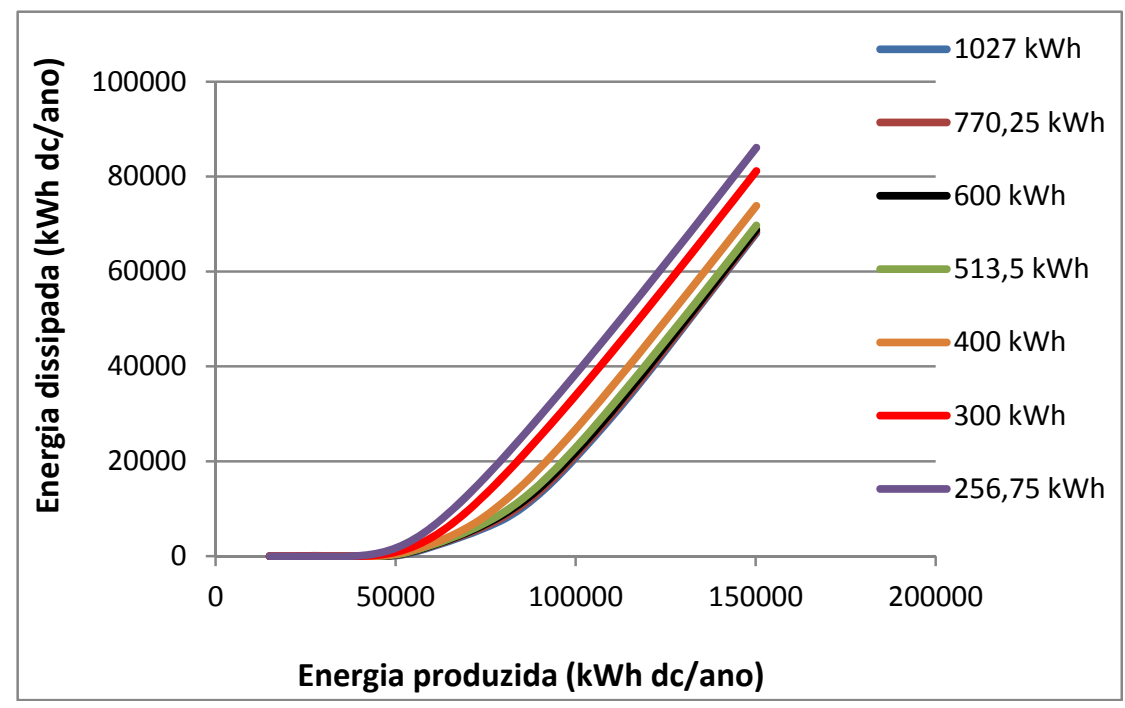

Figura 40: Simulação horária com $40 \%$ de profundidade de descarga e variação da capacidade total e operacional (energia dissipada versus kWh dc)

Na Fig. 40, é possível ver que os sistemas com capacidade total de 1027, 770 e 513,5 kWh apresentam praticamente as mesmas perdas; então o sistema capacidade total de 513,5 deverá ser escolhido por representar um menor custo da energia e de investimento nesta simulação. $\mathrm{O}$ sistema de baterias deve funcionar o mais próximo do limite, ter um sistema grande e subutilizá-lo não é interessante por representar maior empate de capital. Nas Tab. 15 e 16, são mostrados os valores da melhor simulação com o menor custo da energia produzida conforme foi mostrado na Fig. 40 .

Tabela 12: Dados do sistema

\begin{tabular}{|c|c|c|}
\hline Painel fotovoltaico & Vida útil & 25 anos \\
\hline & Custo médio & $\mathrm{R} \$ 5247.38 / \mathrm{kWp}$ \\
\hline \multirow[t]{5}{*}{ baterias } & Profundidade de descaraa & $40 \%$ \\
\hline & Eficiência & $85 \%$ \\
\hline & Autonomia operacional & Menos de 1 dia \\
\hline & Capacidade total & $300 \mathrm{kWh}$ \\
\hline & Custo & $\mathrm{R} \$ 356.51 / \mathrm{kWh}$ \\
\hline \multirow[t]{2}{*}{2 inversores de $10 \mathrm{~kW}$} & Eficiência & $95 \%$ \\
\hline & Custo & $\mathrm{R} \$ 20135,68$ \\
\hline Custo de instalação & & $30 \%$ sobre valor total \\
\hline \multirow[t]{8}{*}{ Gerador diesel } & Vida útil & 5 anos \\
\hline & Potência de pico & $96 \mathrm{~kW}$ \\
\hline & Custo & $1000 \mathrm{R} \$ / \mathrm{kW}$ \\
\hline & Consumo específico & $0,341 \mathrm{l} / \mathrm{kWh}$ \\
\hline & Demanda elétrica & $70507 \mathrm{kWh} / \mathrm{ano}$ \\
\hline & Consumo anual de diesel & 240681 \\
\hline & Consumo de lubrificante anual & $298 \mid$ \\
\hline & Custo da eneraia elétrica & $1.4740 \mathrm{R} \$ / \mathrm{kWh}$ \\
\hline
\end{tabular}


Tabela 13: Simulação horária com capacidade operacional de 513,5 kWh

\begin{tabular}{|c|c|c|c|c|c|c|c|}
\hline$P V$ & kWh dc & ciclos & vida útil & ñ usada & solar\% & diesel \% & \$/kWh \\
\hline 10 & 15015,2 & 0 & 4,00 & 0,00 & 20,20 & 79,80 & 1.5990 \\
\hline 12 & 18018.2 & 0 & 4.00 & 0.00 & 24.18 & 75.82 & 1.5491 \\
\hline 14 & 21021,3 & 0 & 4,00 & 0,00 & 28,12 & 71,88 & 1,5003 \\
\hline 16 & 24024,3 & 0 & 4,00 & 0,00 & 32,01 & 67,99 & 1,4524 \\
\hline 18 & 27027.3 & 0 & 4.00 & 0.00 & 35.86 & 64.14 & 1.4050 \\
\hline 20 & 30030.4 & 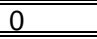 & 4.00 & 0.00 & 39.67 & 60.33 & 1.3579 \\
\hline 22 & 33033,4 & 0 & 4,00 & 0,00 & 43,43 & 56,57 & 1,3113 \\
\hline 24 & 36036.5 & 0 & 4.00 & 0.00 & 47.15 & 52.85 & 1.2649 \\
\hline 26 & 39039.5 & 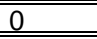 & 4.00 & 0.00 & 50.82 & 499.18 & 1.2187 \\
\hline 28 & 42042,5 & 2 & 4,00 & 0,04 & 54,42 & 45,58 & 1,1731 \\
\hline 30 & 45045,6 & 9 & 4,00 & 0,28 & 57,80 & 42.20 & 1.1302 \\
\hline 32 & 48048,6 & 13 & 4.00 & 0.74 & 60.95 & 39.05 & 1.0901 \\
\hline 34 & 51051,7 & 25 & 4,00 & 1,45 & 63,86 & 36,14 & 1,0532 \\
\hline 36 & 54054,7 & 30 & 4,00 & 2,40 & 66,51 & 33,49 & 1,0195 \\
\hline 38 & 57057.7 & 51 & 4.00 & 3.69 & 68.86 & 31.14 & 0.9901 \\
\hline 40 & 60060.8 & 66 & 4.00 & 5.28 & 70.92 & 29.08 & 0.9647 \\
\hline 42 & 63063,8 & 88 & 4,00 & 7,20 & 72,68 & 27,32 & 0,9435 \\
\hline 44 & 66066.9 & 108 & 4.00 & 9.46 & 74.15 & 25,85 & 0.9267 \\
\hline 46 & 69069.9 & 128 & 4.00 & 11.91 & 75.44 & 24.56 & 0.9124 \\
\hline 48 & 72072.9 & 147 & 4.00 & 14.62 & 76.52 & 23,48 & 0.9013 \\
\hline 50 & 75076,0 & 160 & 4,00 & 17,50 & 77,45 & 22,55 & 0,8923 \\
\hline 52 & 78079.0 & 171 & 4.00 & 20.53 & 78.27 & 21.73 & 0.8851 \\
\hline 54 & 81082.0 & 184 & 4.00 & 23.69 & 78.97 & 21.03 & 0.8796 \\
\hline 56 & 84085,1 & 189 & 4,00 & 26,96 & 79,58 & 20,42 & 0,8753 \\
\hline 58 & 87088,1 & 202 & 4,00 & 30,32 & 80,13 & 19,87 & 0,8721 \\
\hline 60 & 90091.2 & 206 & 4.00 & 33.76 & 80.63 & 19.37 & 0.8697 \\
\hline 62 & 93094,2 & 210 & 4,00 & 37,25 & 81,08 & 18,92 & 0,8679 \\
\hline 64 & 96097,2 & 219 & 4,00 & 40,81 & 81,50 & 18,50 & 0,8667 \\
\hline 66 & 99100.3 & 221 & 4.00 & 44.41 & 81.88 & 18.12 & 0.8660 \\
\hline 68 & 102103,3 & 226 & 4,00 & 48,08 & 82.22 & 17.78 & 0,8659 \\
\hline 70 & 105106,4 & 229 & 4,00 & 51,80 & 82,53 & 17,47 & 0,8663 \\
\hline 72 & 108109,4 & 236 & 4.00 & 55.58 & 82.80 & 17.20 & 0.8671 \\
\hline 74 & 111112.4 & 240 & 4.00 & 59,38 & 83.06 & 16.94 & 0,8683 \\
\hline 76 & 114115,5 & 240 & 4,00 & 63,23 & 83,30 & 16,70 & 0,8697 \\
\hline 78 & 117118,5 & 240 & 4,00 & 67.11 & 83,52 & 16,48 & 0,8714 \\
\hline 80 & 120121.5 & 241 & 4.00 & 71.05 & 83.72 & 16.28 & 0.8735 \\
\hline 82 & 123124.6 & 245 & 4.00 & 75.02 & 83.89 & 16.11 & 0.8759 \\
\hline 84 & 126127,6 & 246 & 4,00 & 79,03 & 84,05 & 15,95 & 0,8784 \\
\hline 86 & 129130,7 & 250 & 4,00 & 83,08 & 84,19 & 15,81 & 0,8813 \\
\hline 88 & 132133.7 & 251 & 4.00 & 87.16 & 84.32 & 15,68 & 0.8843 \\
\hline 90 & 135136,7 & 255 & 4,00 & 91,27 & 84,44 & 15,56 & 0,8875 \\
\hline 92 & 138139,8 & 255 & 4,00 & 95,41 & 84,55 & 15,45 & 0,8908 \\
\hline 94 & 141142.8 & 256 & 4.00 & 99.57 & 84.66 & 15.34 & 0.8941 \\
\hline 96 & 144145.9 & 257 & 4.00 & 103.75 & 84.76 & 15.24 & 0.8975 \\
\hline 98 & 147148,9 & 261 & 4,00 & 107,97 & 84,85 & 15,15 & 0,9011 \\
\hline 100 & 150151,9 & 263 & 4,00 & 112,21 & 84,93 & 15,07 & 0,9048 \\
\hline
\end{tabular}




\subsection{5.}

\section{Sistema autossuficiente (PV)}

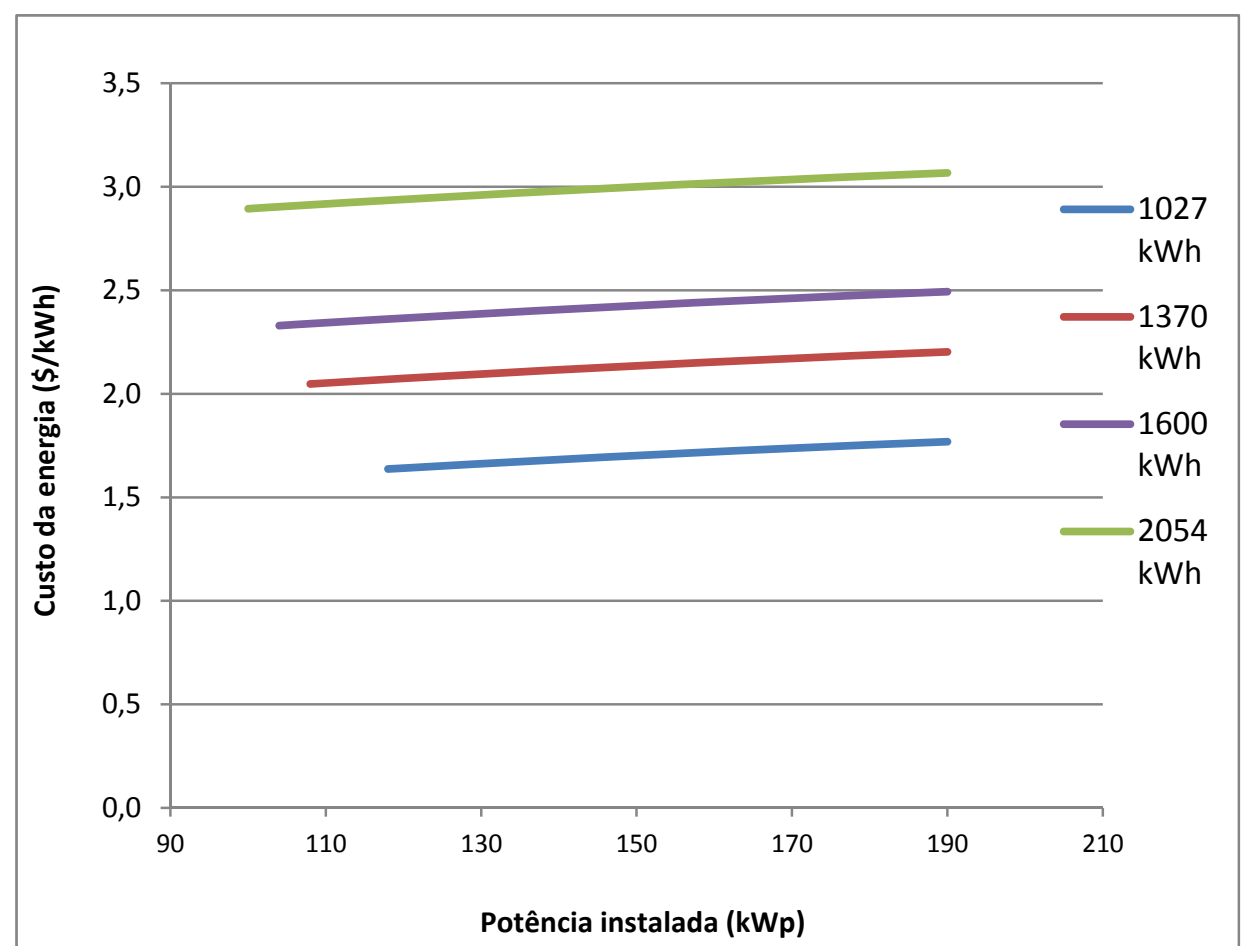

Figura 41: Variação da capacidade total, mas com profundidade de descarga constante (40\%) e sem a contribuição do gerador.

Na Fig. 41 pode-se ver o custo da energia sem a contribuição do gerador diesel e a produção solar sendo a única fonte de energia do sistema autossuficiente. O sistema fotovoltaico fica superdimensionado, ocorrendo um grande aumento das perdas. $\mathrm{O}$ sistema perde também em segurança e confiabilidade devido à falta do gerador, tornando-o vulnerável. A vantagem do sistema híbrido é tornar a produção de energia mais equilibrada e o investimento na energia solar mais competitivo, diminuindo o custo do capital em longo prazo. Na Fig. 42 pode-se ver o aumento da energia dissipada num sistema autossuficiente. 


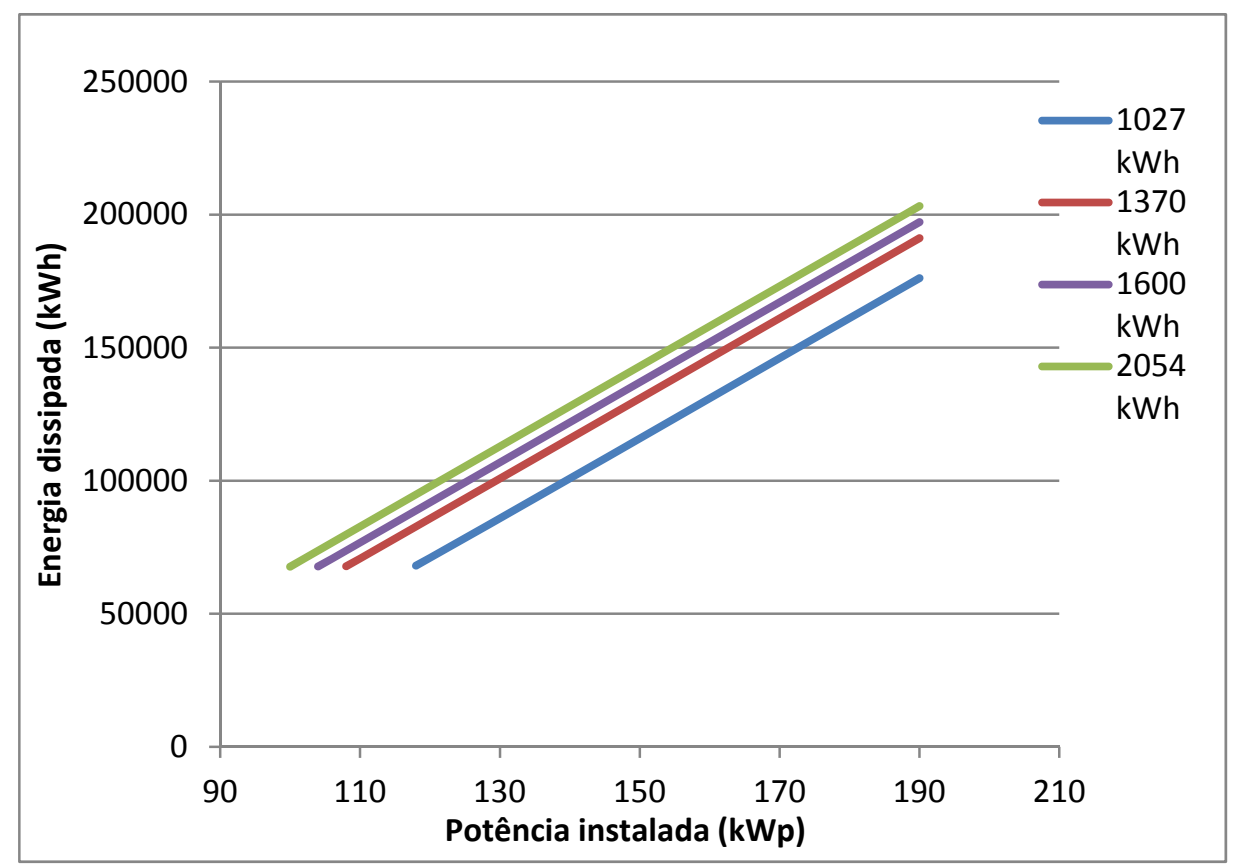

Figura 42: Energia dissipada versus potência instalada

\section{2.}

\section{Comparação entre o cálculo realizado com a do quantil}

Conforme o resultado obtido via previsão determinística da primeira metodologia, encontrou-se o menor custo de $\mathrm{R} \$ 0,8659 / \mathrm{kWh}$ para um sistema fotovoltaico de $68 \mathrm{kwp}$, capacidade total das baterias de $300 \mathrm{kWh}$, profundidade de descarga de $40 \%$, totalizando uma capacidade operacional de $120 \mathrm{kWh}$. Por outro lado, a partir do cálculo do quantil, os resultados apontaram como menor custo de $\mathrm{R} \$ 1,094 / \mathrm{kWh}$ (aproximadamente) para um sistema fotovoltaico de $70 \mathrm{kwp}$, capacidade total das baterias de $256 \mathrm{kWh}$, profundidade de descarga de $40 \%$, totalizando uma capacidade operacional de 102,4 kWh. A Fig. 43 mostra o referido quantil, a Fig. 44 o histograma da distribuição de custos da energia. 


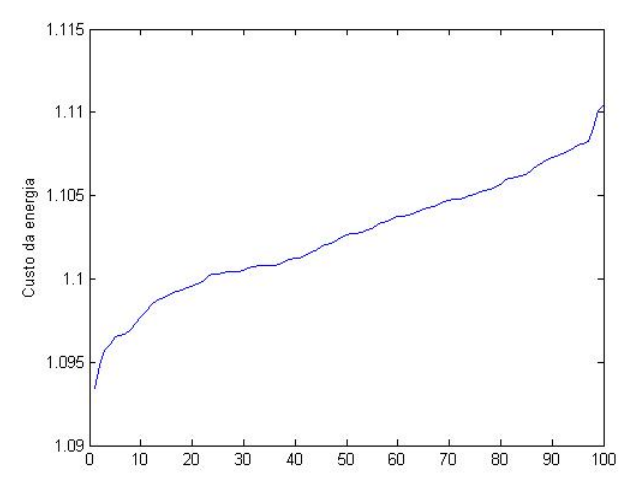

Figura 43: Quantil

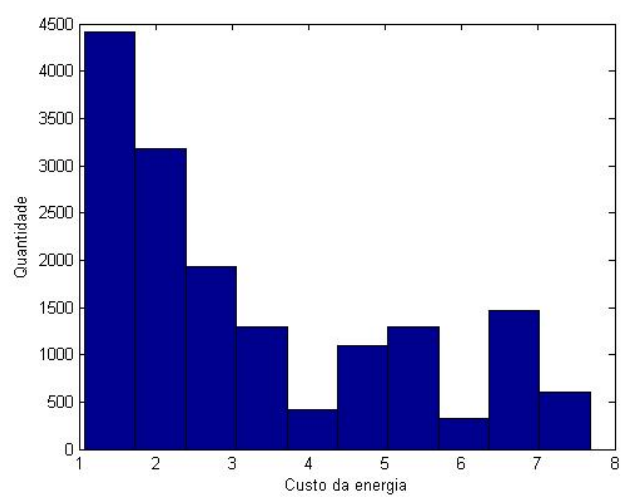

Figura 44: Histograma da distribuição dos custos de energia

Na Fig. 45 mostra-se a potência instalada fotovoltaica escolhida no quantil com uma pequena variação do sistema sendo entre $70 \mathrm{kWp}$ a $76 \mathrm{kWp}$ e na Fig. 46 o sistema de baterias escolhido não ocorrendo nenhuma variação neste exercício.

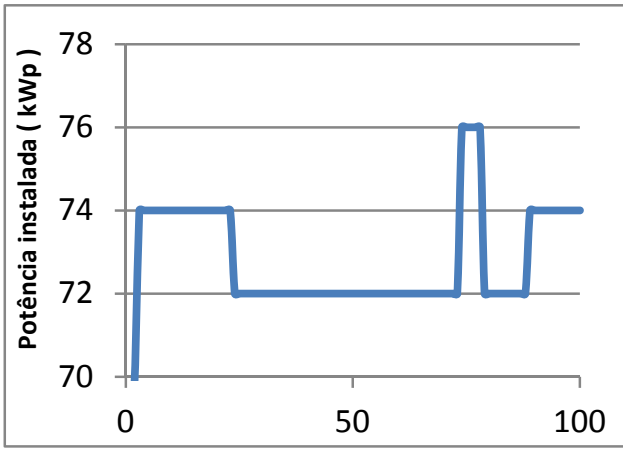

Figura 45: Seleção da potência instalada

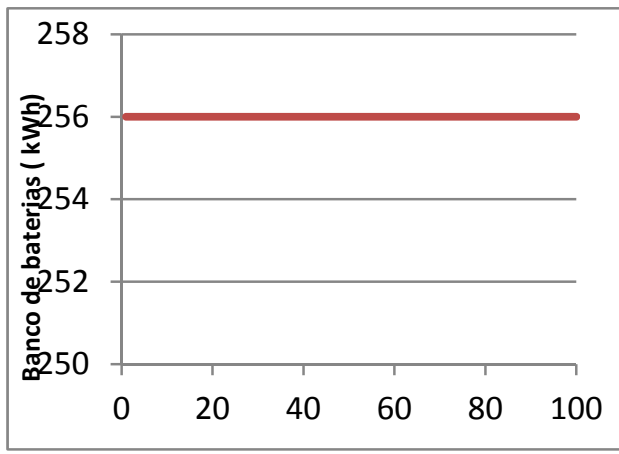

Figura 46: Seleção do sistema de baterias 


\section{Conclusões}

O presente trabalho mostrou a importância da energia fotovoltaica como solução viável para a eletrificação de locais distantes da rede de energia convencional. Entretanto como solução única não é interessante por exigir uma potência instalada superdimensionada, além do que o sistema perde muita energia no horário de pico de produção e isto aumentaria o custo do sistema e da energia produzida.

O banco de baterias é de fundamental importância para um sistema fotovoltaico funcionar bem. Ele resolve o problema do encontro da produção com o consumo devido ao fato que o pico de consumo ser noturno, mas somente em dias operacionalmente médios. Entretanto, em dias com pouca ou nenhuma incidência solar ou então com um consumo exagerado, quer dizer operacionalmente diferentes, ele não resolve. Aumentar este subsistema para armazenar toda energia produzida, também não é vantajoso. Ele ficaria subutilizado e o custo da energia iria aumentar, além do que o prazo máximo para troca delas por motivo de segurança ser de 4 anos independentemente do seu uso. Outro ponto importante com relação às baterias é a profundidade de descarga, neste trabalho é aconselhado a se usar sempre a de $40 \%$. Em termos operacionais, deve-se explorar o máximo delas, mas sempre atentando o fato da segurança e do custo da energia.

A solução é simples e interessante. Agregar um gerador diesel é uma forma barata de agregar segurança ao sistema, além de diminuir o custo da energia como um todo. O gerador produziria a energia complementar ao sistema, então as outras partes do sistema (fotovoltaico e baterias) se tornariam mais otimizadas, diminuindo o custo total da energia produzida. Além disso, sempre existirá a possibilidade de períodos extensos de falta de incidência solar, assim o gerador também agregaria segurança ao sistema a respeito deste risco. Algumas pessoas poderiam pensar então ser mais vantajoso somente o uso do gerador diesel, com toda a certeza a instalação de um gerador é muito mais simples do que um sistema híbrido. Entretanto, a dependência de combustível, óleo e manutenção além do fato de ser poluente e barulhento torna esta opção pouco atraente. Para uma situação tem- 
porária é uma solução viável, mas para uma instalação fixa como uma agrovila ou uma unidade de fronteira do exército, por exemplo, não é interessante. O sistema híbrido ganha em longo prazo justamente por fornecer independência e um custo menor a esta unidade de consumo afastada.

Este trabalho mostra de forma contundente a importância de cada parte (fotovoltaico, baterias e gerador diesel) para um sistema híbrido como também, que o ponto fundamental é uma melhor combinação entre elas. Assim se alcançará um custo de energia mais baixo em longo prazo que é o verdadeiro objetivo, sendo o resultado alcançado de $\mathbf{R} \mathbf{\$} \mathbf{0 , 8 6 5 9} / \mathbf{k W h}$ para um sistema fotovoltaico de 68 $\mathrm{kWp}$, capacidade total das baterias de $300 \mathrm{kWh}$, profundidade de descarga de $40 \%$, totalizando uma capacidade operacional de $120 \mathrm{kWh}$. 


\section{Bibliografia}

Atlas do Desenvolvimento Humano no Brasil. IDH - Índice de Desenvolvimento Humano. Disponível no site: http://www.fjp.mg.gov.br/ produtos/cees/idh/atlas_idh.php. Acesso em: 12-12-2011.

BARBOSA,C. F. O.; PINHO, J. T.; VALE, S.B.(2005) Sistemas Híbridos de Energia Solar/Eólico/Diesel para Eletrificação de Comunidades Isoladas da Região Amazônica Brasileira - Estado Presente e Desenvolvimentos Futuros. Artigo, Grupo de Estudos e Desenvolvimento de Alternativas Energéticas (GEDAE), Departamento de Engenharia Elétrica e de Computação, Centro Tecnológico, Universidade Federal do Pará, Belém, PA, Brasil, 2005.

BOYD Matthew T. (2010). Evaluation and Validation of Equivalent Circuit Photovoltaic Solar Cell Performance Models. 2010.151f. Dissertação (Mestrado em engenharia Mecânica) -University of Wisconsin - MADISON, U.S.A., 2010

B.T. Griffith and P.G. Ellis (2004). Photovoltaic and Solar Thermal Modeling with the EnergyPlus Calculation Engine. 2004. $8 f$.Conference Paper, NREL, Denver, Colorado, U.S.A, 2004

CAMERON C. P., BOYSON W. E., RILEY D. M. (2008). Comparison of PV System Performance-Model Predictions with Measured PV System Performance, 2008, Artigo. Sandia National Laboratories, Albuquerque, U.S.A. 2008.

CAMERON, Christopher P., STEIN, Joshua S., CORYNE A. Tasca, PV Performance Modeling Workshop Summary Report, $92 \mathrm{f}$, Working paper , SANDIA REPORT, SAND2011-3419, Unlimited Release, Sandia National Laboratories, U.S.A, May 2011

DUFFIE.A.J.,BECKMAN.A.W.(1991), Solar Engineering of Thermal Process, 919 p, 2nd ed., John Wiley \& Sons, New York, 1991.

GEOFFREY T., KLISE J., STEIN S. (2009), Models Used to Assess the Performance of Photovoltaic Systems, Working paper 02-046, Sandia National Laboratories Albuquerque, New Mexico, U.S.A.,2009.

GILMAN, Paul, NREL, Solar Advisor Model General Introduction, Workshop, Apresentação, 2004, Solar Advisor Support@nrel.gov, http://www.nrel.gov/analysis/sam, Collorado, U.S.A. 2004.

GOUVEIA J. J. B.(2011) Optimization of Hybrid PV/Wind Power System for Remote Telecom Station, 120f. Dissertação de mestrado, 2011, Department of Mechanical Engineering, University of Aveiro, Portugal, 2011. 
HALL I., PRAIRIE R., ANDERSON H., BOES E., Generation of Typical Meteorological Years for 26 SOLMET Stations. Working paper, SAND78-1601. 1978;

HOCHMUTH G.C.S.(1997).A combined optimisation concet for the design and operation strategy of hybrid-PV energy systems Solar Energy, Volume 61, Issue 2, August 1997, Pages 77-87, ISSN 0038-092X, 10.1016/S0038-092X(97)00028-5.(http://www.sciencedirect.com/science larticle /pii/S0038092X97000285),1997.

HOCHMUTH, Gabriele Seeling,(1998),Optimisation of hybrid energy systems sizing and operation control, 1998, 137f, Dissertação de mestrado, University of Kassel, Germany,1998.

LUQUE et al. (2003). Handbook of Photovoltaic Science and Engineering, 1138p, Willey , Institute of Energy Conversion, University of Delaware, USA

KING, D. L., BOYSON W. E., KRATOCHVIL J. A. (2004), Photovoltaic Array Performance Model, Working paper, Photovoltaic System R\&D Department, Sandia National Laboratories, Albuquerque, New Mexico, U.S.A,2004.

KING, D. L.,(1996) Photovoltaic Module and Array Performance Characterization Methods for All System Operating Conditions, Working paper, Sandia National Laboratories, Photovoltaic Systems Department, Albuquerque, New Mexico,U.S.A,1996.

KING, D.L., BOYSON, W.E., BOWER, W.I., (1998) "Field Experience with a New Performance Characterization Procedure for Photovoltaic Arrays", presented at the $2^{\text {nd }}$ U.S.A., 1998.

WENGER, Howard and Tom Hoff Pacific Energy GroupWalnut Creek, California, Jan Pepper Enertron Consultants Los Altos, California, The Sacramento Municipal Utility District as a Case Study, 107 f, Artigo,1996, Sacramento Municipal Utility District, California Energy Commission, U.S. A., Department of Energy's PVCompact Program, (via North Carolina Solar Center), 1996.

World Conference and Exhibition on Photovoltaic Solar energy Conversion, Vienna, Austria, July 6-10, 1988.

KING, D.L., Boyson, W.E., and Bower, W.I., (1998) "Field Experience with a New Performance Characterization Procedure for Photovoltaic Arrays", presented at the $2^{\text {nd }}$ World Conference and Exhibition on Photovoltaic Solar energy Conversion, Vienna, Austria, July 6-10.

KING, D.L., (2000), "Sandia's PV Module Electrical Performance Model",(Version, 2000), Sandia National Laboratories, Albuquerque, New Mexico, U.S.A.,2000. 
KING, D.L., Boyson, W.E., Kratochvil, J.A., (2003), "Photovoltaic Array Performance Model" (Draft), Working paper, Albuquerque, New Mexico, U.S.A.,2003.

MARION W, URBAN K. User's Manual for TMY2s. NREL, Collorado, U.S.A., 1995;

MYERS K. S.(2010). Assessment of High Penetration of Photovoltaics in Wisconsin,2010. 269f. Dissertação de mestrado, UNIVERSITY OF WISCONSIN-MADISON,U.S.A. 2010.

NREL,2011, Version 2011.6.30, System Advisor Model (SAM) User Guide, Collorado,U.S.A.2011.

NSRDB, 1961-1990: TMY2. Available at: http://rredc.nrel.gov/solar/old data/nsrdb/1961-1990/tmy2/. Acesso 2/17/2011, 2011.

OLIVEIRA M. E., Feltrin A. P. , F. J. Candian, (2006). Investigation of the Relationship Between Load and Loss Factors for a Brazilian Electric Utility, IEEE/PES Transmission \& Distribution Conference and Exposition: Latin America - TDC '06, pp. 1-6, Caracas, 2006.

PATEL M. 2006, Wind and Solar Power Systems, Second Edition, Taylor \& Francis Group, U.S.A., 2006.

PVDI 2007, Solar Energy International, Photovoltaic Design and Installation Manual, New Society Publishers, U.S.A., 2007.

PAUDEL, Subodh, (2011), Optimization of Hybrid PV/Wind Power System for Remote Telecom Station, Dissertação de Mestrado, $111 \mathrm{f}$, 2011,Universidade de Aveiro, Departamento de Engenharia Mecânica, Aveiro, Portugal, 2011.

Pereira.B.E.,Lima.J.H.G.(2008), Solar and Wind Energy Resource Assessment in Brazil, Artigo, National Institute for Space Research - INPE, São José dos Campos, SP, Brasil, 2008.

RIVERA, Miguel Rios (2008). Small Wind / Photovoltaic Hybrid Renewable Energy System Optimization. 2008, 168 f. Dissertação de mestrado - University of Puerto Rico,2008.

MACALPINE, S. BRANDEMUEHL, M., ERICKSON, R. (2010).Modeling and Evaluating Impact of Sub-Array MPPT, University of Colorado at Boulder, Sandia PV Performance Modeling Workshop,U.S.A.,2010.

SEN,ZEKAI.(2008), Solar Energy Fundamentals and Modeling Techniques: atmosphere, environment, climate change and renewable energy, 1nd ed., Springer, London, 2008.

SILVA,P.C.(2006),Pesquisa em energias solar e eólica, Seminário, Departamento de Tecnologias Especiais, CEPEL,ELETROBRÁS,2006. 
SOTO W. (2004). Improvement and Validation of a Model for Photovoltaic Array Performance, 2004, 213f, dissertação de mestrado, Solar Energy Laboratory, University of Wisconsin-Madison,U.S.A.,2004.

SOUZA, A. N., JUNIOR P. C., OLIVEIRA R., ZAGO M. G., PAPA J. P., (2010). Algoritmos para Estimar Curvas de Cargas a Partir de Padrões de Hábitos de Consumo, 2010, artigo, Bauru, UNESP, 2010.

SURYOATMOJO H.(2010). Artificial Intelligence Based Optimal Configuration of Hybrid Power Generation System.2010, Dissertação de mestrado,Kumamoto University, Japan, 2010.

T. Muneer, Solar Radiation and Daylight Models (2004), $347 \mathrm{f}$, Elsevier Butterworth-Heinemann, Napier University, Edinburgh, 2004.

VIJAYAKUMAR, G., Assessment of Solar Radiation Data Used in Analyses of Solar Energy Systems, 2004, 90f. Dissertação de mestrado, University of Wisconsin-Madison, U.S.A., 2004.

WELDEMARIAM L. E.(2010). Genset-Solar-Wind Hybrid Power System of Off-Grid Power Station for Rural Applications, 2010, $137 \mathrm{f}$, Dissertação de mestrado, Delft University of Technology, Holanda, 2010. 